Barriers to the C-Suite: The Impact of Perceptions of Gender Bias on Women Leaders' Senior Leadership Ambitions

by

\title{
Sepinood Parvizian
}

\begin{abstract}
A thesis submitted to the Faculty of Graduate and Postdoctoral Affairs in partial fulfillment of the requirements for the degree of
\end{abstract}

\section{Master of Arts}

in

Psychology

\author{
Carleton University \\ Ottawa, Ontario
}

(C) 2020

Sepinood Parvizian 


\begin{abstract}
The current research examined whether women leaders' senior leadership ambitions are more strongly negatively affected by perceptions of gender bias (i.e., subtle gender bias, inequity, and mistreatment) in the workplace than leaders who are men and whether this association occurs through cynicism towards work. To test this, 347 leaders completed an online survey. It was found that women leaders had similar senior leadership ambitions as men, and contrary to expectations, gender did not affect the relation between gender bias and senior leadership ambitions. However, for both women and men, perceptions of gender bias were related to cynicism towards work, and ultimately, lower senior leadership ambitions. Further, women leaders who worked in male-dominated workplaces reported more issues of subtle gender bias than others. These findings have meaningful implications and suggest that it is likely systemic barriers, and not women's ambitions, that explain the lack of women in the C-suite.

Keywords: Gender, senior leadership ambitions, workplace cynicism, subtle gender bias, inequity, mistreatment
\end{abstract}




\section{Acknowledgements}

First, I would like to extend my deepest thanks to my supervisor, Dr. Janet Mantler. Thank you for the incredible knowledge, support, and guidance you have provided me with - especially in light of the uncertain nature of this year. I have learned more about research and academic writing while working alongside you than I ever dreamed possible.

I would like to thank my committee members, Dr. Kate Dupré and Dr. Catherine Elliott, for their invaluable time and insight. Thank you for making my thesis defence such an enjoyable and beneficial experience.

To my lab mates, Christine, Dorothy, and Nina - thank you for always being there, whether it be to lend a helping hand, answer one of my countless questions, or just chat about life. My experience at Carleton has been more enjoyable with you all. To Natasha, thank you for the million coffee shop work sessions, early mornings and late nights, and always being there to listen or talk. Your friendship has been a vital part of the past two years.

A special thank you to Saghar, for not only being the world's greatest cousin, roommate, and friend, but also keeping me motivated and smiling throughout the entirety

of my academic journey. Your encouragement and positivity continues to mean the world to me.

Last, but certainly not least, I would like to thank my parents for their unconditional love and support. Thank you for teaching me the importance of ambition, perseverance, and doing what you love. Without you both, this thesis would not have been possible. 


\section{Table of Contents}

Abstract..........................................................................

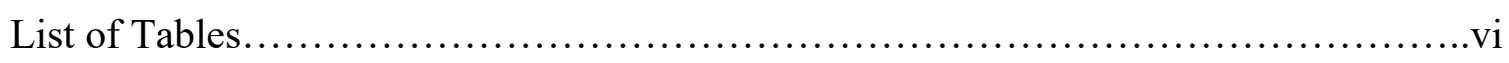

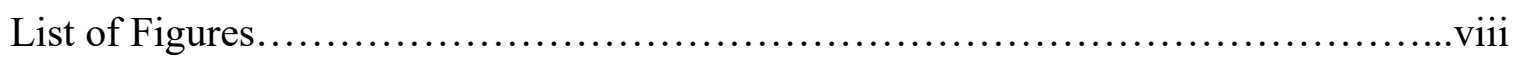

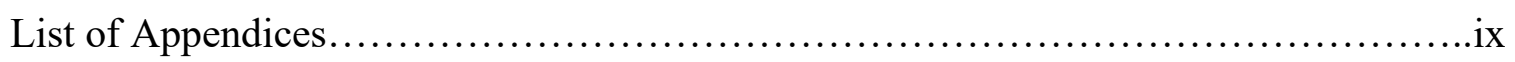

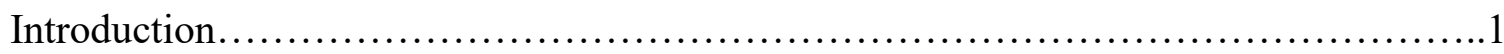

The Benefits of Women's Leadership for Employees and Organizations...........4

Women's Senior Leadership Ambitions...................................6

Stereotype Threat Theory and Senior Leadership Ambitions....................8

Subtle Gender Bias in the Workplace.................................. 10

Women Leaders and the Double Bind............................... 12

The Silencing of Women's Input..................................13

Equity Theory and Senior Leadership Ambitions..........................15

The Responsibility of Workplace Housework.......................17

Inequitable Pay for Women.....................................18

Inequitable Opportunities for Women............................20

A Lack of Women Mentors...............................21

The Perceived Riskiness of Women..........................22

Mistreatment in the Workplace and Senior Leadership Ambitions...............22

Workplace Incivility Towards Women...........................24

Sexual Harassment Towards Women.............................25

The Mediating Effect of Cynicism Towards Work..........................26

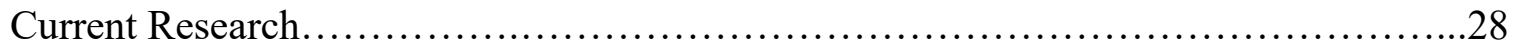




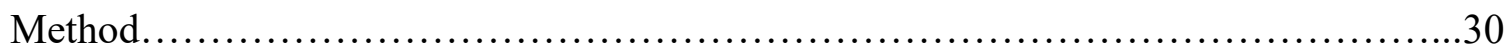

Procedure ................................................................. 30

Participants..................................................... 32

Measures................................................................. 34

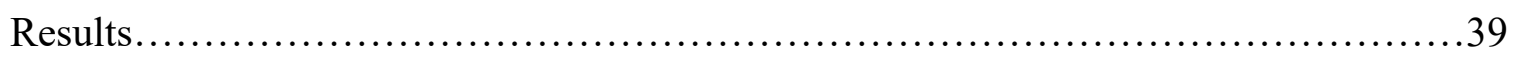

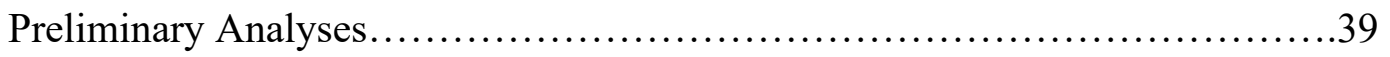

The Effect of Gender on Senior Leadership Ambitions Through Cynicism

Towards Work ...................................................50

Discussion.............................................................61

The Role of Gender and Gender Bias in Senior Leadership Ambitions...........62

The Experience of Women Leaders in Male-Dominated Workplaces............65

The Role of Gender in Cynicism Towards Work............................66

Workplace Housework..............................................68

Sexual Harassment in the Current Workforce................................ 70

Research Limitations and Future Directions............................. 71

Research and Practical Implications..................................... 75

Conclusion............................................................ 77

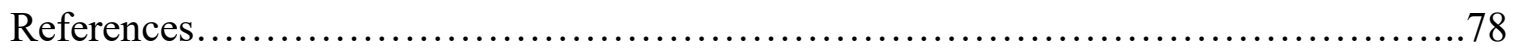




\section{List of Tables}

Table 1. Participant Industries.....................................................

Table 2. Principal Component Analysis Loadings of Silencing Items..................41

Table 3. Principal Component Analysis Loadings of Combined Silencing Items........42

Table 4. Principal Component Analysis Loadings of Housework Items..................43

Table 5. Principal Component Analysis Loadings of Remaining Housework

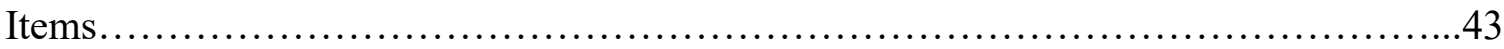

Table 6. Means, Standard Deviations, and Correlations for Key Variables..............45

Table 7. Differences by Gender...............................................46

Table 8 . Differences by Gender Diversity Climate..............................47

Table 9. Two-Way ANOVA for Gender and Gender Diversity Climate.................48

Table 10. Differences by Ethnicity.......................................... 50

Table 11. The Effect of the Double Bind on Senior Leadership Ambitions Through

Cynicism Towards Work as Moderated by Gender..................................52

Table 12. The Effect of Silencing on Senior Leadership Ambitions Through Cynicism

Towards Work as Moderated by Gender........................................54

Table 13. The Effect of Workplace Housework on Senior Leadership Ambitions Through Cynicism Towards Work as Moderated by Gender................................55

Table 14. The Effect of Inequitable Pay on Senior Leadership Ambitions Through

Cynicism Towards Work as Moderated by Gender.................................56

Table 15. The Effect of Inequitable Opportunities on Senior Leadership Ambitions

Through Cynicism Towards Work as Moderated by Gender.........................57 
Table 16. The Effect of Workplace Incivility on Senior Leadership Ambitions Through

Cynicism Towards Work as Moderated by Gender..................................59

Table 17. Summary of Hypotheses Testing Results...............................60 


\section{List of Figures}

Figure 1. Hypothesized Relations Between Variables.................................29

Figure 2. Histogram of Senior Leadership Ambitions by Gender....................44

Figure 3. The Effect of Gender and Gender Diversity Climate on the Double Bind.....49

Figure 4. The Effect of Gender and Gender Diversity Climate on Silencing.............49

Figure 5. Revised Hypothesized Relations Between Variables .......................51

Figure 6. Gender as a Moderator in the Relation Between the Double Bind and Cynicism

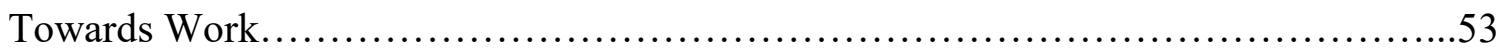

Figure 7. Gender as a Moderator in the Relation Between Inequitable Opportunities and

Cynicism Towards Work.................................................58 


\section{List of Appendices}

Appendix A: Recruitment Notice............................................. 112

Appendix B: Eligibility Screening Form....................................113

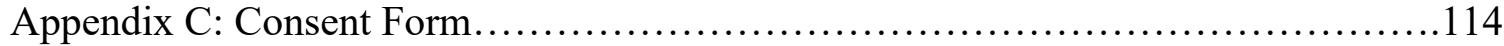

Appendix D: Questionnaire.............................................117

Appendix E: Debriefing Form.......................................... 123

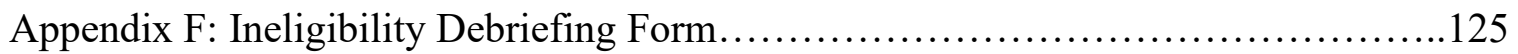


Barriers to the C-Suite: The Impact of Perceptions of Gender Bias on Women Leaders'

\section{Senior Leadership Ambitions}

"One of the main points we're putting forward is understanding that gender equality and including women in our success is not just a moral argument, it's very much an economic argument" says Canadian Prime Minister, Justin Trudeau, in response to Canada's issues on gender equality (Bloomberg, 2018).

Women have had success in attaining lower-level and middle-level leadership positions in recent years, yet the struggle of obtaining senior leadership positions remains (Braun, 2016; Flabbi, Piras, \& Abrahams, 2017; MacDonald, 2019). According to Fortune (2018), women currently represent only 5\% of Chief Executive Officers (CEOs) in the top 500 companies in Canada and the United States. In fact, gender parity in executive positions (commonly referred to as the C-suite) in Canada is among some of the lowest across North America and Europe, with women representing only 4\% of CEOs and $10 \%$ of executive positions (MacDonald, 2019). This issue cannot be attributed to the number of women available to fill such positions, as women now comprise $48 \%$ of the Canadian workforce (Statistics Canada, 2018). The case also cannot be made that women are less qualified for such positions, as women represent $56 \%$ of all undergraduate degrees and $51 \%$ of all graduate degrees that are presented annually in Canada (Statistics Canada, 2016). It is, therefore, likely that gender biases are underlying and perpetuating this issue.

Women may experience gender bias in the workplace in the form of "genderbased behaviors, policies, and actions that adversely affect a person's work by leading to unequal treatment or the creation of an intimidating environment because of one's gender" (Sipe, Johnson, \& Fisher, 2009, p. 342). There is a substantial body of research indicating that a variety of gender biases and systemic barriers prevent women from 
working their way up the corporate ladder, including the glass ceiling (Cook \& Glass, 2014), the glass cliff (Gipson, Pfaff, Mendelsohn, Catenacci, \& Burke, 2017), and the old boys' club (Glauser, 2018). However, recent research has put forward that an additional reason as to why women are not in highly ranked positions is that they themselves choose not to pursue such positions because they associate senior leadership roles with negative outcomes, such as anxiety and trade-offs with other life goals (Gino, Wilmuth, \& Brooks, 2015; McKinsey \& Company, 2018). This is a perplexing finding, as women report having high levels of career ambition (Harman \& Sealy, 2017; Jones \& Goulding, 1999). The underlying question, therefore, for the present research to explore is whether perceptions of gender bias in the workplace negatively affect women leaders' senior leadership ambitions.

When individuals who are in a stigmatized group experience judgement in a particular domain, their ambitions are negatively affected in that area (Flanagan, 2015; Steele, 1997). They may become demotivated if they perceive that the amount of input that they are investing is greater than the output that they are receiving (Adams, 1965). When women are in leadership positions, they are likely to regularly experience subtle gender bias in the form of the double bind (e.g., Eagly \& Karau, 2002) and the silencing of their input (e.g., Brescoll, 2011). Further, gender bias may result in specific workplace inequities, including workplace housework (e.g., Babcock, Recalde, Vesterlund, \& Weingart, 2017), inequitable pay (e.g., MacDonald, 2019), and inequitable opportunities - such as a lack of promotions (e.g., McKinsey \& Company, 2018). Women leaders are also likely to experience more overt forms of gender bias, such as workplace incivility (e.g., Cortina et al., 2013) and sexual harassment (e.g., McDonald, 2012). 
Therefore, the issue may not be that women leaders do not have ambitions for senior leadership more generally, but rather, that their ambitions for senior leadership are negatively affected once they perceive that others treat them like they do not belong in their position, they are not being compensated or recognized fairly, or they are being mistreated and made to feel unsafe at work. Although the research on this relation is limited, there is some evidence to suggest that women's leadership ambitions are negatively affected by these issues (e.g., Centre for Creative Leadership, 2017; Davies, Spencer, \& Steele, 2005; Gupta \& Bhawe, 2007; Leaper \& Starr, 2019). It is also important to determine whether such relations occur through another factor, rather than directly. Specifically, it is possible that perceptions of subtle gender bias, inequity, and mistreatment in the workplace affect senior leadership ambitions through cynicism towards work (Stern, Stone, Hopkins, \& McMillion, 1990).

Guided by stereotype threat theory (Steele, 1997) and equity theory (Adams, 1965), the purpose of this research was to examine whether women leaders' senior leadership ambitions are more strongly negatively affected by perceptions of gender bias (i.e., subtle gender bias, inequity, and mistreatment) in the workplace as compared to leaders who are men, and whether this association occurs via cynicism towards work. The majority of research addressing similar issues has done so using undergraduate students (e.g., Davies et al., 2005; Gupta \& Bhawe, 2007; Leaper \& Starr, 2019). To address this research gap, the present study examined women and men in lower-level and middle-level leadership positions directly, in order to examine the real-world outcomes of these issues on women's senior leadership ambitions. 


\section{The Benefits of Women's Leadership for Employees and Organizations}

Although there is considerable evidence that women and men are equally

effective leaders (Eagly \& Heilman, 2016; Kubu, 2018; Paustian-Underdahl, Walker, \& Woehr, 2014) and demonstrate fairly similar leadership styles, there may be a notable difference (Eagly \& Johannesen-Schmidt, 2001; McLaughlin, Uggen, \& Blackstone, 2017; Nash, Davies, \& Moore, 2017). Research indicates that men often exhibit leadership styles that are known for high standards of performance and control - such as autocratic, task-oriented, directive, and transactional leadership styles. Alternatively, women are more likely to have leadership styles that are more supportive in nature and highlight the importance of rewarding and developing followers - such as participative, democratic, and transformational leadership styles (Eagly \& Johannesen-Schmidt, 2001; Eagly, Johannesen-Schmidt, \& Van Engen, 2003; Van Engen \& Willemsen, 2004; Vial, Napier, \& Brescoll, 2016).

The leadership styles that are common in women have been associated with a variety of positive employee and organizational outcomes. For employees, the benefits include more employee engagement (Ghani et al., 2018; Zenger \& Folkman, 2012), creativity (Li, Liu, \& Luo, 2018), procedural justice, and organizational citizenship behaviours (Zeinabadi, 2013). Women in leadership have also been associated with lower levels of employee turnover (Catalyst, 2018), higher employment rates, and programs which support employee work-life balance (Gagliarducci \& Paserman, 2015). Further, women in leadership are related to better group processes which contribute to team cohesion and communication (Post, 2015). For organizations, an abundance of research has shown that women in leadership are associated with greater job and financial 
performance, profitability, risk management, business volume, and sustainable growth (Ali, Metz, \& Kulik, 2015; Dezso \& Ross, 2012; Flabbi et al., 2017; Francoeur, Labelle, \& Sinclair-Desgagné, 2008; Gagliarducci \& Paserman, 2015; Gipson et al., 2017; Jyoti \& Bhau, 2015; Noland, Moran, \& Kotschwar, 2016; Post \& Byron, 2015).

The benefits of women in senior leadership positions specifically have also been researched, although it is important to note that the findings of these studies may not generalize across all organizations as this research is often conducted with unique samples. From what is known, it has been shown that simply increasing the proportion of women in senior leadership from $0 \%$ to $30 \%$ has been related to a $15 \%$ increase in profitability (Noland et al., 2016). Experts predict that if every country reduced its gender gap at the top, a total of $\$ 12$ trillion could be added to the annual gross domestic product within the next 10 years, globally (McKinsey \& Company, 2015). Additional benefits include greater community relations and board accountability (Chadwick \& Dawson, 2018), positive reactions from shareholder and investors (Kolev, 2012; Martin, Nishikawa, \& Williams, 2009), and more ethical organizational practices (Melero, 2011; Post, 2015). More women in senior leadership positions is also associated with more women in lower and middle-level leadership positions, thus potentially increasing the diversity of organizations (Kurtulus \& Tomaskovic-Devey, 2012). These potential outcomes are extremely valuable for employees and organizations alike and highlight the importance of women in leadership.

However, despite the positive outcomes associated with women in lower and middle-level leadership, as well as the potential benefits of women in senior leadership, the number of women being promoted into senior leadership is scarce (Barling, 2014). 
Recently, part of the reason for this issue has been attributed to women's ambitions for such positions.

\section{Women's Senior Leadership Ambitions}

Ambition in the workplace has been defined as "the motivation to actively further one's career by having a strong focus on one's work life and career (operationalized via the concept of career orientation) in combination with a high motivation to excel (reflected by the concept of achievement motivation)" (Otto, Roe, Sobiraj, Baluku, \& Garrido Vásquez, 2017, p. 24). Those with high levels of ambition often engage in proactive behaviours to develop and further their careers (Barrick, Mount, \& Li, 2013; Otto et al., 2017; Schoon \& Polek, 2011). Ambition has been related to extrinsic career success, as those with high levels of career ambition have been shown to be more likely to attain their ideal or desired job position (Otto et al., 2017; Schoon \& Polek, 2011). These findings suggest that women who have senior leadership ambitions will likely seek or accept a senior leadership position if they are offered one.

Research has shown that many women report having high career ambitions and ambitions for leadership (e.g., Accenture, 2017; Boston Consulting Group, 2017; Harman \& Sealy, 2017; Jones \& Goulding, 1999). However, a series of nine studies conducted by Gino and colleagues (2015) across a variety of samples (i.e., leaders, online panels, students, recent graduates) indicate that women themselves may choose not to pursue high-level positions because they find these positions less desirable than do their male counterparts. McKinsey \& Company (2018) found similar results in a large study of American women in the workplace. Such research may be perpetuating a negative stereotype that puts the onus on women for this gap, as the researchers state that women 
themselves choose not to ascend in the corporate world, and therefore, are less likely to choose to develop professionally. Findings like this lead one to ponder why exactly several studies have found that women have lower ambitions for senior leadership positions than men.

While McKinsey \& Company (2018) do not ascribe these lower ambitions to a particular reason, Gino and colleagues (2015) attribute this to women's perceptions of more negative outcomes, such as anxiety and trade-offs/conflict with other life goals - as they explain that women are more likely to have multiple life goals (i.e., marriage and family goals as well as employment goals). However, research has shown that having children does not negatively impact women's ambition (Boston Corporate Group, 2017) and women with children are as likely as women without children to seek and have ambitions for senior leadership (Accenture, 2017). Therefore, it is unlikely that this is the sole reason.

A recent report from the Centre for Creative Leadership (2017) indicates that women and men have different reasons for turning down a leadership role. In this study, while both women and men typically reported refusing due to work-related issues (e.g., working longer hours), women specifically often refused due to a lack of confidence, in that they did not know whether they were genuinely wanted for the leadership role or whether they themselves could truly be leaders (Centre for Creative Leadership, 2017). Women also refused because they believed that they would not be given adequate resources for success. This has been reiterated in the literature, as women often report feeling that they are given fewer opportunities and resources to develop professionally than men in the workplace, and further indicate that they are not taken seriously by their 
colleagues and superiors (De Mascia, 2015). Further, recent research examining undergraduate women in the male-dominated fields of science, technology, engineering, and math (STEM) suggests that women who report experiencing gender bias and sexual harassment in their program have lower STEM career ambitions (Leaper \& Starr, 2019).

These findings provide an additional lens by which to view the findings of Gino and colleagues (2015), as it is possible that women may have lower ambitions for senior leadership because of external factors that shape the ways in which they view themselves as leaders and affect the opportunities that they are given. While previous research and traditional theories have shown that gender bias has indeed stopped women from entering into senior leadership positions (e.g., glass ceiling, Cook \& Glass, 2014; glass cliff, Gipson et al., 2017; old boys' club, Glauser, 2018), very little research has examined why women themselves may not have ambitions for such positions. Specifically, these findings appear to suggest that perceptions of gender bias in the workplace in the form of subtle gender bias, inequity, and mistreatment may affect women leaders' ambitions for senior leadership positions.

\section{Stereotype Threat Theory and Senior Leadership Ambitions}

According to stereotype threat theory (Steele \& Aronson, 1995), when individuals who are in a stigmatized group experience judgement in a particular domain, their ambitions are negatively affected (Flanagan, 2015; Spencer, Logel, \& Davies, 2016; Steele, 1997). This is particularly true in cases in which the stereotypes in question are widely held, such as in the case of leadership, which has traditionally been considered agentic in nature and associated primarily with men (Eagly \& Karau, 2002; Gupta \& Bhawe, 2007; Smith \& White, 2002). For example, when female undergraduate students 
are told that there is no difference between men and women's leadership effectiveness, they become as interested in taking on a leadership role as their male counterparts; however, when they are reminded of gender stereotypes, they become less interested in having a leadership role (Davies et al., 2005). This phenomenon has also been demonstrated with other occupations, as women's intentions to pursue careers in the male-dominated field of entrepreneurship have been shown to be negatively affected by stereotype threat (Gupta \& Bhawe, 2007).

Stereotype threat theory also indicates that individuals may begin to believe the various stereotypes that pertain to them (Flanagan, 2015; Schmader \& Johns, 2003; Steele, 1997). For example, when women are asked to indicate their gender before filling out a leadership description of themselves, they are more likely to rate their own leadership skills, and the way that others perceive their leadership skills, poorly (Flanagan, 2015). Similarly, women have been shown to underestimate how positively their leadership abilities will be evaluated by their supervisors (Sturm, Taylor, Atwater, \& Braddy, 2014).

In the workplace, women in lower-level and middle-level leadership positions are likely to be aware of and regularly experience subtle gender biases (Glauser, 2018; Hoyt \& Burnette, 2013; McKinsey \& Company, 2018; Vial et al., 2016). In the presence of such constraints, stereotype threat theory may help explain the difference in women leaders' ambitions for senior leadership positions, in that women leaders who perceive these issues in the workplace may have lower senior leadership ambitions than those who are not as heavily impacted by these issues. 


\section{Subtle Gender Bias in the Workplace}

In the past, gender biases in the workplace were overt in nature in that women would experience explicit and unconcealed forms of discrimination (e.g., Carr et al., 2000; Coombs \& King, 2005). However, in recent years societal norms have shifted and human resource departments have developed formal policies and procedures to protect employees against overt issues (Abad-Merino, Dovidio, Tabernero, González, 2018; Salles et al., 2019). This does not mean that the issues facing women are resolved and that women leaders do not regularly experience gender biases in the workplace. Instead, gender biases are more likely to be primarily subtle in nature (Abad-Merino et al., 2018).

Subtle gender biases occur when individuals have unconscious beliefs that come from stereotypes and negatively affect the ways in which they associate with others who are in social minorities, such as women (Moss-Racusin, Dovidio, Brescoll, Graham, \& Handelsman, 2012; Salles et al., 2019). For example, in a study by Moss-Racusin and colleagues (2012) that analyzed how likely academic science faculty were to hire a student who was a man or a woman for a laboratory manager position, the student who was a man was more likely to be perceived as competent and hirable than the student who was a woman with the same application. Subtle or unconscious biases can also make individuals think or behave in ways that are inconsistent with their externally held beliefs, morals, or values (Salles et al., 2019), as subtle gender biases are even held by individuals who strongly believe in equal rights, as well as by women themselves (MossRacusin et al., 2012; Nosek, Banaji, \& Greenwald, 2002).

Experiencing subtle forms of bias may be extremely harmful to women, as a recent meta-analysis indicates that subtle forms of discrimination (e.g., being treated with 
less courtesy than others) can negatively impact employees' stress levels, turnover intentions, job performance, career satisfaction, and career success - over and above overt forms of discrimination (Jones, Peddie, Gilraine, King, \& Gray, 2016). The researchers attribute this to the human need to understand the way that we are treated. In other words, if a woman experiences overt discrimination in the workplace, she will attribute this to a specific factor. When discrimination is subtle in nature, an individual will likely spend more mental resources trying to identify exactly why they are being treated the way that they are (Jones et al., 2016). Further, the researchers note that subtle forms of discrimination occur at a much higher frequency than overt forms, and are much harder to legally identify and handle. This indicates that subtle gender biases can indeed be damaging to those who perceive them.

Women in leadership positions may frequently experience subtle gender biases in the workplace (Hoyt \& Burnette, 2013; International Labour Organization, 2017; Powell, 2012). In fact, a recent global report indicates that women identify subtle gender biases specifically the social roles that women and men must follow - as one of the top barriers to leadership for women (International Labour Organization, 2017). This issue can affect women's performance evaluations, project assignments, access to leadership development programs, and social interactions (International Labour Organization, 2015). Importantly, these subtle gender biases may negatively affect how women see themselves as leaders, which is often an important factor in succeeding in senior leadership roles (DeRue \& Ashford, 2010; Ely, Ibarra, \& Kolb, 2011). In the current research, subtle gender bias encompasses the double bind (e.g., Eagly \& Karau, 2002) 
and silencing (e.g., Brescoll, 2011), which are gender biases that cannot be documented or easily proven, but can be felt.

\section{Women Leaders and the Double Bind}

According to gender stereotypes, women are expected to display communal behaviours, in that they must be warm, nurturing, and kind, whereas men are expected to display agentic behaviours, in that they must be assertive, self-confident, and strong (Cuddy, Fiske, \& Glick, 2007; Eagly \& Karau, 2002; Heilman, 2012; Koenig, 2018). For this reason, when we think leader, we often think man (Jackson, Engstrom, \& EmmersSommer, 2007) as the characteristics that are associated with leadership are agentic in nature (Koenig, Eagly, Mitchell, \& Ristikari, 2011; Schein, Mueller, Lituchy, \& Liu, 1996). Here a double bind presents itself, in which women must prove that they have characteristics such as competence, which are synonymous with leadership roles in order to meet the conditions of being a leader, while simultaneously softening their behaviour with caring or nurturing behaviours in order to meet the conditions of being a woman (Cuddy, Glick, \& Beninger, 2011; Eagly \& Johannesen-Schmidt, 2001; Gipson et al., 2017).

The double bind places an unrealistic condition on women that prevents them from progressing or meeting their true potential, as women who are in leadership are often hired into positions that are not as visible or positions that provide a support function, as opposed to those that are involved in the main operations of an organization (Bowles \& McGinn, 2005; Eagly \& Johannesen-Schmidt, 2001; Gipson et al., 2017; Rudman, Moss-Racusin, Glick, and Phelan, 2012). It is important to note that these issues are magnified when women are employed in male-dominated work environments, which 
is often the case for leadership (Bruckmüller \& Branscombe, 2010; Heilman, 2012;

Koenig, 2018; McLaughlin et al., 2017).

It is possible that, in line with stereotype threat theory, women leaders who report perceptions of the double bind in their workplace will have lower ambitions for senior leadership, as women have been shown to be aware of this issue and report that leadership is perceived as a man's job (International Labour Organization, 2017). As a result, women may be discouraged by the subtle perceptions of those around them and believe that they themselves would not make suitable senior leaders.

Hypothesis 1: Gender would moderate the relation between the double bind and senior leadership ambitions, such that the negative relation would be stronger for women than for men.

\section{The Silencing of Women's Input}

Women leaders may experience subtle gender biases by having their input silenced by others (Brescoll, 2011; Diehl \& Dzubinski, 2016; Hancock \& Rubin, 2015), which occurs when women's ideas and suggestions are interrupted, overlooked, or disregarded in the workplace (Dice, 2018). This is an adverse phenomenon that Facebook Chief Operating Officer (COO) Sheryl Sandberg has widely discussed (e.g., Sandberg, 2013; Sandberg \& Grant, 2015). While her articles are personal rather than empirical, Sandberg talks about her own and her colleagues' experiences as women in the leadership world. She explains that women's ideas in the workplace are more likely to be scrutinized or even ignored until they have been restated by a man - a notion which has been reinforced by many women at her talks, as well as other studies (e.g., Dice, 2018; Diehl \& Dzubinski, 2016). In fact, it appears that people prefer if a woman speaks less, as 
research indicates that women CEOs who speak regularly are perceived as less competent or suitable for leadership positions, whereas CEOs who are men and are talkative are rated as more competent and suited to leadership (Brescoll, 2011). A recent study indicates that men who speak promotively - in that they propose positive and new suggestions or ideas - are more likely to be rated as a leader in a group setting, whereas women who do the same are not (McClean, Martin, Emich, \& Woodruff, 2018). When women speak, they are also more likely to be interrupted (Hancock \& Rubin, 2015), which suggests that women's input is not valued as highly as men's input. It is important to note that both men and women tend to silence women in this way (Hancock \& Rubin, 2015; McClean et al., 2018; Rudman et al., 2012).

In turn, perceptions of silencing may be detrimental to how women view themselves and their own ideas. In fact, women often report feeling apprehensive about speaking too much in meetings or other situations as they fear backlash for appearing too controlling (Brescoll, 2011). Women are also less likely to give themselves verbal credit for the work that they have done if they are working with a man (Haynes \& Heilman, 2013). As such, it appears that these experiences may hinder women's confidence regarding their own abilities (Brescoll, 2011; Haynes \& Heilman, 2013). In accordance with stereotype threat theory, it is possible that women leaders who perceive silencing at work will have lower ambitions for senior leadership positions, as they may internalize these subtle notions against them and assume that they themselves would not make good senior leaders. 
Hypothesis 2: Gender would moderate the relation between silencing and senior leadership ambitions, such that the negative relation would be stronger for women than for men.

\section{Equity Theory and Senior Leadership Ambitions}

Equity theory (Adams, 1965) posits that one's motivation is affected by the balanced ratio of what they put in (e.g., hard work, commitment, sacrifice) and the output that they receive (e.g., recognition, salary, benefits), in that employees will become demotivated if they perceive that the amount of input that they are investing is greater than the output that they are receiving. Perceptions of inequity occur when an employee compares themselves to a similar other and observes that an employee in a similar position, who is investing a similar amount of effort, is receiving more positive outcomes in the form of rewards or opportunities than they are (Adams, 1965; Walster, Berscheid, \& Walster, 1973). In turn, employees will respond in a multitude of ways - most commonly by investing less input into their job, requesting more output from their employer, or quitting to rebalance the ration of inputs to outputs (Adams, 1965).

Women leaders may experience a great deal of inequity in the workplace, as women often allocate the same or greater effort (or input) as their counterparts who are men, and receive fewer rewards (or a lower output) (Hoobler et al., 2011; MacDonald, 2019; McKinsey \& Company, 2018). This is a prevalent issue that many women are aware of, as a recent survey (Salary Finance, 2019) identified that more than $50 \%$ of women feel that they are not treated equally to men in the workplace. However, recent qualitative research provides some evidence that when women do approach their employers regarding perceived inequities, they may be disregarded (Ontario Nonprofit 
Network, 2018). For example, one woman leader explained that when she approached her board asking for fair compensation, she was told that she would have to fundraise for a raise. Similarly, another woman leader explained that when she decided to come forward for a raise, she had to create a case for herself and indicate exactly why she deserved one, whereas the men in her workplace simply stated that they should be paid more (Ontario Nonprofit Network, 2018).

In situations in which women are receiving inequitable treatment and being rebuffed when seeking increased fairness, they may become demotivated for senior leadership roles - as research shows that women who perceive unfairness at work and recognize that they are given inadequate resources for development are more likely to 'opt out' of leadership positions (Ellemers, 2014; Rink, Ryan, \& Stoker, 2012). In this context, equity theory can help explain why women leaders may become demotivatedor have less ambition for - senior leadership positions. Women who perceive that they are investing as much or more than their counterparts, and are receiving less, may have lower ambitions for senior leadership than those who do not perceive such inequities.

In the current research, inequity encompasses workplace housework (e.g., Babcock et al., 2017), inequitable pay (e.g., MacDonald, 2019), and inequitable opportunities, such as a lack of promotions (e.g., McKinsey \& Company, 2018). These are gender biases that continue to be more subtle in nature, but can be pointed to. For example, one can show that a co-worker is being paid more than them because it is documented. 


\section{The Responsibility of Workplace Housework}

Women are likely to report being given roles and responsibilities that go beyond their typical job requirements (Babcock et al., 2017; Viewpoint Leadership, 2018). In other words, the meaningful responsibilities that women should be given are often replaced with more thankless ones, as women are expected to do more workplace housework in the form of non-promotable tasks such as taking notes, planning events, participating in committees, orienting new employees, and filling in for colleagues (Babcock et al., 2017; Williams, Dempsey, \& Slaughter, 2018). This issue occurs at the leadership level as well, as women in such positions may also be expected to engage in the aforementioned tasks which are not in their job description, such as helping interns or planning holiday parties (Grant \& Sandberg, 2015; Williams et al., 2018). It is important to note that women may report feeling the pressure of saying no to such tasks, as this often labels them as snarky or selfish - which can further impact the evolution of their careers (Kolb \& Porter, 2015).

Such tasks may take an emotional toll on women, as many report feeling more emotionally exhausted in the workplace than men do (Purvanova \& Muros, 2010). Women who engage in such tasks often do not receive any benefits as well. This notion was demonstrated in a study conducted by Heilman and Chen (2005) in which a woman who chose to stay late to help a colleague received the same evaluations as a man who chose not to. However, a man who chose to do so was evaluated much more favourably and was more likely to be recommended for various rewards, such as a raise or promotion. This may occur because women are expected to go above and beyond their standard job requirements in order to be successful, as organizational citizenship 
behaviours are more likely to be considered feminine and participated in by women (Cameron \& Nadler, 2013).

Therefore, it is possible that in accordance with equity theory, women leaders who perceive that they must engage in workplace housework will have lower ambitions for senior leadership positions. Women leaders who participate in such tasks may perceive that doing so is an additional requirement that does not provide additional benefits, and as such, may believe that they are not receiving fair output relative to others for the input that they are investing.

Hypothesis 3: Gender would moderate the relation between workplace housework and senior leadership ambitions, such that the negative relation would be stronger for women than for men.

\section{Inequitable Pay for Women}

In Canada, women are paid less than men for the same work, with women making \$0.83 for every dollar that men earn (MacDonald, 2019). MacDonald (2019) explains that some critics believe that this gap becomes nonexistent when different considerations, such as education, age, and experience are included. However, a study by Catalyst (2013) examined recently graduated women and men with MBA degrees in Canada and found that men earned a starting salary averaging $\$ 8,200$ more than women who were the same age, with the same educational qualifications, and the same level of experience. This trend has also been shown in recent female graduates who indicate that they have ambitions to be senior leaders (Catalyst, 2013; MacDonald 2019), indicating that women's career ambitions are not a contributing reason for this difference in pay. 
At the senior leadership level, this gap is even larger. Women executives make \$0.68 for every dollar that a man makes - which indicates that, in Canada, a top leader who is a woman earns approximately $\$ 950,000$ less per year than her male counterparts (MacDonald, 2019). It is important to note that it is not necessarily the base salary that differs at this level, but rather, the bonus pay. While bonus pay is often based on the share price of the company - which is a result of the company's performance - research has shown that women leaders continue to earn less bonus pay than men in companies with the same share price (ADP Research Institute, 2018; MacDonald, 2019).

MacDonald (2019) states that there are two main reasons for the gender pay gap. First, women are less likely to be placed or promoted into higher ranking positions that will allow them to be paid more. Second, women are less likely to be hired or promoted as leaders in larger sized companies or companies in larger sectors (e.g., industrial, energy, etc.), which pay more. However, while the aforementioned reasons account for $77 \%$ of the pay gap, the outstanding 23\% cannot be explained (MacDonald, 2019).

In this regard, women in lower or middle-level leadership positions are likely to be paid less than men, and may even be aware that this issue extends to senior leadership positions as well. It is possible that in accordance with equity theory, women leaders who perceive that they are being paid less than their counterparts will have lower ambitions for senior leadership positions, as they may feel that they are not receiving fair output relative to others for the input that they are investing at work.

Hypothesis 4: Gender would moderate the relation between inequitable pay and senior leadership ambitions, such that the negative relation would be stronger for women than for men. 


\section{Inequitable Opportunities for Women}

Despite requesting promotions at a similar rate to men, women are often given less recognition or career development opportunities than men - which can directly affect their progression to senior leadership (Bishu \& Alkadry, 2017; Diehl \& Dzubinski, 2016; Lyness \& Grotto, 2018). In Canada, women who are working full time have been shown to receive fewer promotions than men do, and even receive a lower increase in salary following a promotion (Javdani \& McGee, 2019). One reason for this issue is that subtle biases affect how performance is evaluated, with women's performance often undervalued and men's performance overvalued (Hoobler et al., 2011; McKinsey \& Company, 2018). However, a meta-analysis conducted by Joshi, Son, and Roh (2015) shows that while the allocation of rewards (e.g., bonuses, promotions, etc.) is indeed greater for men than it is for women, this difference is 14 times greater than the difference between performance evaluations. As such, it appears that differences in opportunities given cannot be attributed to performance evaluations alone (Joshi et al., 2015; Van Esch et al., 2018).

The role of gender in inequitable opportunities is a reality that women may be aware of, as they have been shown to report that their gender plays a strong role in the allocation of opportunities and rewards that they are given (e.g., McKinsey \& Company, 2018; Ontario Nonprofit Network, 2018). In fact, research suggests that women particularly those in leadership positions - believe that their gender will affect their ability to progress professionally in the future (McKinsey \& Company, 2018). Therefore, it is possible that in line with equity theory, women leaders who perceive that they are being given fewer opportunities at work relative to their counterparts will have lower 
ambitions for senior leadership positions, as they may believe that they are not receiving fair output relative to others for the input that they are investing.

A Lack of Women Mentors. One reason for inequitable opportunities is that men in lower-ranked positions are likely to have a variety of men mentors in the workplace, while women leaders are less likely to have access to women mentors (Cook \& Glass, 2014; De Mascia, 2015; Hoobler et al., 2011). This is an issue that many women experience, with the Ontario Nonprofit Network (2018) reporting that approximately $60 \%$ of women do not have a mentor in the workplace. This can be attributed to how few women there are in senior leadership positions, as research shows that those who are in such positions will often provide mentorship opportunities to women (Gagliarducci \& Paserman, 2015). Instead, the predominance of men in senior leadership positions directly limits women in lower-ranked leadership positions, as men is such positions will often feel more loyal and inclined to supporting other men (Cook \& Glass, 2014). This is often a result of in-group preferences, which favour and lend opportunities to those in the in-group and limit opportunities to those who are not (Cook \& Class, 2014; Powell \& Butterfield, 2002). This is an important disparity, as employees who solidify working relationships with their senior leaders are more likely to receive opportunities, such as promotions, and have greater leadership ambitions themselves (Mattis, 2001; McKinsey \& Company, 2018). In turn, women are less likely to have mentors who will give them access to opportunities such as promotions and support them through the often political nature of the workplace - which negatively affects career progression (De Mascia, 2015; Hoobler et al., 2011). 
The Perceived Riskiness of Women. An additional reason for this discrepancy is that organizations are often more reluctant to promote women leaders or help them develop for senior leadership positions because they deem it a bigger risk (Van Esch et al., 2018; Barsh \& Yee, 2011). In other words, despite the fact that support from organizations is crucial for women's advancement and development (Chesterman \& Ross-Smith, 2006), employers may subtly discriminate against promoting a woman in the event that she will leave the position following a pregnancy or related family issue (Hewlett \& Luce, 2005; Javdani \& McGee, 2019). While women are less likely to have linear career paths than men are (Hewlett \& Luce, 2005; Van Esch et al., 2018), this is an issue that is often perpetuated by unreliable evidence - such as word of mouth or media coverage - and maintains the notion that women are not committed to their jobs (DunnJensen \& Stroh, 2007; Van Esch et al., 2018). For this reason, men will often be prepared for senior leadership positions and given opportunities that women are not (Van Esch et al., 2018).

Hypothesis 5: Gender would moderate the relation between inequitable opportunities and senior leadership ambitions, such that the negative relation would be stronger for women than for men.

\section{Mistreatment in the Workplace and Senior Leadership Ambitions}

In addition to issues of subtle gender bias and inequity, women are also subject to mistreatment in the workplace, whether it be by colleagues, subordinates, clients, or those in upper leadership (Chan, Chow, Lam, \& Cheung, 2008; McDonald, 2012; Ontario Nonprofit Network, 2018). In other words, while there are laws in place to prevent mistreatment (e.g., the Occupational Health and Safety Act) (Lippel, Vézina, 
Bourbonnais, \& Funes, 2016; Ontario Ministry of Labour, 2010), and while many forms of overt discrimination have been reduced in recent years, workplace mistreatment is an issue that women continue to deal with (Abad-Merino et al., 2018; Chan et al., 2008; McDonald, 2012). Mistreatment has been shown to be more common in some workplaces than others, and therefore, may be a product of organizational culture - as some organizations do not reprimand such behaviour (Chan et al., 2008; Deery, Walsh, \& Guest, 2011).

Importantly, research suggests that women who are in positions of leadership or power are more likely to be mistreated than those who are not (Berdahl, 2007; McDonald, 2012; McKinsey \& Company, 2018; Ontario Nonprofit Network, 2018). This distinction may occur because some individuals believe that women who behave outside of the realm of conventional roles or personality characteristics need to be punished (Berdahl, 2007; McDonald, 2012; McLaughlin, Uggen, \& Blackstone, 2012).

Additionally, women in such roles are more likely to be the only woman in a group of men, which further places them in a vulnerable position for mistreatment (McKinsey \& Company, 2018).

Such experiences of mistreatment have been associated with a variety of negative consequences, such as lower job commitment, lower job satisfaction, and absenteeism (Chan et al., 2008; McDonald, 2012; Nielsen \& Einarsen, 2012). Further, women who are being mistreated at work may report turnover intentions (Chan et al., 2008; Dionisi, Barling, \& Dupré, 2012; Merkin \& Shah, 2014). These are prominent examples of how mistreatment may negatively affect women's work motivation. Therefore, it is possible that women leaders who perceive mistreatment in the workplace may be less likely to 
have ambitions for senior leadership in that they may experience a loss in work motivation and have increased intention to leave their organization. In the current research, mistreatment encompasses workplace incivility (e.g., Cortina, 2008) and sexual harassment (e.g., McDonald, 2012). These are gender biases that are more overt in nature and include specific, unwanted actions. It is important to note that while workplace incivility and sexual harassment are indeed broader constructs, they are often related to issues of gender discrimination and may be behavioural indicators of gender bias (Bobbitt-Zeher, 2011; Jenner, Djermester, Prügl, Kurmeyer, \& Oertelt-Prigione, 2019).

\section{Workplace Incivility Towards Women}

Workplace incivility has been defined as "low-intensity deviant behavior with ambiguous intent to harm the target, in violation of workplace norms for mutual respect" (Andersson \& Pearson, 1999, p. 457) and includes acts such as ignoring others, giving dirty looks, and speaking to others with a condescending tone (Andersson \& Pearson, 1999; Cortina, Magley, Williams, \& Langhout, 2001). Those who are in positions of leadership are not excluded from experiencing this issue, as recent research shows that managers are likely to perceive workplace incivility from their subordinates, co-workers, and superiors (Holmvall \& Sobhani, 2019). Specifically, the prominence of selective incivility has become known, wherein those in vulnerable groups (e.g., women, racial minorities, etc.) are more likely to be the target of incivil acts in the form of disguised sexism or racism (e.g., Cortina, 2008; Cortina et al., 2013; Saxena, Geiselman, \& Zhang, 2019).

Workplace incivility has been shown to have a multitude of negative repercussions on women's psychological health, such as lower satisfaction with life and 
more depressive symptoms (Miner, Settles, Pratt-Hyatt, \& Brady, 2012). Further, women who perceive incivility in the workplace often report negative career outcomes, such as greater turnover intentions, lower organizational commitment, and lower job satisfaction (Cortina et al., 2013; Spence-Laschinger, Leiter, Day, \& Gilin, 2009). As such, it is possible that women leaders who perceive incivility in the workplace may be less likely to have ambitions for senior leadership.

Hypothesis 6: Gender would moderate the relation between workplace incivility and senior leadership ambitions, such that the negative relation would be stronger for women than for men.

\section{Sexual Harassment Towards Women}

Sexual harassment in the workplace is defined as unwelcome sexual behaviour, which ranges from suggestive and inappropriate emails and comments to assault (Chan et al., 2008; Fitzgerald et al., 1997; McDonald, 2012). This is an issue that is prevalent among women leaders, as more women in leadership positions report being sexually harassed - outnumbering women in non-leadership roles (McKinsey \& Company, 2018; McLaughlin et al., 2012; Ontario Nonprofit Network, 2018). Such a problem also poses a threat to women's career progression, as recent research suggests that experiencing sexual harassment can stall women's advancement, and sometimes, even end women's careers (Denissen \& Saguy 2014; McLaughlin et al., 2017). This is because women may be ostracized by their co-workers after reporting an issue, classified as a 'troublemaker' by upper leadership, or quit their jobs following a case of sexual harassment that remains unresolved (McLaughlin et al., 2017; Quinn, 2002). In addition, sexual harassment has been associated with a variety of negative psychological and workplace outcomes for 
women, such as decreased psychological well-being, decreased job satisfaction, and greater turnover intentions (McDonald, 2012; McLaughlin et al., 2012; Rospenda et al., 2009). Therefore, it is possible that women leaders who experience sexual harassment in the workplace may be less likely to have ambitions for senior leadership.

Hypothesis 7: Gender would moderate the relation between sexual harassment and senior leadership ambitions, such that the negative relation would be stronger for women than for men.

\section{The Mediating Effect of Cynicism Towards Work}

Cynicism towards work has been defined as an attitude of pessimism, hopelessness, and frustration towards work. Those who have cynicism towards work often believe that work is unrewarding, unfulfilling, and not worth the effort (Andersson \& Bateman, 1997; Stern et al., 1990). There is evidence to suggest that negative work experiences are related to cynicism towards work. For example, when employees experience a psychological contract breach, in that their organization fails to comply with an expected mutual promise or obligation, they report more cynicism towards work (Chiaburu, Peng, Oh, Banks, \& Lomeli, 2013; Li \& Chen, 2018). Role overload, role conflict, and organizational injustice have been related to cynicism towards work (Chiaburu et al., 2013). Importantly, there is evidence to suggest that perceptions of inequity in the workplace may be associated with cynicism towards work, as employees who perceive favouritism at work (Abubakar, Namin, Harazneh, Arasli, \& Tunç, 2017) and disproportionate pay at the executive level (Andersson \& Bateman, 1997) may be more likely to report cynicism towards work. Recent research also suggests that perceptions of workplace incivility may be related to cynicism towards work (Manzoor, 
Manzoor, \& Khan, 2020). Taken together, these findings suggest that perceptions of gender bias in the workplace may be related to cynicism towards work.

There is also evidence to suggest that cynicism towards work is related to lower senior leadership ambitions. While no direct association has been made between the two, cynicism towards work has been related to various negative work motivation outcomes, such as more workplace withdrawal (Abubakar et al., 2017), lower job satisfaction (Chiaburu et al., 2013; Scott \& Zweig, 2016), greater counterproductive work behaviours (Li \& Chen, 2018), lower organizational commitment, lower job performance, and greater turnover intentions (Chiaburu et al., 2013).

Therefore, it is likely that perceptions of subtle gender bias, inequity, and mistreatment in the workplace do not affect senior leadership ambitions directly, but rather, via cynicism towards work - which occurs when individuals perceive gender bias in the workplace - and, ultimately, results in lower senior leadership ambitions.

Hypothesis 8: Cynicism towards work would mediate the relation between (a) the double bind and senior leadership ambitions, (b) silencing and senior leadership ambitions, (c) workplace housework and senior leadership ambitions, (d) inequitable pay and senior leadership ambitions, (e) inequitable opportunities and senior leadership ambitions, (f) workplace incivility and senior leadership ambitions, and (g) sexual harassment and senior leadership ambitions.

It is possible that perceptions of gender bias in the workplace may be more strongly related to cynicism towards work for women than for men. A variety of issues related to gender bias, such as perceptions of inequitable pay (Andersson \& Bateman, 1997), inequitable opportunities (Abubakar et al., 2017), and incivility (Manzoor et al., 
2020) have been associated with cynicism towards work. These are issues that women are likely aware they experience more than men (e.g., Basford, Offermann, \& Behrend, 2014; Cortina et al., 2013; McKinsey \& Company, 2018). Therefore, women may attribute such experiences to issues of gender bias in their workplace, which may affect their cynicism levels more strongly, compared to men who may attribute these issues to other matters.

Hypothesis 9: Gender would moderate the relation between (a) the double bind and cynicism towards work, (b) silencing and cynicism towards work, (c) workplace housework and cynicism towards work, (d) inequitable pay and cynicism towards work, (e) inequitable opportunities and cynicism towards work, (f) workplace incivility and cynicism towards work, and (g) sexual harassment and cynicism towards work, such that the positive relation would be stronger for women than for men.

\section{Current Research}

Although research has identified that there is a lack of women in senior leadership and has examined the various forms of subtle gender bias (i.e., the double bind and silencing), inequity (i.e., workplace housework, inequitable pay, and inequitable opportunities), and mistreatment (i.e., workplace incivility and sexual harassment) that women leaders may perceive in the workplace, it was not yet understood how these issues may affect women leaders' senior leadership ambitions and cynicism towards work. In order to assess this, the hypothesized relations presented in Figure 1 were tested by administering a survey to a sample of leaders who were currently employed in lower and middle-level leadership positions. Men were included as a comparison group in order to determine whether these relations were perceived more strongly by women leaders. Participants were recruited through the online crowdsourcing company, Prolific. 


\section{Figure 1}

Hypothesized Relations Between Variables

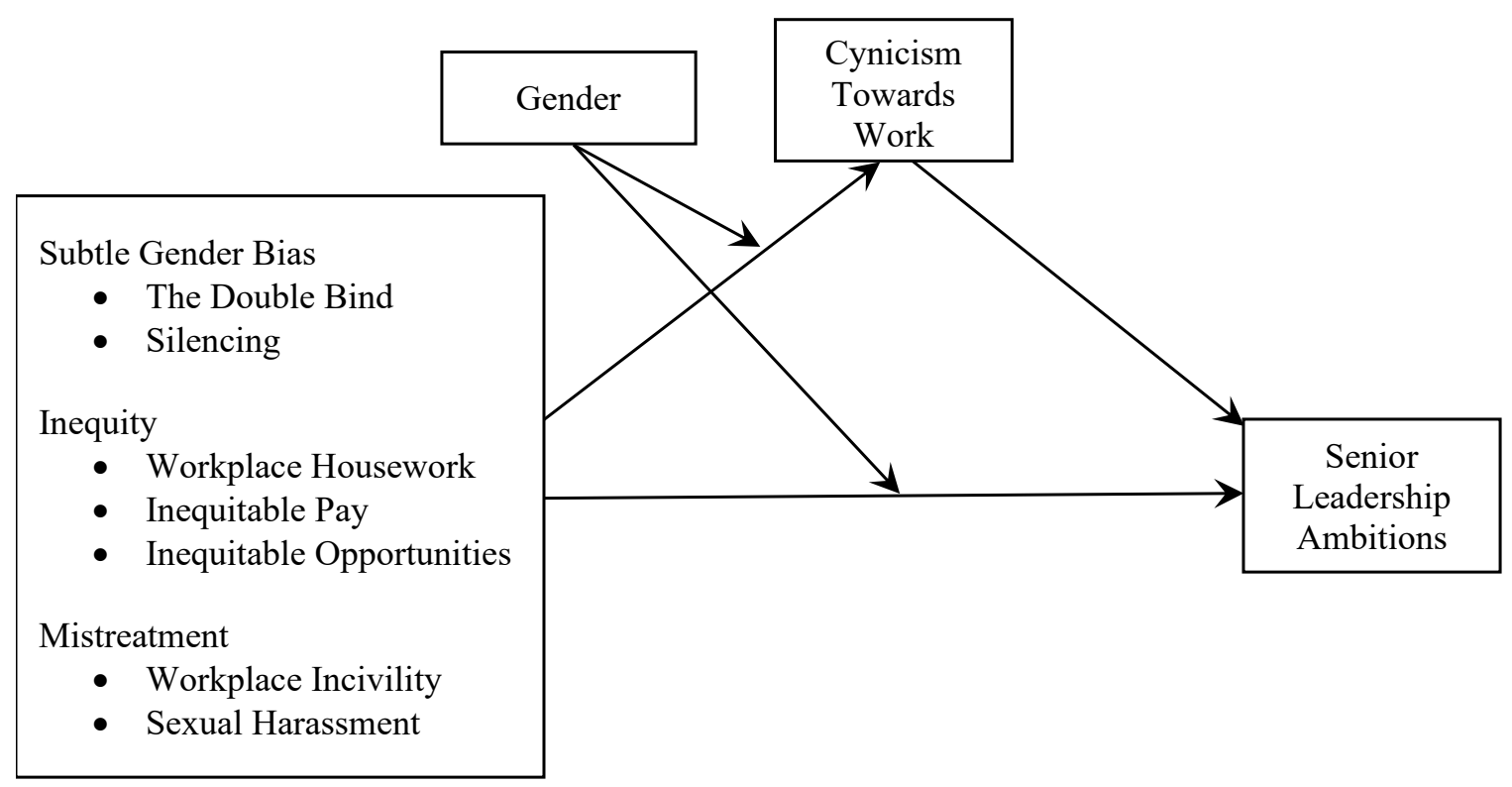

Due to the importance that has been placed on women and their caregiving roles in the literature (e.g., Elmuti, Jia, \& Davis, 2009; Harlow, 2002; Hoobler et al., 2011; Lyness \& Grotto, 2018; Stone \& Hernandez, 2013), I controlled for whether participants had children living with them. Additionally, I controlled for gender diversity climate, in that I assessed whether participants worked in a male-dominated workplace, one with gender diversity, or one that is female-dominated (e.g., Jansen et al., 2017; Konrad et al., 2010; Lyness \& Grotto, 2018; Nishii, 2013). Gender diversity climate was chosen as a control variable because it has been shown to impact issues of gender bias in the workplace (Konrad, Cannings, \& Goldberg, 2010). Specifically, in organizations with a gender diverse climate, women often perceive less mistreatment, gender discrimination, and conflict (Konrad et al., 2010; Nishii, 2013). However, in male-dominated workplaces, women are more likely to report perceptions of gender bias, such as exclusion (Konrad et al., 2010; Jansen, Otten, \& Van Der Zee, 2017). As such, these 
specific control variables were selected because they have been shown to be important confounds in women's leadership outcomes.

This research offers both theoretical significance and practical relevance by providing a more comprehensive understanding regarding the absence of women in senior leadership positions. The present research also advances knowledge on the impact of the subtle gender bias, inequity, and mistreatment that women may perceive in the workplace. Further, to my knowledge, this research is the first quantitative study to examine the real-world effects of these issues on women's senior leadership ambitions by directly examining a group of leaders.

\section{Method}

\section{Procedure}

Participants were recruited using the online crowdsourcing company, Prolific. Despite being a newer company, Prolific was chosen because it has been shown to provide high quality data and can easily acquire employees with specific job titles across organizations (Palan \& Schitter, 2018; Peer, Brandimarte, Samat, \& Acquisti, 2017). According to Prolific's website (https://www.prolific.co/), their services have been used to recruit samples for hundreds of published studies. Data from commercial online panels such as Prolific have also been shown to have comparable reliability and validity to data from traditional convenience samples (Walter, Seibert, Goering, \& O’Boyle, 2019).

Prolific operates by sending email invitations to individuals who have registered to participate in research studies once an online survey for which they are eligible becomes available. Individuals are then presented with the recruitment notice (see Appendix A for an example) and can decide whether they would like to participate. In 
order to be eligible to participate, participants must have: (a) identified as a man, a woman, or as a transgender man or woman (i.e., so as to identify with a specific gender), (b) been employed in a full-time or part-time lower-level or middle-level leadership position, and (c) resided in Canada, the United Kingdom, or the United States. The individuals who met this eligibility criteria (see Appendix B) were given access to the survey located on Qualtrics. They were presented with the consent form (see Appendix C) which defined the purpose of the study, stated that participation was completely voluntary, and informed individuals that there would be one or more attention check items within the survey. All relevant measures and demographics that participants completed can be found in Appendix D. Upon completion or withdrawal from the study, participants were directed to the debriefing information (see Appendix E) that provided them with the objective of the study, as well as additional resources in the unlikely event that they experienced psychological distress as a result of the study. Participants were compensated the equivalent of \$3.87 CAD through Prolific for their participation in the study. The mean time for completion of the survey was 15.77 minutes.

In order to minimize issues of common method bias, proactive steps were taken in the study's design (Conway \& Lance, 2010). Participants were assured of their anonymity, given the freedom to complete the online survey wherever was most comfortable and private for them, and reminded that they should answer all questions honestly (Conway \& Lance, 2010; Podsakoff, MacKenzie, Lee, \& Podsakoff, 2003; Podsakoff, MacKenzie, \& Podsakoff, 2012). Further, priming effects were avoided by asking participants about their senior leadership ambitions prior to asking about issues of 
gender bias in the questionnaire's design (Schwarz, Rizzuto, Carraher-Wolverton, Roldán, \& Barrera-Barrera, 2017).

\section{Participants}

The initial sample comprised 426 cases. A total of 77 cases were removed as individuals did not meet the study's eligibility criteria, did not consent to participate in the study, or did not complete any of the demographic items. Further, two cases were removed for failing to respond correctly to the attention check items within the study, resulting in a final sample of 347 participants. No cases were removed for speeding (i.e., surveys that were completed in less than one-third of the study's estimated completion time, or 4 minutes). All participants who successfully completed the survey completed it in full; there were no missing data present in the dataset.

The final sample $(N=347)$ consisted of 174 women and 173 men, with a mean age of $39.29(S D=10.26)$, ranging from 19 to 68 years old. Participants were primarily Caucasian (84.70\%), with the next largest groups identifying as Black (4.30\%), Hispanic/Latin American (1.70\%), East Asian (2.30\%), South Asian (1.70\%), South East Asian (.90\%), and West Asian (.60\%). Additionally, 3.70\% of participants indicated that they were biracial. The majority of participants resided in the United Kingdom $(68.90 \%)$, while $26.20 \%$ resided in the United States, and $4.90 \%$ resided in Canada. In terms of relationship status, $48.10 \%$ of participants reported that they were married, $25.10 \%$ were in a relationship, $19.30 \%$ were single, and $7.50 \%$ were separated, divorced, or widowed. With regard to dependents, $52.20 \%$ of participants reported having children living in their home, whereas $47.80 \%$ did not. 
In total, $88.80 \%$ of participants indicated that they worked full-time, while $11.20 \%$ worked part-time. Just over half of the participants $(53.60 \%)$ indicated that they were lower-level leaders, while $46.40 \%$ indicated that they were employed in a middlelevel leadership position. In terms of leadership tenure, $4.60 \%$ of participants reported being in a leadership role for less than a year, $33.20 \%$ had 1 to 3 years of leadership experience, $28.50 \%$ had 4 to 6 years, $11.80 \%$ had 7 and 10 years, and $21.90 \%$ had more than 10 years of leadership experience. Participants worked in a variety of industries, such as health, information and technology, government, education, and retail (see Table $1)$.

\section{Table 1}

\section{Participant Industries}

\begin{tabular}{lcc}
\hline & Frequency & Percent \\
\cline { 2 - 3 } Health & 62 & 17.87 \\
Information and Technology & 46 & 13.26 \\
Government & 41 & 11.82 \\
Education & 41 & 11.82 \\
Retail & 33 & 9.51 \\
Business & 31 & 8.93 \\
Manufacturing & 23 & 6.63 \\
Construction & 16 & 4.61 \\
Transportation & 10 & 2.88 \\
Arts and Entertainment & 10 & 2.88 \\
Restaurant & 8 & 2.31 \\
Non-Profit & 6 & 1.73 \\
Law & 5 & 1.44 \\
Research & 4 & 1.15 \\
Social Services & 4 & 1.15 \\
Other & 4 & 1.15 \\
Real Estate & 2 & .58 \\
Military & 1 & .29 \\
\hline
\end{tabular}


Participants were asked to self-report the gendered natured of their workplace. Altogether, $40.60 \%$ of participants indicated that their workplace was gender diverse, while $29.70 \%$ indicated that their workplace was male-dominated, and $29.70 \%$ indicated that their workplace was female-dominated.

\section{Measures}

\section{Senior Leadership Ambitions}

Seven items from the leadership aspirations subscale of the Career Aspiration Scale developed by Gregor and O’Brien (2016) were used to assess senior leadership ambitions. The original measure has been shown to have good test-retest reliability and construct validity (Gregor \& O’Brien, 2016). In the current study, the items of this scale were modified to reflect ambitions for senior leadership and were assessed on a 5-point Likert scale ranging from $1=$ Untrue of me, to $5=$ True of me. Sample items include: "I hope to become a senior leader in my career field," "I want to have responsibility for the future direction of my organization or business," and "I hope to move up to a senior leadership position in my organization or business." Three items were reverse coded. Higher scores on this scale reflected higher senior leadership ambitions. The alpha coefficient for the Career Aspiration Scale was $\alpha=.95$.

\section{The Double Bind}

Six items from the Women as Managers Scale developed by Peters, Terborg, and Taynor (1974) were used to measure participants' perceptions of the double bind. The prompt for this scale was modified for the current study and asked participants about their perceptions of others' beliefs regarding women/men in leadership in their workplace. For this reason, participants in the study were given a modified version of the scale 
depending on their gender (i.e., that is, male participants read the version referring to men). Both versions of the scale were the same, with the exception of the gender used. Examples of items include: "It is not acceptable for women/men to assume leadership roles as often as men/women," "Women/men are not ambitious enough to be successful in the working world," and "To be a successful leader, a woman/man must sacrifice some of her/his femininity/masculinity." The items were assessed on a 5-point Likert scale ranging from $1=$ Strongly disagree, to $5=$ Strongly agree. Higher scores on this measure reflected higher perceptions of the double bind. The alpha coefficient for this scale was $\alpha$ $=.89$.

\section{Silencing}

A four-item measure developed by Lin, Kain, and Fritz (2013) was used to assess participants' perceptions of the silencing of their input; the authors reported a Cronbach's alpha of .86 for this measure. While the original measure examined work interruptions in general, for the current study items were modified to assess speaking interruptions for the current study. Sample items include: "I am frequently interrupted by others when I am speaking at work," "People frequently disturb me while I am trying to speak in meetings," and "Being interrupted while I am speaking is a frequent occurrence." The items of this scale were assessed on a 5-point Likert scale ranging from $1=$ Strongly disagree, to $5=$ Strongly agree. One scale item was reverse coded. Higher scores on this measure indicated higher instances of silencing.

Since there was no available measure of workplace silencing beyond speaking interruptions, four items were written for this study to assess being ignored, scrutinized, or hesitant to speak, based on recent literature in this area (e.g., Brescoll, 2011; Dice, 
2018). These items were evaluated by three subject matter experts to determine their face validity. The four items are as follows: "My ideas or suggestions are ignored by others at work," "My ideas or suggestions are negatively scrutinized by others at work," "I avoid sharing my ideas or suggestions during meetings," and "I avoid speaking too much during meetings." The items were assessed on a 5-point Likert scale ranging from $1=$ Strongly disagree, to $5=$ Strongly agree. Higher scores on this measure reflected higher instances of silencing.

\section{Workplace Housework}

Since there was no available measure to examine workplace housework and the specific, gendered tasks that women may feel obligated to do in the workplace, six items were written for this study based on recent research in this area (e.g., Babcock et al., 2017; Williams et al., 2018). All items were evaluated by three subject matter experts for face validity. Examples of items include: "Help others by taking notes during meetings," "Plan events (e.g., holiday parties) although it is not required," and "Ensure that there are snacks or beverages for meetings." The items were assessed on a 5-point Likert scale ranging from $1=$ Strongly disagree, to $5=$ Strongly agree. Higher scores reflected higher instances of workplace housework.

\section{Inequitable Pay and Inequitable Opportunities}

The six-item Distributive Justice Index developed by Price and Mueller (1986) was used separately as a measure of both inequitable pay (i.e., with the prompt reading "To what extent are you paid fairly at work compared to your co-workers who have the same job title as you...") and inequitable opportunities (i.e., with the prompt reading "To what extent are you given fair opportunities (such as promotions) at work compared to 
your co-workers who have the same job title as you..."). This measure has been shown to have high convergent and discriminant validity (Howard, 1999; Price \& Mueller, 1986). Sample items include: "Considering the responsibilities that you have?," "For the amount of effort that you put forth?," and "For work that you have done well?" The items of the Distributive Justice Index were assessed on a 5-point Likert scale ranging from $1=$ Not at all fair, to $5=$ Very much fair. All items of the scale were reverse coded so higher scores on this measure indicated higher perceptions of inequitable pay and inequitable opportunities. The alpha coefficients for both of the inequitable pay and inequitable opportunities scales was 94 .

\section{Workplace Incivility}

The seven-item Workplace Incivility Scale was used to assess workplace incivility (Cortina et al., 2001). Sample items include: "Put you down or were condescending to you?," "Ignored or excluded you from professional camaraderie?," and “Doubted your judgment on a matter over which you have responsibility?" The items of the Workplace Incivility Scale were assessed on a 5-point Likert scale ranging from $1=$ Never, to $5=$ Many times. Higher scores on this measure indicated higher instances of workplace incivility. The alpha coefficient for the Workplace Incivility Scale was $\alpha=$ 90 .

\section{Sexual Harassment}

Twelve items from the Sexual Experiences Questionnaire measuring gender harassment, sexual hostility, and unwanted sexual attention were used to assess women's experiences of sexual harassment in the workplace (Fitzgerald, Magley, Drasgow, \& Waldo, 1999). This scale has been shown to have high content and criterion-related 
validity and test-retest reliability (Fitzgerald et al., 1999; Lim \& Cortina, 2005).

Examples of items include: "Stared, leered, or ogled you in a way that made you feel uncomfortable?," "Continued to ask you for dates, drinks, dinner, etc., even though you said no?," and "Touched you in a way that made you feel uncomfortable?" The items of the Sexual Experiences Questionnaire were measured on a 5-point Likert scale ranging from $1=$ Never, to $5=$ Many times. Higher scores on this measure indicated higher instances of sexual harassment. The alpha coefficient for the Sexual Experiences Questionnaire was $\alpha=.95$.

\section{Cynicism Towards Work}

The ten-item Workplace Cynicism Scale was used to assess cynicism towards work (Stern et al., 1990). Examples of items include: "To me, working is nothing more than making a living," "There's no such thing as a company that cares about its employees," and "Most people today are stuck in dead-end, go-nowhere jobs." The items of this measure were assessed on a 5-point Likert scale ranging from $1=$ Strongly disagree, to $5=$ Strongly agree. Higher scores on this measure reflected higher instances of cynicism towards work. The alpha coefficient for the Workplace Cynicism Scale was $\alpha=.83$.

\section{Attention Check Items}

Participants were subject to two attention check items in order to improve data quality (Paolacci \& Chandler, 2014). Participants were instructed to select 'Disagree' on one item near the beginning of the questionnaire and 'Often' on one item near the end of the questionnaire, in order to ensure that they were being attentive. Those who did not respond correctly to these items were excluded from the statistical analyses. 


\section{Demographics}

Participants were asked to report their gender, ethnicity, age, relationship status, and how many children they had living with them. Further, participants answered questions relating to their job level (i.e., lower-level or middle-level leadership), industry (e.g., health, education, information and technology, etc.), leadership tenure, whether they had full-time or part-time status, and whether their current work environment was male-dominated, gender diverse, or female-dominated.

\section{Results}

\section{Preliminary Analyses}

\section{Assumptions Testing}

Before undertaking the main analyses, tests for assumptions of normality, linearity, homoscedasticity, and multicollinearity were conducted. Normality was examined using the Shapiro-Wilks test, box plots, histograms, normal Q-Q plots, and tests of skew and kurtosis. Plots of standardized predicted values (zpred) and standardized residuals (zresid) were created to test assumptions of linearity and homoscedasticity. Finally, multicollinearity was examined using correlation matrices and multicollinearity statistics in the form of tolerance and VIF scores.

Assumptions for linearity, homoscedasticity, and multicollinearity were met. However, the assumption of normality was only met for senior leadership ambitions, workplace housework, and inequitable pay. For all other variables, with the exception of sexual harassment, the absolute skewness and kurtosis scores never exceeded 1.26 (SE = $.13)$ and $1.40(S E=.26)$, respectively. For sexual harassment, the skewness score of 4.08 $(S E=.13)$ and kurtosis score of $18.94(S E=.26)$ indicate that this variable was indeed 
skewed. While floor effects are common in the workplace sexual harassment literature (e.g., O'Reilly \& Garrett, 2019; Zhu, Lyu, \& Ye, 2019), this variable was extremely skewed, and as a result, was not included in subsequent analyses.

\section{Outliers}

The data were examined for univariate outliers using box plots for each of the variables. Two outliers (i.e., cases that were three standard deviations from the mean) were identified for the double bind and two outliers were found for workplace housework. To determine the presence of multivariate outliers within the data, Mahalanobis distance and studentized deleted residuals were examined. Mahalanobis distance indicated that there were eight outliers present in the data; however, the studentized deleted residuals indicated that there were no outliers. Therefore, all 347 cases were retained for analyses.

\section{Examining the New Silencing and Workplace Housework Items}

Since the four-item measure developed by Lin and colleagues (2013) did not quite reflect the full scope of the construct of silencing and there was no available measure for the construct of workplace housework, new items written for the present research were included in the questionnaire. To assess these new items, two principal component analyses (PCA) were conducted for the silencing items and two PCAs were conducted for the workplace housework items in total.

Silencing Items. The first PCA for silencing (rotation = Direct Oblimin; Eigenvalue $=1$ ) included the established and new silencing items and resulted in two components, explaining $72.38 \%$ of the variance (see Table 2). Items with loadings of 32 or greater (Tabachnick, Fidell, \& Ullman, 2019) were considered to be loading on a 
component. The four items from the established scale loaded on the first component. Two of the new items cross-loaded on both components and the other two new items loaded only on the second component. It was decided to drop the two items that loaded solely on the second component ('I avoid sharing my ideas or suggestions during meetings' and 'I avoid speaking too much during meetings').

\section{Table 2}

Principal Component Analysis Loadings of Silencing Items

\begin{tabular}{|c|c|c|}
\hline & \multicolumn{2}{|c|}{ Component } \\
\hline & 1 & 2 \\
\hline 1. I am frequently interrupted by others when I am speaking at work. & .91 & -.03 \\
\hline $\begin{array}{l}\text { 2. I am able to make my point when I speak at work without someone } \\
\text { interrupting me. }\end{array}$ & .78 & .00 \\
\hline 3. People frequently disturb me while I am trying to speak in meetings. & .88 & -.01 \\
\hline 4. Being interrupted while I am speaking is a frequent occurrence. & .93 & -.03 \\
\hline 5. ${ }^{a}$ My ideas or suggestions are ignored by others at work. & .39 & .54 \\
\hline 6. ${ }^{a}$ My ideas or suggestions are negatively scrutinized by others at work. & .46 & .44 \\
\hline 7. ${ }^{\text {a }}$ I avoid sharing my ideas or suggestions during meetings. & .00 & .90 \\
\hline 8. ${ }^{\text {a }}$ I avoid speaking too much during meetings. & -.10 & .91 \\
\hline
\end{tabular}

Note. Kaiser-Meyer-Olkin value of .87, Bartlett's test of sphericity $p<.001$. Rotation method: Oblimin with Kaiser Normalization. Items that are bolded loaded successfully onto the component. ${ }^{\text {a }}$ New items created for the current research.

The PCA was run a second time with the six remaining silencing items (rotation = Direct Oblimin; Eigenvalue $=1$ ), all of which loaded on a single component that explained $66.45 \%$ of the variance, with component loadings of .76 or greater (see Table 3). Therefore, these six items were combined into one scale. It is important to note that the addition of the two new items does not affect the reliability of the scale (i.e., Cronbach's alpha $=.90$ with and without the addition of the two new items) and the two new items add an important element to the silencing measure. Specifically, the original silencing items take into account how often participants reported being interrupted while 
they were speaking, whereas the two new items consider whether participants perceived that their ideas or suggestions were ignored or negatively scrutinized by others at work.

\section{Table 3}

Principal Component Analysis Loadings of Combined Silencing Items

Component

1. I am frequently interrupted by others when I am speaking at work. .86

2. I am able to make my point when I speak at work without someone interrupting me.

3. People frequently disturb me while I am trying to speak in meetings. .85

4. Being interrupted while I am speaking is a frequent occurrence. .89

$5 .{ }^{a}$ My ideas or suggestions are ignored by others at work. .76

$6 .{ }^{\mathrm{a}}$ My ideas or suggestions are negatively scrutinized by others at work. .76 Note. Kaiser-Meyer-Olkin value of .87, Bartlett's test of sphericity $p<.001{ }^{\text {a }}$ New items created for the current research.

Workplace Housework Items. The first PCA for workplace housework (rotation $=$ Direct Oblimin; Eigenvalue $=1$ ) resulted in two components, explaining $65.29 \%$ of the variance (see Table 4). Two of the items ('Fill in for colleagues who are absent' and 'Engage in tasks that go beyond my typical job requirements') loaded onto only the second component. Therefore, these items were dropped.

A second PCA was then conducted on the four remaining workplace housework items $($ rotation $=$ Direct Oblimin; Eigenvalue $=1)$, which loaded onto a single component - explaining $60.85 \%$ of the variance, with component loadings of .65 and greater (see Table 5). It is important to note that these items asked participants whether they felt obligated to engage in workplace housework. 


\section{Table 4}

Principal Component Analysis Loadings of Housework Items

\begin{tabular}{lcc} 
& \multicolumn{2}{c}{ Component } \\
\hline & 1 & 2 \\
\cline { 2 - 3 } 1. Help others by taking notes during meetings. & $\mathbf{. 5 6}$ & $\mathbf{. 3 3}$ \\
2. Fill in for colleagues who are absent. & -.20 & $\mathbf{. 9 6}$ \\
3. Plan events (e.g., holiday parties) although it is NOT required. & $\mathbf{. 7 6}$ & .10 \\
4. Ensure that there are snacks or beverages for meetings. & $\mathbf{. 8 7}$ & -.03 \\
5. Provide my employees with informal incentives (e.g., treats). & $\mathbf{. 8 8}$ & -.10 \\
6. Engage in tasks that go beyond my typical job requirements. & .31 & $\mathbf{. 4 5}$ \\
\hline
\end{tabular}
Note. Rotation method: Oblimin with Kaiser Normalization. Kaiser-Meyer-Olkin value of .78, Bartlett's test of sphericity $p<.001$. Items that are bolded loaded successfully onto the component.

\section{Table 5}

Principal Component Analysis Loadings of Remaining Housework Items

\begin{tabular}{lc}
\hline & Component \\
\cline { 2 - 2 } 1. Help others by taking notes during meetings. & .65 \\
2. Plan events (e.g., holiday parties) although it is NOT required. & .81 \\
3. Ensure that there are snacks or beverages for meetings. & .85 \\
4. Provide my employees with informal incentives (e.g., treats). & .79 \\
\hline
\end{tabular}

Note. Kaiser-Meyer-Olkin value of .77, Bartlett's test of sphericity $p<.001$.

\section{Descriptive Statistics}

Means, standard deviations, zero-order Pearson correlations, and internal consistency reliabilities can be found in Table 6. All established and new scale items demonstrated strong internal consistency, comparable to that of previous research. Among participants, cynicism towards work was moderately low and senior leadership ambitions were moderately high. Specifically, the distribution for senior leadership ambitions was somewhat flat, and had a slightly negative skew (see Figure 2 for a breakdown by gender). The mode for senior leadership ambitions among all participants 
was 5 , and when this was split by gender, men reported a mode of 5 and women reported a mode of 4 . This indicates that many participants had high senior leadership ambitions.

\section{Figure 2}

Histogram of Senior Leadership Ambitions by Gender

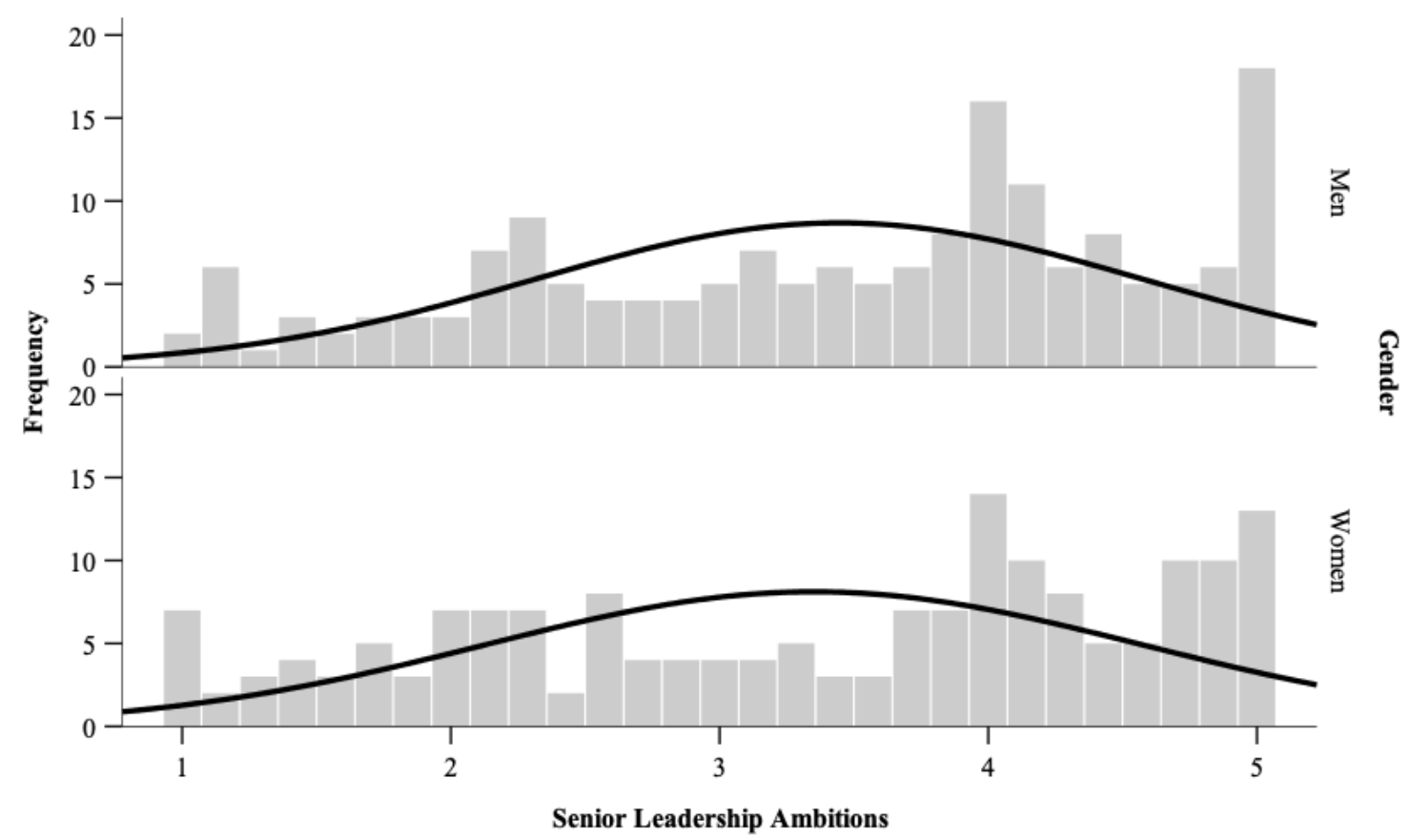

Correlations between the variables indicate that cynicism towards work was negatively related to senior leadership ambitions. Inequitable pay had a moderately high correlation with inequitable opportunities. However, these variables were not very highly correlated (i.e., .80 or higher), and therefore, can be considered to be separate constructs. Gender was significantly and negatively correlated with cynicism towards work, but otherwise was not related to any of the other study variables. Gender diversity climate and whether participants have children living with them, which were selected to be control variables, were significantly correlated with a number of key study variables, although these correlations were relatively low. 


\section{Table 6}

Means, Standard Deviations, and Correlations for Key Variables

\begin{tabular}{|c|c|c|c|c|c|c|c|c|c|c|c|c|c|c|}
\hline & & $M$ & $S D$ & 1 & 2 & 3 & 4 & 5 & 6 & 7 & 8 & 9 & 10 & 11 \\
\hline 1. & Senior Leadership Ambitions & 3.40 & 1.18 & $(.95)$ & & & & & & & & & & \\
\hline 2. & Double Bind & 1.78 & .79 & -.04 & $(.89)$ & & & & & & & & & \\
\hline 3. & Silencing & 2.26 & .81 & -.04 & $.43 * * *$ & $(.90)$ & & & & & & & & \\
\hline 4. & Workplace Housework & 2.57 & .92 & $.17 * *$ & $.12^{*}$ & $.19 * * *$ & $(.78)$ & & & & & & & \\
\hline 5. & Inequitable Pay & 2.63 & 1.05 & -.08 & $.15^{* *}$ & $.20 * * *$ & .01 & $(.94)$ & & & & & & \\
\hline 6. & Inequitable Opportunities & 2.52 & 1.01 & -.09 & $.23 * * *$ & $.31 * * *$ & -.01 & $.70 * * *$ & $(.94)$ & & & & & \\
\hline 7. & Workplace Incivility & 1.76 & .73 & -.06 & $.36^{* * *}$ & $.60 * * *$ & .10 & $.29 * * *$ & $.40 * * *$ & $(.90)$ & & & & \\
\hline 8. & Cynicism Towards Work & 2.35 & .66 & $-.23 * *$ & $.20 * * *$ & $.39 * * *$ & .10 & $.28 * * *$ & $.35 * * *$ & $.33 * * *$ & $(.83)$ & & & \\
\hline 9. & Gender $^{\mathrm{a}}$ & .50 & .50 & -.04 & .08 & .06 & .08 & .04 & .00 & .08 & $-.21 * * *$ & -- & & \\
\hline & Children ${ }^{b}$ & .52 & .50 & .08 & .00 & $-.11 *$ & .01 & -.04 & -.09 & -.07 & $-.15^{* *}$ & .04 & -- & \\
\hline 11. & Gender Diversity Climate $^{c}$ & .30 & .46 & .00 & $-.18 * * *$ & $-.12 *$ & -.05 & .04 & -.06 & -.06 & -.04 & $.12 *$ & -.03 & -- \\
\hline
\end{tabular}

Note. $N=347$. Cronbach's alphas are listed in the diagonal.

${ }^{a}$ Men coded as 0 ; women coded as $1 .{ }^{\text {b }}$ No children living at home coded as 0 ; one or more children living at home coded as 1.

${ }^{\mathrm{c}}$ Male-dominated workplace coded as 0 , female-dominated workplace/gender diverse workplace coded as 1.

$* p<.05 . * * p<.01 . * * * p<.001$. 


\section{Gender, Senior Leadership Ambitions, and Workplace Experiences}

To examine differences between men and women on the study variables, nine independent samples $t$-tests were run. The only significant difference observed was that men were significantly more likely to report cynicism towards work compared to women $t(345)=3.97, p<.001($ see Table 7$)$.

\section{Table 7}

Differences by Gender

\begin{tabular}{lrrrrrr}
\hline & \multicolumn{2}{c}{ Men } & \multicolumn{2}{c}{ Women } & & \multirow{2}{*}{ Cohen's $d$} \\
\cline { 2 - 5 } & $M$ & $S D$ & $M$ & $S D$ & & \multicolumn{1}{c}{ S } \\
\cline { 2 - 5 } Senior Leadership Ambitions & 3.44 & 1.14 & 3.35 & 1.22 & .75 & .08 \\
Double Bind & 1.72 & .62 & 1.84 & .92 & -1.43 & -.16 \\
Silencing & 2.21 & .78 & 2.30 & .83 & -1.10 & -.12 \\
Workplace Housework & 2.49 & .89 & 2.64 & .95 & -1.47 & -.16 \\
Inequitable Pay & 2.58 & 1.02 & 2.68 & 1.09 & -.83 & -.09 \\
Inequitable Opportunities & 2.52 & .97 & 2.53 & 1.05 & -.09 & -.10 \\
Workplace Incivility & 1.70 & .65 & 1.82 & .79 & -1.46 & -.16 \\
Cynicism Towards Work & 2.48 & .66 & 2.21 & .64 & $3.97 * * *$ & .43 \\
\hline
\end{tabular}

Note. Women $(n=174)$, men $(n=173)$. Levene's test for equality of variances was significant for the double bind and workplace incivility, and therefore, equal variances were not assumed for those variables.

$* p<.05 . * * p<.01 . * * * p<.001$.

\section{Gender Diversity Climate, Senior Leadership Ambitions, and Workplace Experiences}

To examine differences between participants who worked in a male-dominated workplace or a female-dominated/gender diverse workplace on the study variables, nine independent samples $t$-tests were performed. The gender diversity climate variable was dummy coded so that male-dominated was coded as 0 and was compared to femaledominated/gender diverse, which was coded as 1 . Participants who worked in a maledominated workplace were significantly more likely to report perceptions of the double 
bind and silencing compared to participants who worked in a female-dominated/gender diverse workplace, after adjusting for unequal variances (see Table 8).

\section{Table 8}

Differences by Gender Diversity Climate

\begin{tabular}{lcrrrrr}
\hline & \multicolumn{2}{c}{$\begin{array}{c}\text { Male- } \\
\text { Dominated }\end{array}$} & \multicolumn{2}{c}{$\begin{array}{c}\text { Gender } \\
\text { Diverse/Female } \\
\text { Dominated }\end{array}$} & & \\
\cline { 2 - 6 } & $M$ & $S D$ & $M$ & $S D$ & & Cohen's $d$ \\
\hline Senior Leadership Ambitions & 3.39 & 1.16 & 3.40 & 1.19 & -.03 & .00 \\
Double Bind & 2.00 & .91 & 1.68 & .71 & $3.13 * *$ & .50 \\
Silencing & 2.41 & .87 & 2.19 & .77 & $2.21^{*}$ & .34 \\
Workplace Housework & 2.64 & 1.00 & 2.54 & .89 & .94 & .10 \\
Inequitable Pay & 2.56 & 1.06 & 2.66 & 1.05 & -.75 & -.08 \\
Inequitable Opportunities & 2.62 & 1.02 & 2.48 & 1.01 & 1.14 & .12 \\
Workplace Incivility & 1.83 & .73 & 1.73 & .72 & 1.19 & .13 \\
Cynicism Towards Work & 2.39 & .69 & 2.33 & .65 & .76 & .08 \\
\hline
\end{tabular}

Note. Male-dominated $(n=103)$, female-dominated/gender diverse $(n=244)$.

$* p<.05 . * * p<.01 . * * * p<.001$.

\section{Gender and Gender Diversity Climate}

It is possible that the lack of gender differences noted earlier is because there was an interaction of gender and gender diversity climate. To explore this idea, a series of two-way ANOVAs (gender X gender diversity climate) on all study variables were conducted (see Table 9). There were two significant interactions of gender and gender diversity climate - women who were working in a male-dominated workplace were significantly more likely to report perceptions of the double bind $(M=2.45, S D=1.07$; see Figure 3$)$ and silencing $(M=2.68, S D=.87$; see Figure 4$)$ in their workplace. Taken together, these results appear to suggest that the gender diversity climate of a workplace may influence the subtle gender biases that women perceive. There was also a particular main effect of note. Women $(M=1.82, S D=.79)$ were significantly more likely to report 
perceptions of workplace incivility compared to men $(M=1.70, S D=.65)$, regardless of the gender diversity climate of their workplace.

\section{Table 9}

Two-Way ANOVA for Gender and Gender Diversity Climate

\begin{tabular}{|c|c|c|c|c|c|c|}
\hline \multirow[b]{3}{*}{ Senior Leadership Ambitions } & \multicolumn{2}{|c|}{ Gender $(G)^{a}$} & \multicolumn{2}{|c|}{$\begin{array}{l}\text { Gender Diversity } \\
\text { Climate (C) }{ }^{\mathrm{b}}\end{array}$} & \multicolumn{2}{|c|}{$G \times C^{c}$} \\
\hline & $F$ & $\eta p^{2}$ & $F$ & $n p^{2}$ & $F$ & $n p^{2}$ \\
\hline & .35 & .00 & .01 & .00 & .05 & .00 \\
\hline Double Bind & $14.44^{* * *}$ & .04 & $18.34^{* * *}$ & .05 & $23.54 * * *$ & .06 \\
\hline Silencing & $5.45^{*}$ & .02 & $7.59 * *$ & .02 & $6.30 * *$ & .02 \\
\hline Workplace Housework & 3.64 & .01 & 1.53 & .00 & 1.20 & .00 \\
\hline Inequitable Pay & .27 & .00 & .47 & .00 & .14 & .00 \\
\hline Inequitable Opportunities & .27 & .00 & 1.51 & .00 & .55 & .00 \\
\hline Workplace Incivility & $4.57^{*}$ & .01 & 2.39 & .01 & 2.53 & .01 \\
\hline Cynicism Towards Work & $7.63 * *$ & .02 & .24 & .00 & 3.57 & .01 \\
\hline
\end{tabular}

Note. Women in male-dominated workplaces $(n=42)$, women in femaledominated/gender diverse workplaces $(n=132)$. Men in male-dominated workplaces $(n=$ $61)$, men in female-dominated/gender diverse workplaces $(n=112)$.

$\eta p^{2}=$ partial eta squared.

${ }^{\text {a }}$ Men coded as 0 ; women coded as $1 . d f=1,343 .{ }^{\mathrm{b}}$ Male-dominated workplace coded as 0 , female-dominated workplace and gender diverse workplace coded as $1 . d f=1,343 .{ }^{\mathrm{c}} d f$ $=1,343 . * p<.05 . * * p<.01 . * * * p<.001$. 
Figure 3

The Effect of Gender and Gender Diversity Climate on the Double Bind

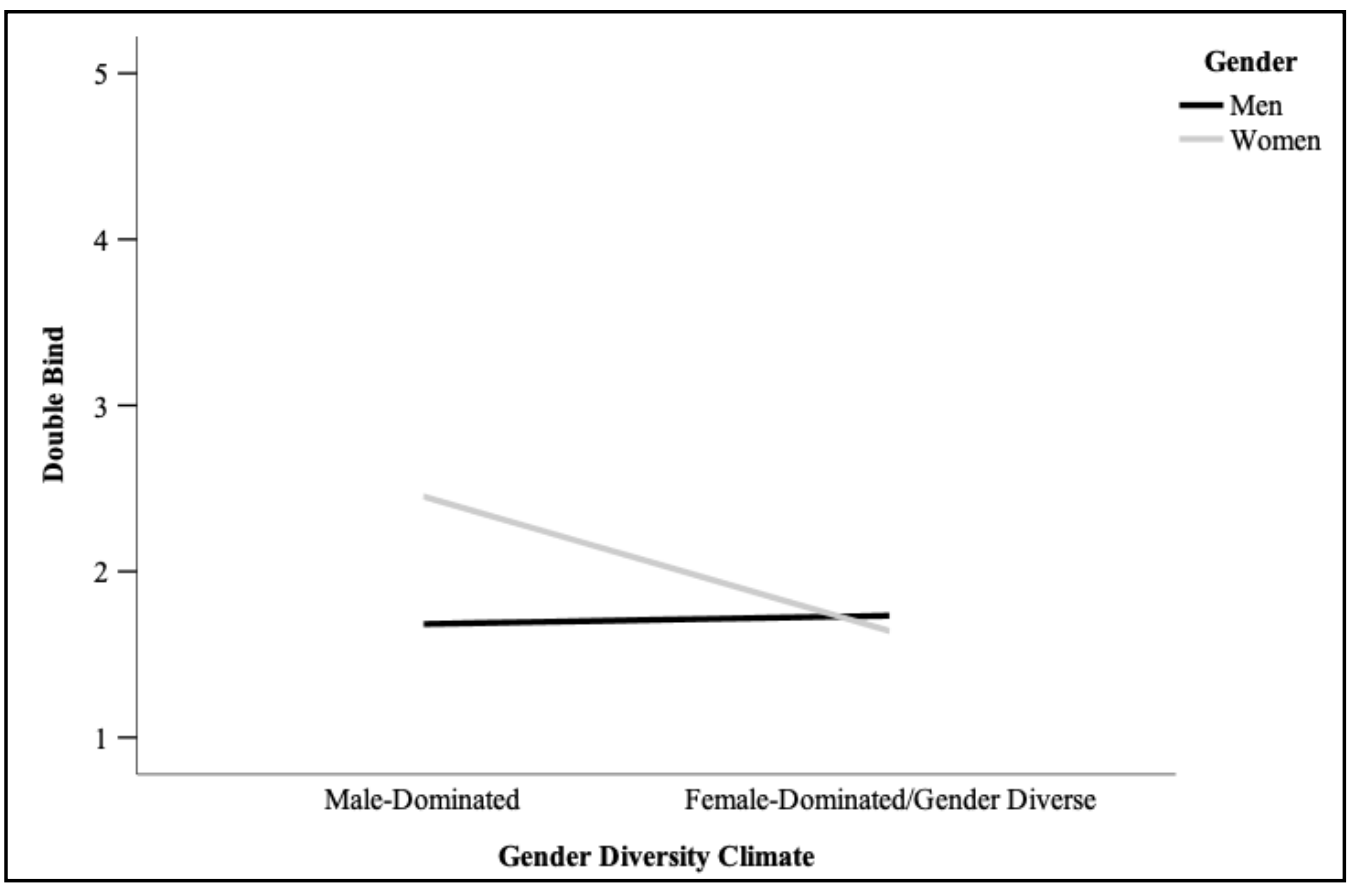

Figure 4

The Effect of Gender and Gender Diversity Climate on Silencing

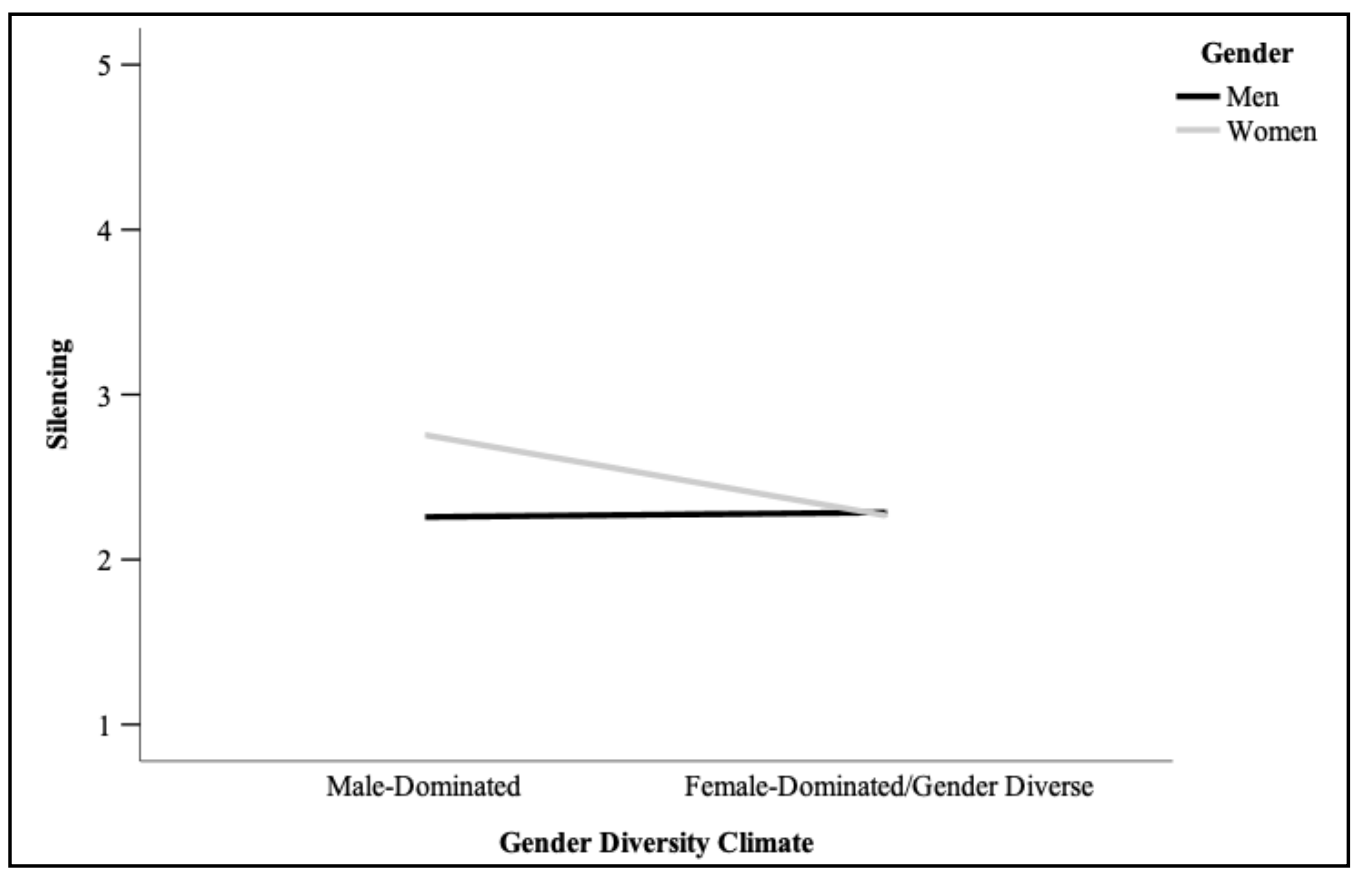




\section{Ethnicity, Senior Leadership Ambitions, and Workplace Experiences}

Although there were insufficient participants of colour $(n=53 ; 15.30 \%)$ to use

ethnicity as a study variable, it is important to explore how ethnicity may affect

experiences in the workplace. Acknowledging that the group sizes were vastly unequal, I

conducted nine independent samples $t$-tests to examine differences between participants

who were a person of colour and those who were Caucasian for the study variables (see

Table 10). Participants who were people of colour were significantly more likely to report

having senior leadership ambitions, more silencing, and more cynicism towards work

compared to participants who were Caucasian.

Table 10

Differences by Ethnicity

\begin{tabular}{lcrrrrr}
\hline & \multicolumn{7}{c}{ Person of Colour } & \multicolumn{2}{c}{ Caucasian } & \multicolumn{1}{c}{} \\
\cline { 2 - 5 } & $M$ & $S D$ & $M$ & \multicolumn{1}{c}{$S D$} & \multicolumn{1}{c}{$t$} & Cohen's $d$ \\
\hline Senior Leadership Ambitions & 3.89 & 1.05 & 3.31 & 1.18 & $-3.63^{* * *}$ & -.83 \\
Double Bind & 1.92 & .94 & 1.75 & .75 & -1.29 & -.32 \\
Silencing & 2.49 & .90 & 2.21 & .78 & $-2.09^{*}$ & -.51 \\
Workplace Housework & 2.74 & 1.05 & 2.54 & .90 & -1.45 & -.16 \\
Inequitable Pay & 2.70 & 1.03 & 2.62 & 1.06 & -.56 & -.03 \\
Inequitable Opportunties & 2.57 & 1.09 & 2.51 & 1.00 & -.40 & -.04 \\
Workplace Incivility & 1.83 & .86 & 1.75 & .70 & -.64 & -.16 \\
Cynicism Towards Work & 2.54 & .68 & 2.31 & .65 & $-2.33^{*}$ & -.25 \\
\hline
\end{tabular}

Note. Caucasian $(n=294)$, person of colour $(n=53)$. Caucasian coded as 0 ; person of colour coded as 1 . Levene's test for equality of variances was significant for senior leadership ambitions, the double bind, silencing, and workplace incivility, and therefore, equal variances were not assumed for those variables. ${ }^{*} p<.05 . * * p<.01 . * * * p<.001$.

\section{The Effect of Gender on Senior Leadership Ambitions Through Cynicism Towards}

\section{Work}

In order to examine whether perceptions of gender bias in the workplace affect participants' cynicism towards work, and ultimately, their senior leadership ambitions, 
and whether this effect is stronger for women than for men, Hayes' (2013) PROCESS macro model 8 was used to test for moderated mediation (see Figure 5 for the revised hypothesized relations). The double bind, silencing, workplace housework, inequitable pay, inequitable opportunities, and workplace incivility $(\mathrm{X})$ were expected to have a direct effect on lowered ambitions for senior leadership (Y) and an indirect effect through cynicism towards work (M). In addition, the relation between each $\mathrm{X}$ variable and cynicism towards work (M) and senior leadership ambitions (Y) was anticipated to be moderated by gender (W), after controlling for gender diversity climate and whether participants have children living with them. Confidence intervals of $95 \%$ and bootstrapping of 10,000 samples were used.

\section{Figure 5}

Revised Hypothesized Relations Between Variables

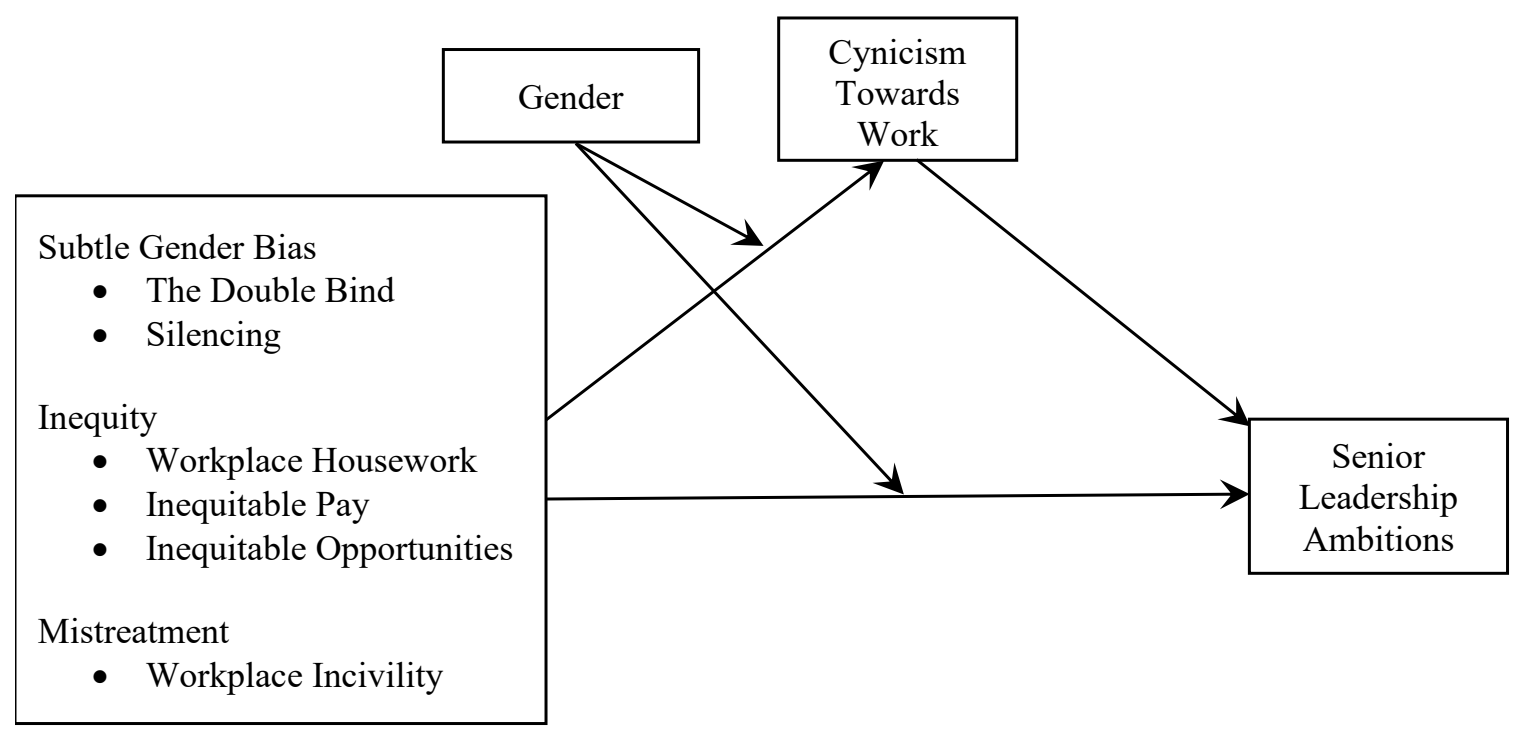

Note. The original hypothesized relations were revised to reflect the removal of sexual harassment.

\section{The Effect of the Double Bind}

With the double bind as the predictor variable, gender moderated the relation between the double bind and cynicism towards work, however, this positive effect was 
only significant for men (see Figure 6), contrary to expectations. Similarly, the indirect effect of the double bind on senior leadership ambitions through cynicism towards work was significant only for men. There was no moderated effect of the double bind on senior leadership ambitions (see Table 11). Taken together, these results provide support that men who report perceptions of the double bind in their workplace may be more affected than women, in that they may become more cynical towards work.

\section{Table 11}

The Effect of the Double Bind on Senior Leadership Ambitions Through Cynicism Towards Work as Moderated by Gender

\begin{tabular}{|c|c|c|c|c|c|c|c|c|}
\hline & \multicolumn{4}{|c|}{ Cynicism Towards Work $(M)$} & \multicolumn{4}{|c|}{ Senior Leadership Ambitions $(Y)$} \\
\hline & Path & Coeff. ${ }^{\text {a }}$ & $S E$ & $\begin{array}{l}95 \% \mathrm{CI} \\
\mathrm{LL}, \mathrm{UL}^{\mathrm{c}}\end{array}$ & Path & Coeff. ${ }^{\text {a }}$ & $S E$ & $\begin{array}{l}95 \% \text { CI } \\
\text { LL, UL } \\
\end{array}$ \\
\hline Double Bind $(X)$ & $a_{1}$ & $.38 * * *$ & .08 & $.23, .53$ & $c_{1}^{\prime}$ & .11 & .15 & $-.18, .40$ \\
\hline $\begin{array}{l}\text { Cynicism } \\
\text { Towards Work } \\
(M)\end{array}$ & - - & - - & -- & - - & $b$ & $-.44 * * *$ & .10 & $-.64,-.24$ \\
\hline Gender $(W)$ & $a_{2}$ & .21 & .18 & $-.14, .56$ & $c^{\prime} 2$ & -.00 & .33 & $-.66, .65$ \\
\hline$X \times W$ & $a_{3}$ & $-.29 * *$ & .09 & $-.47,-.10$ & $c^{\prime} 3$ & -.13 & .18 & $-.47, .22$ \\
\hline $\begin{array}{l}\text { Indirect Effect }\left(a_{1} b\right) \\
\text { for Men }\end{array}$ & - - & - - & - - & - - & $a_{1} b$ & -.17 & .05 & $-.28,-.08^{\mathrm{D}}$ \\
\hline $\begin{array}{l}\text { Indirect Effect }\left(a_{2} b\right) \\
\text { for Women }\end{array}$ & - - & - - & -- & - - & $a_{2} b$ & -.04 & .03 & $-.11, .01^{\mathrm{b}}$ \\
\hline Constant & $i_{1}$ & $1.91^{* * *}$ & .15 & $1.62,2.22$ & $i_{2}$ & $4.29 * * *$ & .34 & $3.61,4.97$ \\
\hline \multirow[t]{2}{*}{ Model Summary } & \multicolumn{4}{|c|}{$R^{2}=.14$} & \multicolumn{4}{|c|}{$R^{2}=.06$} \\
\hline & \multicolumn{4}{|c|}{$F(5,341)=10.65, p<.001$} & \multicolumn{4}{|c|}{$F(6,340)=3.83, p=.001$} \\
\hline
\end{tabular}

Note. $N=347$. Gender diversity climate and children were used as control variables.

${ }^{a}$ Unstandardized $b$ coefficient. ${ }^{b}$ Bias-corrected bootstrap CI using 10,000 resamples. ${ }^{c} \mathrm{LL}=$ Lower limit; $\mathrm{UL}=$ Upper limit.

$* p<.05$. ${ }^{* *} p<.01$. $* * * p<.001$. 


\section{Figure 6}

Gender as a Moderator in the Relation Between the Double Bind and Cynicism Towards Work

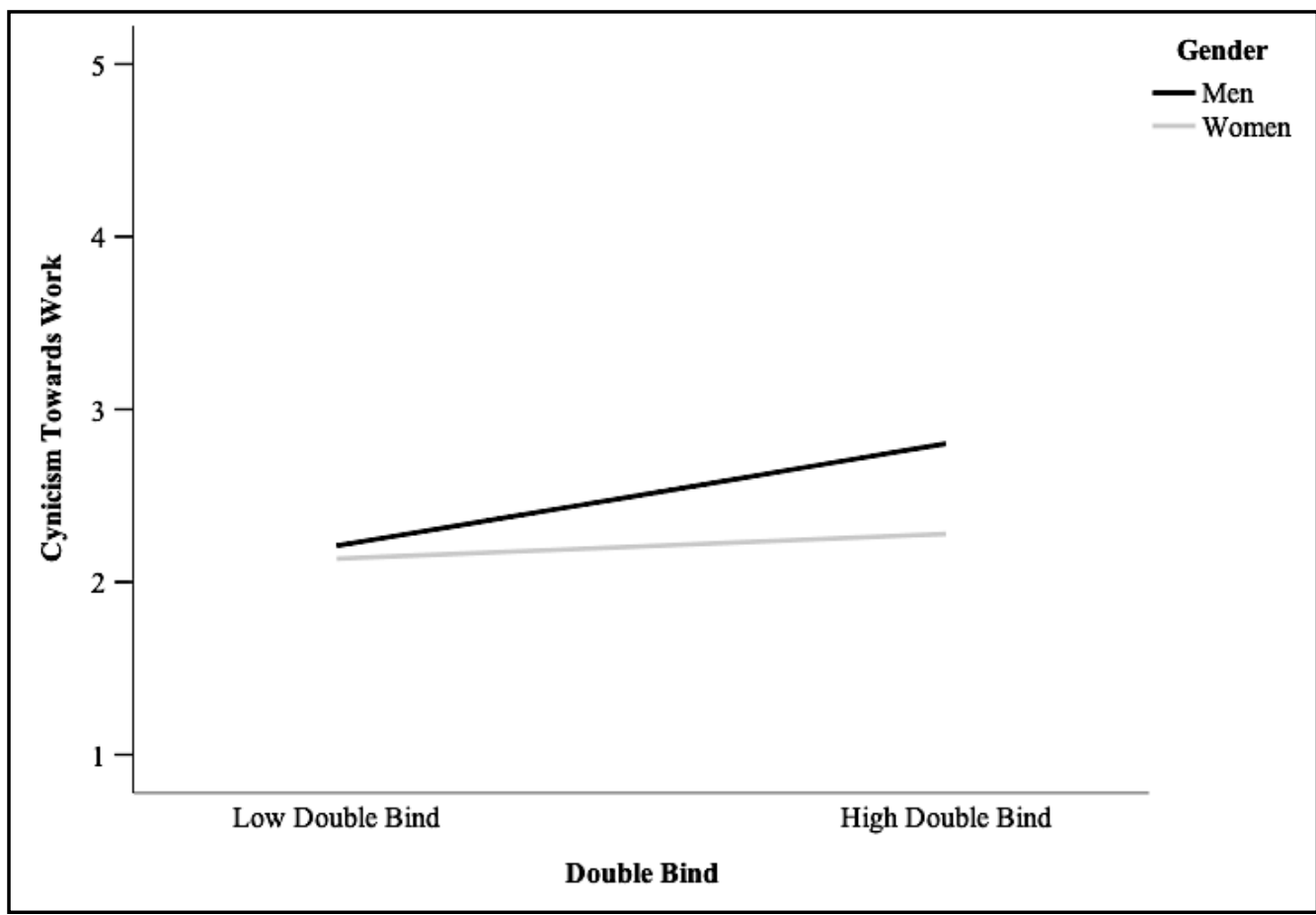

\section{The Effect of Silencing}

For the next analysis, silencing was examined as the predictor variable. Contrary to expectations, it was found that the direct effect between silencing and senior leadership ambitions was not significantly moderated by gender. Further, while a direct relation was observed between silencing and cynicism towards work, gender did not moderate this relation. As expected, there was a significant indirect effect between silencing and senior leadership ambitions through cynicism towards work for both women and men (see Table 12). These results suggest that while perceptions of silencing at work may affect leaders' cynicism towards work, this is not dependent on gender. Further, perceptions of silencing at work may not impact leaders' senior leadership ambitions, regardless of gender. 
Table 12

The Effect of Silencing on Senior Leadership Ambitions Through Cynicism

Towards Work as Moderated by Gender

\begin{tabular}{|c|c|c|c|c|c|c|c|c|}
\hline & \multicolumn{4}{|c|}{ Cynicism Towards Work $(M)$} & \multicolumn{4}{|c|}{ Senior Leadership Ambitions $(Y)$} \\
\hline & Path & Coeff. ${ }^{\text {a }}$ & $S E$ & $\begin{array}{l}95 \% \text { CI } \\
\text { LL, UL } \\
\end{array}$ & Path & Coeff. ${ }^{\text {a }}$ & $S E$ & $\begin{array}{l}95 \% \mathrm{CI} \\
\mathrm{LL}, \mathrm{UL}^{\mathrm{c}} \\
\end{array}$ \\
\hline Silencing $(X)$ & $a_{1}$ & $.35 * * *$ & .06 & $.24, .47$ & $c_{1}^{\prime}$ & .09 & .12 & $-.15, .32$ \\
\hline $\begin{array}{l}\text { Cynicism } \\
\text { Towards Work } \\
(M)\end{array}$ & -- & -- & -- & -- & $b$ & $-.48 * * *$ & .11 & $-.69,-.27$ \\
\hline Gender $(W)$ & $a_{2}$ & -.19 & .19 & $-.56, .19$ & $c^{\prime} 2$ & -.39 & .37 & $-1.12, .35$ \\
\hline$X \times W$ & $a_{3}$ & -.05 & .08 & $-.21, .10$ & $c^{\prime} 3$ & -.06 & .15 & $-.24, .37$ \\
\hline $\begin{array}{l}\text { Indirect Effect }\left(a_{1} b\right) \\
\text { for Men }\end{array}$ & -- & -- & -- & -- & $a_{1} b$ & -.17 & .05 & $-.27,-.09^{\mathrm{D}}$ \\
\hline $\begin{array}{l}\text { Indirect Effect }\left(a_{2} b\right) \\
\text { for Women }\end{array}$ & - - & - - & -- & -- & $a_{2} b$ & -.15 & .04 & $-.24,-.07^{\mathrm{b}}$ \\
\hline Constant & $i_{1}$ & $1.74 * * *$ & .15 & $1.45,2.04$ & $i_{2}$ & $4.36^{* * *}$ & .34 & $3.68,5.03$ \\
\hline \multirow{2}{*}{ Model Summary } & \multicolumn{4}{|c|}{$R^{2}=.22$} & \multicolumn{4}{|c|}{$R^{2}=.07$} \\
\hline & \multicolumn{4}{|c|}{$F(5,341)=19.06, p<.001$} & \multicolumn{4}{|c|}{$F(6,340)=4.11, p<.001$} \\
\hline
\end{tabular}

Note. $N=347$. Gender diversity climate and children were used as control variables.

${ }^{a}$ Unstandardized $b$ coefficient. ${ }^{b}$ Bias-corrected bootstrap CI using 10,000 resamples. ${ }^{\mathrm{c}} \mathrm{LL}=$ Lower limit; $\mathrm{UL}=$ Upper limit.

$* p<.05 . * * p<.01 . * * * p<.001$.

\section{The Effect of Workplace Housework}

With workplace housework as the predictor variable, it was found that there was a direct effect between workplace housework and senior leadership ambitions, however, this was not moderated by gender. Similarly, gender did not moderate the relation between workplace housework and cynicism towards work. There was also no significant indirect effect between workplace housework and senior leadership ambitions through cynicism towards work (see Table 13). These results indicate that, regardless of gender, 
feeling obligated to engage in workplace housework may impact leaders' senior leadership ambitions and cynicism towards work.

\section{Table 13}

The Effect of Workplace Housework on Senior Leadership Ambitions Through Cynicism Towards Work as Moderated by Gender

\begin{tabular}{|c|c|c|c|c|c|c|c|c|}
\hline & \multicolumn{4}{|c|}{ Cynicism Towards Work $(M)$} & \multicolumn{4}{|c|}{ Senior Leadership Ambitions $(Y)$} \\
\hline & Path & Coeff. ${ }^{\text {a }}$ & $S E$ & $\begin{array}{l}95 \% \mathrm{CI} \\
\mathrm{LL}, \mathrm{UL}^{\mathrm{c}} \\
\end{array}$ & Path & Coeff. ${ }^{\text {a }}$ & $S E$ & $\begin{array}{l}95 \% \mathrm{CI} \\
\mathrm{LL}, \mathrm{UL}^{\mathrm{c}} \\
\end{array}$ \\
\hline Workplace Housework $(X)$ & $a_{1}$ & $.11^{*}$ & .06 & $.01, .22$ & $c_{1}^{\prime}$ & $.30 * *$ & .10 & $.11, .49$ \\
\hline $\begin{array}{l}\text { Cynicism } \\
\text { Towards Work } \\
(M)\end{array}$ & -- & -- & -- & -- & $b$ & $-.47 * * *$ & .10 & $-.66,-.28$ \\
\hline Gender $(W)$ & $a_{2}$ & -.13 & .21 & $-.53, .28$ & $c^{\prime} 2$ & -.10 & .36 & $-.81, .61$ \\
\hline$X \times W$ & $a_{3}$ & -.06 & .08 & $-.21, .09$ & $c^{\prime} 3$ & -.07 & .13 & $-.33, .20$ \\
\hline $\begin{array}{l}\text { Indirect Effect }\left(a_{1} b\right) \\
\text { for Men }\end{array}$ & - - & - - & - - & - - & $a_{1} b$ & -.05 & .03 & $-.12, .00^{\mathrm{b}}$ \\
\hline $\begin{array}{l}\text { Indirect Effect }\left(a_{2} b\right) \\
\text { for Women }\end{array}$ & -- & -- & -- & -- & $a_{2} b$ & -.03 & .03 & $-.09, .03^{\mathrm{b}}$ \\
\hline Constant & $i_{1}$ & $2.31 * * *$ & .16 & $2.01,2.62$ & $i_{2}$ & $3.80 * * *$ & .34 & $3.09,4.49$ \\
\hline \multirow[t]{2}{*}{ Model Summary } & \multicolumn{4}{|c|}{$R^{2}=.08$} & \multicolumn{4}{|c|}{$R^{2}=.10$} \\
\hline & \multicolumn{4}{|c|}{$F(5,341)=5.90, p<.001$} & \multicolumn{4}{|c|}{$F(6,340)=6.56, p<.001$} \\
\hline
\end{tabular}

Note. $N=347$. Gender diversity climate and children were used as control variables.

${ }^{a}$ Unstandardized $b$ coefficient. ${ }^{b}$ Bias-corrected bootstrap CI using 10,000 resamples. ${ }^{\mathrm{c}} \mathrm{LL}=$ Lower limit; $\mathrm{UL}=$ Upper limit.

$* p<.05 .{ }^{* *} p<.01 .{ }^{* * *} p<.001$.

\section{The Effect of Inequitable Pay}

For the next analysis, inequitable pay was assessed as the predictor variable. Gender did not significantly moderate the direct effect between inequitable pay and senior leadership ambitions, contrary to expectations. Gender also did not moderate the relation between inequitable pay and cynicism towards work, although a direct effect was observed. As predicted, an indirect effect was found between inequitable pay and senior 
leadership ambitions through cynicism towards work, for both women and men (see

Table 14). These results suggest that while reporting inequitable pay at work may affect leaders' cynicism towards work, this is not dependent on gender. Moreover, reporting inequitable pay may not impact leaders' senior leadership ambitions, regardless of gender.

\section{Table 14}

The Effect of Inequitable Pay on Senior Leadership Ambitions Through Cynicism Towards Work as Moderated by Gender

\begin{tabular}{|c|c|c|c|c|c|c|c|c|}
\hline & \multicolumn{4}{|c|}{ Cynicism Towards Work $(M)$} & \multicolumn{4}{|c|}{ Senior Leadership Ambitions $(Y)$} \\
\hline & Path & Coeff. ${ }^{\text {a }}$ & $S E$ & $\begin{array}{l}95 \% \mathrm{CI} \\
\mathrm{LL}, \mathrm{UL}^{\mathrm{c}} \\
\end{array}$ & Path & Coeff. ${ }^{\text {a }}$ & $S E$ & $\begin{array}{l}95 \% \text { CI } \\
\text { LL, UL }\end{array}$ \\
\hline Inequitable Pay $(X)$ & $a_{1}$ & $.13 * *$ & .05 & $.04, .22$ & $c_{1}^{\prime}$ & .02 & .09 & $-.15, .19$ \\
\hline $\begin{array}{l}\text { Cynicism } \\
\text { Towards Work } \\
(M)\end{array}$ & -- & -- & -- & -- & $b$ & $-.42 * * *$ & .10 & $-.62,-.22$ \\
\hline Gender $(W)$ & $a_{2}$ & $-.53 * *$ & .18 & $-.88,-.18$ & $c^{\prime} 2$ & -.08 & .34 & $-.75, .58$ \\
\hline$X \times W$ & $a_{3}$ & .10 & .06 & $-.03, .22$ & $c^{\prime} 3$ & -.05 & .12 & $-.28, .18$ \\
\hline $\begin{array}{l}\text { Indirect Effect }\left(a_{1} b\right) \\
\text { for Men }\end{array}$ & - - & -- & -- & -- & $a_{1} b$ & -.05 & .03 & $-.11,-.01^{\mathrm{b}}$ \\
\hline $\begin{array}{l}\text { Indirect Effect }\left(a_{2} b\right) \\
\text { for Women }\end{array}$ & -- & -- & -- & - & $a_{2} b$ & -.09 & .03 & $-.16,-.04^{b}$ \\
\hline Constant & $i_{1}$ & $2.28^{* * *}$ & .14 & $2.00,2.56$ & $i_{2}$ & $4.36^{* * *}$ & .35 & $3.67,5.05$ \\
\hline \multirow[t]{2}{*}{ Model Summary } & \multicolumn{4}{|c|}{$R^{2}=.15$} & \multicolumn{4}{|c|}{$R^{2}=.06$} \\
\hline & \multicolumn{4}{|c|}{$F(5,341)=12.06, p<.001$} & \multicolumn{4}{|c|}{$F(6,340)=3.76, p=.001$} \\
\hline
\end{tabular}

Note. $N=347$. Gender diversity climate and children were used as control variables.

${ }^{a}$ Unstandardized $b$ coefficient. ${ }^{b}$ Bias-corrected bootstrap CI using 10,000 resamples. ${ }^{c} \mathrm{LL}=$ Lower limit; $\mathrm{UL}=$ Upper limit.

$* p<.05 .{ }^{* *} p<.01 .{ }^{* * *} p<.001$.

\section{The Effect of Inequitable Opportunities}

With inequitable opportunities as the predictor variable, gender moderated the relation between inequitable opportunities and cynicism towards work, and as expected, 
this positive effect was stronger for women (see Figure 7). However, there was no moderated effect of inequitable opportunities on senior leadership ambitions. As proposed, inequitable opportunities had a significant, indirect effect on senior leadership ambitions through cynicism towards work for both genders (see Table 15). These results indicate that perceptions of inequitable opportunities at work may affect participants' cynicism towards work, and this relation may be stronger for women than for men.

\section{Table 15}

The Effect of Inequitable Opportunities on Senior Leadership Ambitions Through Cynicism Towards Work as Moderated by Gender

\begin{tabular}{|c|c|c|c|c|c|c|c|c|}
\hline & \multicolumn{4}{|c|}{ Cynicism Towards Work $(M)$} & \multicolumn{4}{|c|}{ Senior Leadership Ambitions $(Y)$} \\
\hline & Path & Coeff. ${ }^{\text {a }}$ & $S E$ & $\begin{array}{l}95 \% \mathrm{CI}^{\mathrm{c}} \\
\mathrm{LL}, \mathrm{UL}^{\mathrm{c}}\end{array}$ & Path & Coeff. ${ }^{\text {a }}$ & $S E$ & $\begin{array}{l}95 \% \mathrm{CI}^{\mathrm{c}} \\
\mathrm{LL}, \mathrm{UL}^{\mathrm{c}}\end{array}$ \\
\hline $\begin{array}{l}\text { Inequitable Opportunities } \\
(X)\end{array}$ & $a_{1}$ & $.11 *$ & .05 & $.02, .20$ & $c^{\prime}{ }_{1}$ & .03 & .09 & $-.15, .21$ \\
\hline $\begin{array}{l}\text { Cynicism } \\
\text { Towards Work } \\
(M)\end{array}$ & - - & -- & -- & -- & $b$ & $-.41 * * *$ & .11 & $-.62,-.20$ \\
\hline Gender $(W)$ & $a_{2}$ & $-.81 * * *$ & .17 & $-1.15,-.47$ & $c^{\prime} 2$ & -.04 & .35 & $-.71, .64$ \\
\hline$X \times W$ & $a_{3}$ & $.21 * * *$ & .06 & $.09, .34$ & $c^{\prime} 3$ & -.07 & .12 & $-.32, .18$ \\
\hline $\begin{array}{l}\text { Indirect Effect }\left(a_{1} b\right) \\
\text { for Men }\end{array}$ & - - & - - & - - & - - & $a_{1} b$ & -.04 & .03 & $-.10,-.00^{\mathrm{D}}$ \\
\hline $\begin{array}{l}\text { Indirect Effect }\left(a_{2} b\right) \\
\text { for Women }\end{array}$ & - - & -- & -- & -- & $a_{2} b$ & -.13 & .04 & $-.21, .06^{\mathrm{b}}$ \\
\hline Constant & $i_{1}$ & $2.28 * * *$ & .14 & $2.00,2.55$ & $i_{2}$ & $4.33 * * *$ & .36 & $3.61,5.04$ \\
\hline \multirow{2}{*}{ Model Summary } & \multicolumn{4}{|c|}{$R^{2}=.21$} & \multicolumn{4}{|c|}{$R^{2}=.06$} \\
\hline & \multicolumn{4}{|c|}{$F(5,341)=17.86, p<.001$} & \multicolumn{4}{|c|}{$F(6,340)=3.78, p=.001$} \\
\hline
\end{tabular}

Note. $N=347$. Gender diversity climate and children were used as control variables.

${ }^{a}$ Unstandardized $b$ coefficient. ${ }^{b}$ Bias-corrected bootstrap CI using 10,000 resamples. ${ }^{\mathrm{c}} \mathrm{LL}=$ Lower limit; $\mathrm{UL}=$ Upper limit.

$* p<.05 . * * p<.01 . * * * p<.001$. 


\section{Figure 7}

Gender as a Moderator in the Relation Between Inequitable Opportunities and Cynicism Towards Work

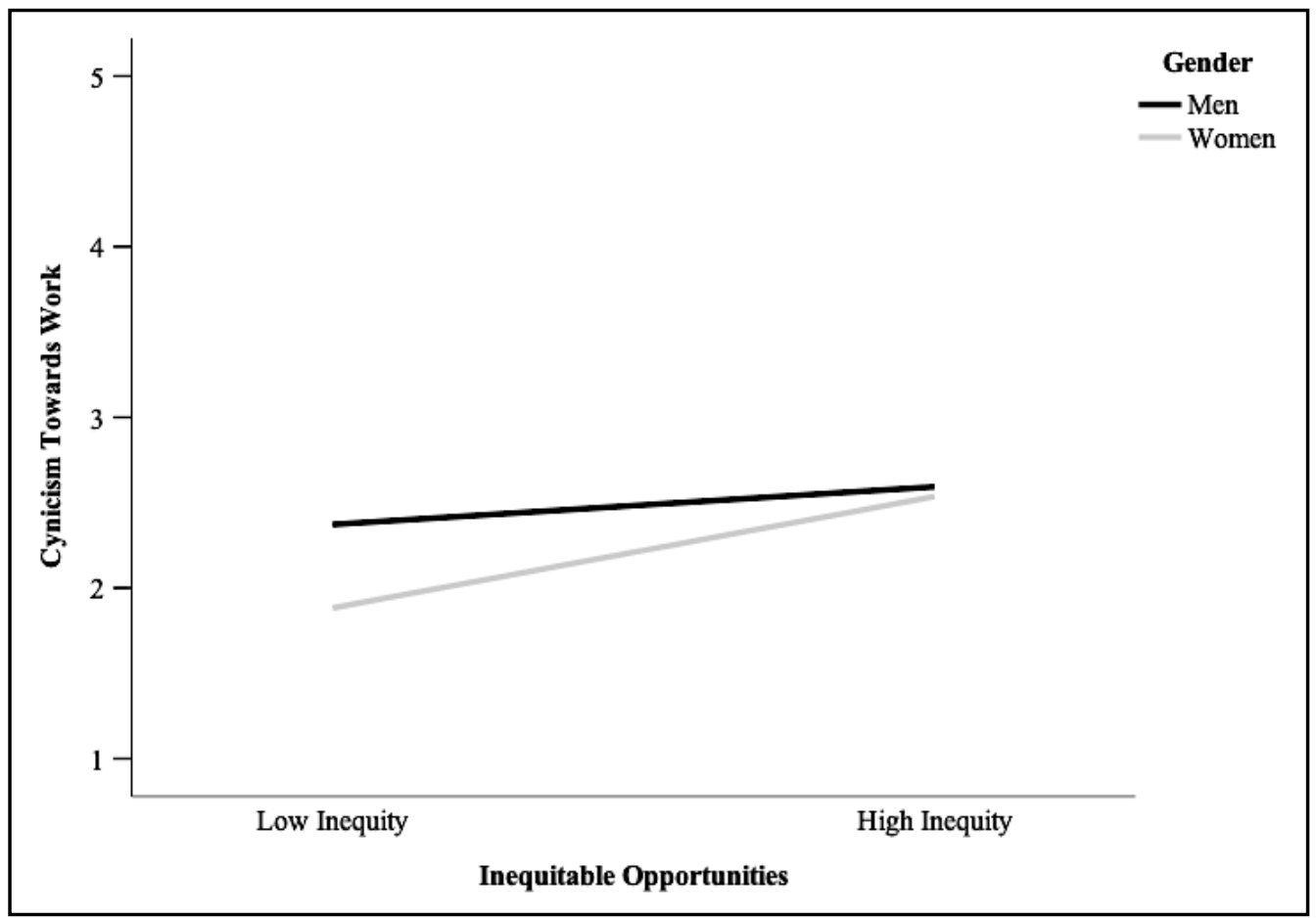

\section{The Effect of Workplace Incivility}

The final analysis examined workplace incivility as the predictor variable. The direct effect between workplace incivility and senior leadership ambitions was not significantly moderated by gender. Further, although there was a direct effect of workplace incivility on cynicism towards work, gender did not moderate this relation. Finally, as expected, workplace incivility had an indirect effect on senior leadership ambitions through cynicism towards for both women and men (see Table 16). These findings suggest that while perceptions of workplace incivility may affect leaders' cynicism towards work, this is not dependent on gender. In addition, perceptions of 
workplace incivility may not impact leaders' senior leadership ambitions, regardless of gender.

\section{Table 16}

The Effect of Workplace Incivility on Senior Leadership Ambitions Through Cynicism Towards Work as Moderated by Gender

\begin{tabular}{|c|c|c|c|c|c|c|c|c|}
\hline & \multicolumn{4}{|c|}{ Cynicism Towards Work $(M)$} & \multicolumn{4}{|c|}{ Senior Leadership Ambitions $(Y)$} \\
\hline & Path & Coeff. ${ }^{\text {a }}$ & $S E$ & $\begin{array}{l}95 \% \mathrm{CI} \\
\mathrm{LL}, \mathrm{UL}^{\mathrm{c}}\end{array}$ & Path & Coeff. ${ }^{\text {a }}$ & $S E$ & $\begin{array}{l}95 \% \text { CI } \\
\text { LL, UL }\end{array}$ \\
\hline Workplace Incivility $(X)$ & $a_{1}$ & $.29 * * *$ & .07 & $.15, .43$ & $c^{\prime}{ }_{1}$ & .10 & .14 & $-.18, .37$ \\
\hline $\begin{array}{l}\text { Cynicism } \\
\text { Towards Work } \\
(M)\end{array}$ & -- & -- & -- & -- & $b$ & $-.44 * * *$ & .10 & $-.65,-.24$ \\
\hline Gender $(W)$ & $a_{2}$ & $-.35^{*}$ & .17 & $-.69,-.01$ & $c^{\prime} 2$ & -.10 & .33 & $-.75, .56$ \\
\hline$X \times W$ & $a_{3}$ & .02 & .09 & $-.16, .20$ & $c^{\prime} 3$ & -.08 & .17 & $-.42, .27$ \\
\hline $\begin{array}{l}\text { Indirect Effect }\left(a_{1} b\right) \\
\text { for Men }\end{array}$ & - & - & -- & -- & $a_{1} b$ & -.13 & .05 & $-.23,-.05^{b}$ \\
\hline $\begin{array}{l}\text { Indirect Effect }\left(a_{2} b\right) \\
\text { for Women }\end{array}$ & -- & - & - - & - - & $a_{2} b$ & -.14 & .04 & $-.24,-.06^{\mathrm{b}}$ \\
\hline Constant & $i_{1}$ & $2.06^{* * *}$ & .14 & $1.78,2.34$ & $i_{2}$ & $4.31 * * *$ & .35 & $3.63,4.99$ \\
\hline \multirow{2}{*}{ Model Summary } & \multicolumn{4}{|c|}{$R^{2}=.18$} & \multicolumn{4}{|c|}{$R^{2}=.06$} \\
\hline & \multicolumn{4}{|c|}{$F(5,341)=14.54, p<.001$} & \multicolumn{4}{|c|}{$F(6,340)=3.81, p=.001$} \\
\hline
\end{tabular}

Note. $N=347$. Gender diversity climate and children were used as control variables.

${ }^{\mathrm{a}}$ Unstandardized $b$ coefficient. ${ }^{\mathrm{b}}$ Bias-corrected bootstrap CI using 10,000 resamples. ${ }^{\mathrm{c}} \mathrm{LL}=$ Lower limit; $\mathrm{UL}=$ Upper limit.

$* p<.05 .{ }^{* *} p<.01 .{ }^{* * *} p<.001$.

Table 17 provides a summary of the results relative to the hypotheses and gives a snapshot of which hypotheses were, or were not, supported. 
Table 17

Summary of Hypotheses Testing Results

\begin{tabular}{lll}
\hline Hypothesis & & Relation \\
\hline H1 & Double Bind $\rightarrow$ Lower Senior Leadership Ambitions (Moderated by Gender) & Not Supported \\
H8a & Double Bind $\rightarrow$ Cynicism Towards Work $\rightarrow$ Senior Leadership Ambitions & Partially Supported \\
H9a & Double Bind $\rightarrow$ Cynicism Towards Work (Moderated by Gender) & Not Supported \\
H2 & Silencing $\rightarrow$ Lower Senior Leadership Ambitions (Moderated by Gender) & Not Supported \\
H8b & Silencing $\rightarrow$ Cynicism Towards Work $\rightarrow$ Senior Leadership Ambitions & Supported \\
H9b & Silencing $\rightarrow$ Cynicism Towards Work (Moderated by Gender) & Not Supported \\
H3 & Workplace Housework $\rightarrow$ Lower Senior Leadership Ambitions (Moderated by Gender) & Not Supported \\
H8c & Workplace Housework $\rightarrow$ Cynicism Towards Work $\rightarrow$ Senior Leadership Ambitions & Not Supported \\
H9c & Workplace Housework $\rightarrow$ Cynicism Towards Work (Moderated by Gender) & Not Supported \\
H4 & Inequitable Pay $\rightarrow$ Lower Senior Leadership Ambitions (Moderated by Gender) & Not Supported \\
H8d & Inequitable Pay $\rightarrow$ Cynicism Towards Work $\rightarrow$ Senior Leadership Ambitions & Supported \\
H9d & Inequitable Pay $\rightarrow$ Cynicism Towards Work (Moderated by Gender) & Not Supported \\
H5 & Inequitable Opportunities $\rightarrow$ Lower Senior Leadership Ambitions (Moderated by Gender) & Not Supported \\
H8e & Inequitable Opportunities $\rightarrow$ Cynicism Towards Work $\rightarrow$ Senior Leadership Ambitions & Supported \\
H9e & Inequitable Opportunities $\rightarrow$ Cynicism Towards Work (Moderated by Gender) & Supported \\
H6 & Workplace Incivility $\rightarrow$ Lower Senior Leadership Ambitions (Moderated by Gender) & Not Supported \\
H8f & Workplace Incivility $\rightarrow$ Cynicism Towards Work $\rightarrow$ Senior Leadership Ambitions & Supported \\
H9f & Workplace Incivility $\rightarrow$ Cynicism Towards Work (Moderated by Gender) & Not Supported \\
\hline
\end{tabular}




\section{Discussion}

The overall purpose of this research was to examine whether women leaders' senior leadership ambitions are more strongly negatively affected by perceptions of subtle gender bias (i.e., the double bind and silencing), inequity (i.e., workplace housework, inequitable pay, and inequitable opportunities), and mistreatment (i.e., workplace incivility and sexual harassment) in the workplace relative to leaders who are men and whether this association occurs through cynicism towards work. Individuals who reported perceptions of silencing, inequitable pay, inequitable opportunities, and workplace incivility were likely to report higher cynicism towards work, and ultimately, lower senior leadership ambitions - regardless of gender. Further, as expected, the relation between inequitable opportunities and cynicism towards work was stronger for women. Contrary to predictions, only men who reported perceptions of the double bind were more likely to report cynicism towards work. Gender was not shown to affect the direct relation between any perceptions of gender bias and senior leadership ambitions and women and men had similar senior leadership ambitions.

As expected, women reported more instances of workplace incivility than men. However, no other differences in perceptions of gender bias were observed. Further, men indicated higher levels of cynicism towards work relative to women. Importantly, the gender diversity climate of a workplace was found to be a central element in the experiences of women leaders, in that those who worked in a male-dominated workplace reported greater perceptions of subtle gender bias (i.e., the double bind and silencing) than others. Overall, these findings suggest that while issues of gender bias towards women may be decreasing in workplaces with a female-dominated or gender diverse 
climate, issues of gender bias may remain more prominent for women in male-dominated workplaces and when they involve issues of workplace incivility.

\section{The Role of Gender and Gender Bias in Senior Leadership Ambitions}

The current study aimed to examine the influence of gender on senior leadership ambitions. Notably, and contrary to the recent organizational discourse (e.g., Gino et al., 2015; McKinsey \& Company, 2018), women reported having the same level of senior leadership ambitions as did men. Interestingly, the distributions of senior leadership ambitions among both women and men were also remarkably similar. This finding directly challenges the notion expressed by Gino and colleagues (2015) that there are fewer women in executive positions because women do not have ambition for such roles. Instead, this finding provides support for the concept that there may be systemic barriers that are preventing women from succeeding.

Contrary to expectations, the preliminary analyses revealed that there was only one observed gender difference between women and men in their perceptions of subtle gender bias, inequity, and incivility in the workplace. That is, women were significantly more likely to report perceptions of workplace incivility compared to men, regardless of the gender diversity climate of their workplace. This finding was expected, as workplace incivility is likely to be selective in nature, and therefore, more likely to be perceived by women (Cortina et al., 2013; Saxena et al., 2019), although men have been shown to report the same negative effects as women when they do perceive incivility (Cortina et al., 2001).

Gender was not shown to affect the relation between any of the predictor variables and senior leadership ambitions. This was surprising, as such findings are 
incongruent with stereotype threat theory (Steele, 1997), equity theory (Adams, 1965), and the previous research associated with these relations. It is possible that these null findings may be due in part to the lack of gender differences observed between men and women in their perceptions of gender bias in the workplace, as while there was one difference observed in workplace incivility, the overall lack of differences was not consistent with previous research (e.g., Babcock et al., 2017; MacDonald, 2019; McKinsey \& Company, 2018).

There are a number of reasons that may help explain why gender differences were not observed in perceptions of gender bias in the current research. First, the gender diversity climate of the organizations that participants worked in was fairly positive, in that almost three-quarters of participants worked in a gender diverse or female-dominated workplace. Overall, issues of gender bias and inequity have been shown to affect women less in such conditions (e.g., Jansen et al., 2017), often because organizations that incorporate employees of all genders maintain a norm that allows employees to be treated with fairness and respect (Konrad et al., 2010; Nishii, 2013).

Second, it is possible that employing a sample of participants who were already leaders may have affected the study results. That is, those in leadership positions may feel reluctant to report issues of gender bias, as they themselves are partially responsible for the behaviour of those in their workplace and should be positively influencing the workplace culture to avoid these issues (Guillaume, Dawson, Otaye-Ebede, Woods, \& West, 2017). Therefore, issues related to cognitive dissonance (Festinger, 1957) may be affecting the gender biases that leaders report. In addition, those in leadership positions may be different than others in that they may have enough financial stability or resources 
to change jobs and move into a new workplace if they are experiencing issues of gender bias, whereas those in lower-ranking positions may not (e.g., De Gieter \& Hofmans, 2015; McLaughlin et al., 2017).

Third, and importantly, although the present research was dependent on women recognizing the gender biases that they experience in the workplace, and research has indicated that women are indeed aware of these issues (e.g., Basford et al., 2014; McKinsey \& Company, 2018; Ryan, Haslam, \& Postmes, 2007), contrasting research indicates that women do not always recognize these problems (Lyness \& Grotto, 2018; Pryce \& Sealy, 2013; Stone \& Hernandez, 2013). Despite a variety of established organizational and societal gender barriers, women and men may report ideals that align with the myth of meritocracy (Lyness \& Grotto, 2018), which posits that everyone has "an equal chance to succeed or fail based on their own merit and efforts" (Pryce \& Sealy, 2013, p. 451).

The myth of meritocracy is a potentially dangerous viewpoint, as it does not take into account the various forms of disparity and inequality that are present within organizations (Pryce \& Sealy, 2013; Sealy, 2010). As a result, instead of attributing negative workplace experiences and outcomes to issues of gender bias, women may justify the issue, take responsibility, or blame themselves (Lyness \& Grotto, 2018; Stone \& Hernandez, 2013). This issue is even more prevalent in situations wherein the biases experienced are subtle or ambiguous in nature (Lyness \& Grotto, 2018), which is one of the forms of gender bias assessed in the current study. Further, these beliefs are more likely to be held by women who hold business degrees, are married without children, or are in highly ranked positions within an organization. As such, successful women in 
leadership positions may be more likely to hold meritocratic views (Cech \& Blair-Loy, 2010), and therefore, may be unable to recognize and report the various gender biases that they experience in the workplace.

Ultimately, it is also possible that it may not be differences between women and men that are driving senior leadership ambitions, but rather, factors such as the heavier workload, the responsibility, the stress, and the loss of personal time that a senior leadership role may be associated with (e.g., Centre for Creative Leadership, 2017). Additional research needs to be done to examine why exactly individuals may or may not choose to pursue a senior leadership track, as there may be important factors that are not yet identified which impact these ambitions.

\section{The Experience of Women Leaders in Male-Dominated Workplaces}

The lack of differences in the gender biases reported by women and men in the present research can further be explained by looking at those who were working in maledominated workplaces versus female-dominated/gender diverse workplaces. Of the 174 women who participated in the current research, 42 indicated that they worked in a maledominated workplace. It is among these women where differences were observed, as women in male-dominated workplaces were more likely to report perceptions of the double bind and silencing. These findings are in accordance with that of previous research, as women in male-dominated workplaces have been shown to report a variety of negative experiences, such as more mistreatment, interpersonal conflict, and gender discrimination (Jansen et al., 2017; Konrad et al., 2010; Nishii, 2013).

It is important to note that the gender diversity climate of men's workplaces did not affect their experiences, and this finding is consistent with Konrad and colleagues 
(2010), who reported that the gender composition of a workplace was unrelated to men's perceptions of gender harassment, exclusion, gender discrimination, and organizational support. In fact, men who are working in female-dominated workplaces may experience benefits. Men in non-traditional occupations are likely to encounter a phenomenon known as the glass escalator (Williams, 1992), wherein they have an easier time excelling into the top positions of an organization and often experience more benefits - such as better pay - despite being in the minority (Dill, Price-Glynn, \& Rakovski, 2016; Muench, Busch, Sindelar, \& Buerhaus, 2016; Simpson, 2004).

\section{The Role of Gender in Cynicism Towards Work}

The current study aimed to examine whether increased perceptions of gender bias are related to lower senior leadership ambitions through cynicism towards work. As expected, gender notwithstanding, individuals who reported perceptions of silencing, inequitable pay, inequitable opportunities, and workplace incivility were likely to report higher cynicism towards work, and ultimately, lower senior leadership ambitions. The present research also examined whether the relation between perceptions of gender bias and cynicism towards work was stronger for women, and as anticipated, this was observed for women who reported inequitable opportunities.

Cynicism towards work mediated the indirect effect between the double bind and senior leadership ambitions, and this was moderated by gender - but, surprisingly, only for men. In other words, women who reported perceptions of the double bind did not report experiencing cynicism towards work, and therefore, lower senior leadership ambitions. In addition, women did not experience significantly more cynicism towards work when they did report the double bind, compared to men. It is possible that this may 
have occurred because, while women leaders are likely used to recognizing or experiencing some form of subtle gender bias in the workplace, leaders who are men are likely not. Therefore, when these issues occur - men may be affected by them more than women.

Men reported higher levels of cynicism towards work than did women. This is an interesting finding, as although it was not formally hypothesized, it was expected that women would have higher levels of cynicism towards work than men due to the biases that they may have experienced. Previous research has also shown men to be more cynical overall than women. For example, Sjogren, Kristenson, and Linquestgroup (2006) found that men reported higher levels of cynicism than did women, and that this relation was even stronger in educated men. Leung, Li, and Zhou (2012) found similar results, with the authors attributing this to men's concern for competition - and a competitive environment breeding more feelings of mistrust and cynicism. In a recent study conducted with a sample of early childhood teachers, Sak (2018) found that men were more likely to have higher levels of organizational cynicism than women. These results indicate that men may indeed have more cynicism towards work than women, despite the greater instances of gender bias that women may experience in the workplace (Hoyt \& Burnette, 2013).

It is important to note that, while men often already had higher levels of cynicism towards work prior to experiencing issues of bias, in some cases, experiencing the aforementioned gender biases made women in the current study more cynical- making for a more negative workforce overall. This has important implications for organizational culture, as a negative workplace can bring about a variety of adverse outcomes, such as 
lower job satisfaction (Dimitrios \& Athanasios, 2014) and turnover intentions (Bosomtwe \& Obeng, 2018).

\section{Workplace Housework}

The current study examined how feeling obligated to engage in workplace housework may negatively impact one's cynicism towards work and senior leadership ambitions. These relations were proposed because engaging in similar behaviours has been related to a negative impact on career advancement opportunities and other careerbased outcomes (e.g., Bergeron, Shipp, Rosen, \& Furst, 2013; Heilman \& Chen, 2005), as well as work stress, emotional exhaustion, and a lack of benefits (Bolino, Klotz, Turnley, \& Harvey, 2013; Bolino \& Turnley, 2005; Purvanova \& Muros, 2010). In accordance with equity theory (Adams, 1965), it was expected that women leaders who felt obligated to engage in workplace housework would perceive that doing so was an additional requirement that did not provide additional benefits relative to others, affecting perceptions of inequity in the workplace.

Although it was expected that feeling obligated to engage in workplace housework would be associated with lower ambitions for senior leadership, the opposite was found. Indeed, feeling obligated to engage in workplace housework had a small but significant positive correlation to senior leadership ambitions, and was the only key study variable to be directly related to senior leadership ambitions in the moderated mediation analyses - however, this was not moderated by gender. While the research on workplace housework is limited and cannot be drawn upon, there is some evidence to suggest that engaging in organizational citizenship behaviours may be associated with positive employee outcomes, such as lower turnover intentions, turnover, and absenteeism 
(Podsakoff, Whiting, Podsakoff, \& Blume, 2009). For this reason, it is possible that despite feeling obligated to do so - engaging in such tasks may have some positive outcomes for those who do so. Alternatively, it is also possible that it is not positive outcomes driving the positive association between workplace housework and senior leadership ambitions, but rather, that those who are perhaps more ambitious or want to excel in their organization will engage in more of these behaviours (Bourdage, Lee, Lee, \& Shin, 2012).

The findings of the current study did not support the notion that women engage in workplace housework more than men, as no significant gender differences were observed in the means of the two groups. Research needs to be done quantitatively examining whether there are indeed gender differences, as such evidence has often been anecdotal (e.g., Grant \& Sandberg, 2015). Such research may have important implications for the leadership literature, as the current study indicates that workplace housework may indeed be related to individuals' senior leadership ambitions.

Workplace housework should also be formally defined in the literature. While it has often been described as roles and responsibilities that are beneath or go beyond one's typical job requirements and are assigned to women (Babcock et al., 2017; Williams et al., 2018), a concrete definition of workplace housework may aid the research in this area. In addition, a measure of workplace housework should be developed, as it is currently not possible to quantitatively assess workplace housework with an established scale. 


\section{Sexual Harassment in the Current Workforce}

I was unable to assess sexual harassment in the current research due to the low level of reported instances. It is possible that the lower cases of sexual harassment reported in the current research may be due to the \#MeToo movement, which empowered women to take a stand against sexual abuse and resulted in important shifts in what is tolerated in workplaces. Recent research has explored how this movement has impacted the workplace, noting that victims may now feel less ostracized after reporting sexual harassment (Brown \& Battle, 2019). In addition, workplace policies have likely been altered to reflect these issues (Gousman \& Erb, 2019). Such changes may suggest that perpetrators of sexual harassment will avoid harassing others, so as to not face the negative implications of their actions. However, experiences of sexual harassment are very important when they do occur. Incidents of sexual harassment are very defining and can result in a variety of negative psychological and workplace outcomes for women, such as lower psychological well-being, lower job satisfaction, and higher turnover intentions (e.g., McDonald, 2012; McLaughlin et al., 2012; Rospenda et al., 2009), and therefore, should not be minimized.

It is important to note that while the present study examined the subscales of the Sexual Experiences Questionnaire (Fitzgerald et al., 1999) together, recent research has often examined the various components of sexual harassment (e.g., sexual coercion, unwanted sexual attention, and gender harassment) separately. Further, although this study used a version of the Sexual Experiences Questionnaire (Fitzgerald et al., 1999) that was recommended by Donovan and Drasgow (1999) as a measure of sexual harassment for both women and men, some researchers recommend using separate scales 
for each gender (e.g., Berdahl \& Moore, 2006). It is possible that the findings of the present study may have changed if these methods were employed.

\section{Research Limitations and Future Directions}

\section{Prolific Sample}

Although the current study has contributed to our understanding of gender bias and senior leadership ambitions in the workplace, it is important to recognize that the generalizability of this research may be limited because of the sample composition. Participants were recruited using the online crowdsourcing company, Prolific. While online samples have been shown to offer high-quality data that resembles the general workforce (Roulin, 2015; Walter et al., 2019), such platforms often recruit individuals with specific characteristics, such as those who are interested in research and are comfortable with using the Internet (Azzam \& Jacobson, 2013). Further, the leaders on Prolific may not be representative of the general population of leaders because they have the time and mental resources to complete surveys after work, and therefore, are likely not feeling overwhelmed or having signs of burnout from work. Therefore, the current study did not include the qualities of certain individuals who may have chosen not to participate in online panels.

The sample obtained from Prolific for the current study was also predominantly white. While further assessing these issues was not possible due to the low number of participants of colour, the preliminary analyses of the current research suggest that leaders of colour may experience more instances of silencing in the workplace than their Caucasian colleagues, and may also have more cynicism towards work. However, despite these issues, the results suggest that leaders of colour may continue to have senior 
leadership ambitions over and beyond their Caucasian counterparts. This appears to demonstrate the resiliency of leaders of colour in the workplace.

It is important to acknowledge that the lack of participants of colour in this study indicates that people of colour may be having more difficulty attaining leadership positions. While the sample for the current study was composed of half women and half men, only $14.40 \%$ were women of colour and only $16.20 \%$ were men of colour. For this reason, it appears that while Caucasian women have had more success in attaining leadership positions, people of colour may be having more difficulty. This has been discussed in other research, as people of colour often experience more discrimination and are given fewer opportunities in the workplace, which places them at a disadvantage for advancement (e.g., Eagly, \& Chin, 2010; Sanchez-Hucles \& Davis, 2010).

To address these sample limitations, future research should replicate the current study's findings within organizations and different sectors to determine whether the results would be the same. In addition, the findings of this study should be replicated using a more ethnically and racially diverse sample. Such a sample would not only be more representative of the working population, but would also lend itself to examining how race may affect experiences and ambitions in the workplace. Specifically, the barriers and issues that ethnic and racial minority leaders may experience must be identified in order to create interventions which promote ethnic and racial diversity within leadership.

\section{Senior Leadership Ambitions Predictive of Job Seeking and Job Acceptance}

The present research operated under the notion that senior leadership ambitions are predictive of seeking or accepting a senior leadership role. Although some research 
has suggested that ambitions are directly related to job-related behaviours and outcomes (e.g., Otto et al., 2017; Schoon \& Polek, 2011), other research has shown that ambitions have an indirect effect on job-related outcomes through various factors (e.g., taking charge behaviour; El Baroudi, Fleisher, Khapova, Jansen, \& Richardson, 2017). For this reason, it is possible that despite having high senior leadership ambitions, women may not seek or accept a senior leadership role due to various external constraints (Harman \& Ruth, 2017). Future research should examine whether women's senior leadership ambitions are directly related to accepting a senior leadership role, as well as what factors may influence the disparity between high senior leadership ambitions and a low likelihood of seeking or accepting a senior leadership role. Research in this area is scarce and may provide a more in-depth understanding of women in senior leadership positions.

\section{A Binary View of Gender}

While the present study aimed to recruit transgender women and men, the final sample consisted of only cisgender women and men. However, the experiences and ambitions of transgender leaders, as well as non-binary and genderfluid leaders, must also be examined. These experiences are likely different than those that cisgender individuals have and often include more systemic barriers and biases (Fassinger, Shullman, \& Stevenson, 2010). Future research may also examine participants' sexual orientation, as individuals who are openly gay, lesbian, bi, or pansexual may experience more biases in the workplace (Eagly \& Chin, 2010; Fassinger et al., 2010), which is something that was not assessed in the current study. How intersectionality affects these issues may also be observed, as those who are a part of multiple vulnerable and protected groups may experience all the more issues (Sanchez-Hucles \& Davis, 2010). All three of these areas 
of research are largely understudied and would add to our knowledge and understanding of the biases that are experienced by individuals in these groups, as well as how this may affect leadership ambitions.

\section{Research Design}

The present study employed a cross-sectional survey design. For this reason, I was not able to determine how cynicism towards work and senior leadership ambitions are affected when specific, negative events of gender bias occur over time at work. In addition, this design did not allow for the direction of the relations proposed to be studied. Future research should replicate the current study longitudinally in order to assess these relations.

The self-report nature of this study may have also affected the outcomes, as individuals may have not reported instances of sexual harassment or other negative experiences due to social desirability, despite being assured of their anonymity (e.g., Bell \& Naugle, 2007; Yoon, Stiller Funk, \& Kropf, 2010). Self-report studies also often run the risk of common method bias, which has a particularly high risk in the field of leadership (Harms \& Credé, 2010; Judge \& Piccolo, 2004). However, steps were taken in the current study's design to control the effects of common method bias, in that participants were given the freedom to complete the online survey wherever was most comfortable and private for them, assured of their anonymity, and reminded that they should answer all questions honestly (Conway \& Lance, 2010; Podsakoff et al., 2003; Podsakoff et al., 2012). Testing for moderation and mediation based on theory also aided in overcoming this limitation, as participants were likely not aware of the complex relations being examined (Chang, Van Witteloostuijn, \& Eden, 2010). Further, priming 
effects were avoided by asking participants about their senior leadership ambitions prior to asking about issues of gender bias in the questionnaire's design (Schwarz, Rizzuto, Carraher-Wolverton, Roldán, \& Barrera-Barrera, 2017).

\section{Research and Practical Implications}

The current research contributes to the literature by directly examining a sample of leaders in order to determine how real-world experiences of gender bias in the workplace affect senior leadership ambitions. While many studies have used experimental designs or vignette studies with undergraduate students to examine these relations (e.g., Davies et al., 2005; Gupta \& Bhawe, 2007; Leaper \& Starr, 2019), the current study employed a sample of women and men leaders in order to determine whether issues of bias in the workplace are exclusive to women. The current research found support that women leaders are equivalent to leaders who are men in their senior leadership ambitions, that men tended to be somewhat more cynical towards work than women, that perceptions of gender bias in the workplace are associated with cynicism towards work for both women and men, and that women leaders working in maledominated workplaces may perceive more issues of subtle gender bias than others. These findings add to the organizational discourse by providing a more thorough understanding of women in senior leadership positions and advancing knowledge on the impact of gender bias in the workplace.

\section{Decreasing Cynicism Towards Work}

The current research suggests that various issues of gender bias in the workplace (i.e., silencing, inequitable pay, inequitable opportunities, and workplace incivility) may be associated with increased feelings of cynicism towards work, which may negatively 
impact senior leadership ambitions. The association between negative workplace experiences and cynicism towards work has been shown in other research (e.g., Kuo, Chang, Quinton, Lu, \& Lee 2014) and suggests that organizations should foster leadership groups and workplaces that are bias-free and promote support, inclusion, trust, and civility (Nicholson, Leiter, \& Laschinger, 2014; Scott \& Zweig, 2016). Specifically, interventions should be implemented which encourage healthy work environments and highlight the importance of organizational support, healthy work groups, and team bonding (Di Fabio, 2017). Such practices may reduce cynicism towards work, contributing to conditions that may encourage senior leadership ambitions.

\section{Gender Diverse Workplaces and Leadership Teams}

The present research provides support for gender diverse workplaces and leadership teams, as women may perceive less gender bias in such work environments (e.g., Konrad et al., 2010; Nishii, 2013). This may have further benefits for women's ambitions, as women in gender diverse teams have been shown to see leadership roles as more realistic and attainable (Abouzahr, Krentz, Tracey, \& Tsusaka, 2017). Such workplaces and teams may also have advantages for organizations as a whole. Gender diverse leadership teams have been associated with increased innovation, which in turn may help organizations foster new ideas and worthwhile changes (McKinsey \& Company, 2015). Organizations with gender diverse leadership teams are also more likely to have employees that agree with the mission and purpose of their organization, feel that their organization is going in the right direction, and recommend their organization to others (Peakon, 2019). As such, organizations should aim to dismantle the unconscious biases that perpetuate male-dominated leadership teams and workplaces by 
requesting gender-balanced lists of candidates and blind candidate reviews (Abouzahr et al., 2017).

\section{Conclusion}

The lack of women in senior leadership has continued to be called into question in recent years (Barling, 2014; Braun, 2016). While research has examined the various forms of subtle gender bias, inequity, and mistreatment that women leaders may perceive in the workplace (e.g., Brescoll, 2011; Cortina et al., 2013; MacDonald, 2019), it was not yet understood how these issues may affect women leaders' senior leadership ambitions. The present research found that women leaders were just as likely as men to have senior leadership ambitions. For both women and men, several perceptions of gender bias (i.e., silencing, inequitable pay, inequitable opportunities, and workplace incivility) were associated with feelings of cynicism towards work, and ultimately, lower senior leadership ambitions. Further, women leaders were shown to report more instances of workplace incivility, but otherwise, did not report more perceptions of gender bias in the workplace than men. However, a distinction was made when looking at women in maledominated workplaces, wherein women reported greater perceptions of subtle gender bias. Ultimately, this research provides evidence that it is likely systemic barriers, and not women's ambitions, that explain the lack of women in the C-suite - which has moral and economic consequences for organizations across Canada (Bloomberg, 2018). 


\section{References}

Abad-Merino, S., Dovidio, J. F., Tabernero, C., \& González, I. (2018). The systematic study of how subtle forms of bias related to prosocial behavior operate in racial and gender relations. Theory \& Psychology, 28, 104-121.

doi: $10.1177 / 0959354317745588$

Abouzahr, K., Krentz, M., Tracey, C., \& Tsusaka, M. (2017). Dispelling the myths of the gender ambition gap. Retrieved from https://www.bcg.com/enca/publications/2017/people-organization-leadership-change-dispelling-themyths-of-the-gender-ambition-gap

Abubakar, A., Namin, B., Harazneh, I., Arasli, H., \& Tunç, T. (2017). Does gender moderate the relationship between favoritism/nepotism, supervisor incivility, cynicism and workplace withdrawal: A neural network and SEM approach. Tourism Management Perspectives, 23, 129-139. https://doi.org/10.1016/j.tmp.2017.06.001

Accenture. (2017). Getting to equal 2017: Closing the gender pay gap. Retrieved from https://www.accenture.com/_acnmedia/pdf-45/accenture-iwd-2017-researchgetting-to-equal.pdf

Adams, J. S. (1965). Inequity in social exchange. Advances in Experimental Social Psychology, 2, 267-299. http://dx.doi.org/10.1016/S0065-2601(08)60108-2

ADP Research Institute. (2018). Rethinking gender pay inequity in a more transparent world. Retrieved from https://www.adp.com/resources/articles-andinsights/articles/r/rethinking-gender-pay-inequity-in-a-more-transparentworld.aspx 
Ali, M., Metz, I., \& Kulik, C. T. (2015). The impact of work-family programs on the relationship between gender diversity and performance. Human Resource Management, 54, 553-576. doi:10.1002/hrm.21631

Andersson, L., \& Bateman, T. (1997). Cynicism in the workplace: Some causes and effects. Journal of Organizational Behavior, 18, 449-469.

Andersson, L., \& Pearson, C. (1999). Tit for tat? The spiraling effect of incivility in the workplace. The Academy of Management Review, 24, 452-471. https://doi.org/10.2307/259136

Azzam, T., \& Jacobson, M. (2013). Finding a comparison group: Is online crowdsourcing a viable option? American Journal of Evaluation, 34, 372-384. https://doi.org/10.1177/1098214013490223

Babcock, L., Recalde, M. P., Vesterlund, L., \& Weingart, L. (2017). Gender differences in accepting and receiving requests for tasks with low promotability. The American Economic Review, 107, 714-747. doi:10.1257/aer.20141734

Badgett, M. V. L., Sears, B., Lau, H., \& Ho, D. (2009). Bias in the workplace: Consistent evidence of sexual orientation and gender identity discrimination 19982008. Chicago-Kent Law Review, 84, 559.

Barling, J. (2014). The science of leadership: Lessons from research for organizational leaders. New York: Oxford University Press.

Baron, R. M., \& Kenny, D. A. (1986). The moderator-mediator variable distinction in social psychological research: Conceptual, strategic, and statistical considerations. Journal of Personality and Social Psychology, 51, 1173-1182. doi:10.1037/0022-3514.51.6.1173 
Barrick, M., Mount, M., \& Li, N. (2013). The theory of purposeful work behavior: The role of personality, higher-order goals, and job characteristics. The Academy of Management Review, 38, 132-153. https://doi.org/10.5465/amr.2010.0479

Barsh, J., \& Yee, L. (2011). Changing companies' minds about women. Retrieved from https://www.mckinsey.com/business-functions/organization/ourinsights/changing-companies-minds-about-women

Basford, T. E., Offermann, L. R., \& Behrend, T. S. (2014). Do you see what I see? Perceptions of gender microaggressions in the workplace. Psychology of Women Quarterly, 38, 340-349. doi:10.1177/0361684313511420

Bell, K., \& Naugle, A. (2007). Effects of social desirability on students' self-reporting of partner abuse perpetration and victimization. Violence and Victims, 22, 243-256. https://doi.org/10.1891/088667007780477348

Berdahl, J. (2007). The sexual harassment of uppity women. Journal of Applied Psychology, 92, 425-437.

Berdahl, J., \& Moore, C. (2006). Workplace harassment: Double jeopardy for minority women. Journal of Applied Psychology, 91, 426-436. https://doi.org/10.1037/0021-9010.91.2.426

Bergeron, D., Shipp, A., Rosen, B., \& Furst, S. (2013). Organizational citizenship behavior and career outcomes: The cost of being a good citizen. Journal of Management, 39, 958-984. https://doi.org/10.1177/0149206311407508

Bian, L., Leslie, S., \& Cimpian, A. (2017). Gender stereotypes about intellectual ability emerge early and influence children's interests. Science, 355, 389-391. doi:10.1126/science.aah6524 
Biron, M., De Reuver, R., \& Toker, S. (2016). All employees are equal, but some are more equal than others: Dominance, agreeableness, and status inconsistency among men and women. European Journal of Work and Organizational Psychology, 25, 430-446. doi:10.1080/1359432X.2015.1111338

Bishu, S. G., \& Alkadry, M. G. (2017). A systematic review of the gender pay gap and factors that predict it. Administration \& Society, 49, 65-104. doi:10.1177/0095399716636928

Bloomberg. (2018). One in 100: Canada's 'embarrassing' lack of female CEOs among top TSX companies. Retrieved from https://www.bnnbloomberg.ca/female-ceosnoticeably-absent-from-canada-s-c-suite-1.1103584

Bobbitt-Zeher, D. (2011). Gender discrimination at work: Connecting gender stereotypes, institutional policies, and gender composition of workplace. Gender \& Society, 25, 764-786. https://doi.org/10.1177/0891243211424741

Bolino, M. C., Klotz, A., Turnley, W., \& Harvey, J. (2013). Exploring the dark side of organizational citizenship behavior. Journal of Organizational Behavior, 34, 542559. https://doi.org/10.1002/job.1847

Bolino, M. C., \& Turnley, W. H. (2005). The personal costs of citizenship behavior: The relationship between individual initiative and role overload, job stress, and workfamily conflict. Journal of Applied Psychology, 90, 740-748.

Bosomtwe, T., \& Obeng, B. (2018). The link between organizational culture and turnover intention among employees in Ghana. International Journal of Contemporary Research and Review, 9, 20951-20958. https://doi.org/10.15520/ijcrr/2018/9/08/566 
Boston Consulting Group. (2017). Dispelling the myths of the gender “ambition” gap. Retrieved from http://image-src.bcg.com/Images/BCG-Dispelling-Myths-ofGender-Ambition-Gap-Apr-2017-Revised_tcm9-150012.pdf

Bourdage, J., Lee, K., Lee, J., \& Shin, K. (2012). Motives for organizational citizenship behavior: Personality correlates and coworker ratings of OCB. Human Performance, 25, 179-200. https://doi.org/10.1080/08959285.2012.683904

Bowles, H. R., \& McGinn, K. L. (2005). Claiming authority: Negotiating challenges for women leaders. In D. M. Messick \& R. M. Kramer (Eds.), The psychology of leadership: New perspectives and research, 191-208. Mahwah, NJ, US: Lawrence Erlbaum Associates Publishers.

Braun, H. J. (2016). How should we address the pipeline problem? Perspectives on Medical Education, 5, 75-77. doi:10.1007/s40037-016-0266-4

Brescoll, V. L. (2011). Who takes the floor and why: Gender, power, and volubility in organizations. Administrative Science Quarterly, 56, 622-641. doi:10.1177/0001839212439994

Brown, S., \& Battle, J. (2019). Ostracizing targets of workplace sexual harassment before and after the \#MeToo movement. Equality, Diversity and Inclusion an International Journal, 39, 53-67. https://doi.org/10.1108/edi-09-2018-0162

Bruckmüller, S., \& Branscombe, N. R. (2010). The glass cliff: When and why women are selected as leaders in crisis contexts. The British Journal of Social Psychology, 49, 433-451. doi:10.1348/014466609X466594 
Cameron, M. S., \& Nadler, J. T. (2013). Gender roles and organizational citizenship behaviors: Effects on managerial evaluations. Gender in Management: An International Journal, 28, 380-399. doi:10.1108/GM-10-2012-0074

Carr, P., Ash, A., Friedman, R., Szalacha, L., Barnett, R., Palepu, A., \& Moskowitz, M. (2000). Faculty perceptions of gender discrimination and sexual harassment in academic medicine. Annals of Internal Medicine, 132, 889-896. https://doi.org/10.7326/0003-4819-132-11-200006060-00007

Catalyst. (2018). Turnover and retention: Quick take. Retrieved from https://www.catalyst.org/research/turnover-and-retention/

Catalyst. (2013). High-potential employees in the pipeline: Maximizing the talent pool in Canadian organizations. Retrieved from http://www.catalyst.org/knowledge/high-potentialemployees-pipelinemaximizing-talent-pool-canadian-organizations

Catalyst. (2007). The bottom line: Corporate performance and women's representation on boards. Retrieved from https://www.catalyst.org/research/the-bottom-linecorporate-performance-and-womens-representation-on-boards/

Cech, E. A., \& Blair-Loy, M. (2010). Perceiving glass ceilings? Meritocratic versus structural explanations of gender inequality among women in science and technology. Social Problems, 57, 371-397. doi:10.1525/sp.2010.57.3.371

Cech, E. A, \& Pham, M. (2017). Queer in STEM organizations: Workplace disadvantages for LGBT employees in STEM related federal agencies. Social Sciences, 6, 12. doi:10.3390/socsci6010012 
Centre for Creative Leadership. (2017). What women want. Retrieved from https://diversity.ucsf.edu/sites/diversity.ucsf.edu/files/What_Women_WantCCL.pdf

Chadwick, I. C., \& Dawson, A. (2018). Women leaders and firm performance in family businesses: An examination of financial and nonfinancial outcomes. Journal of Family Business Strategy, 9, 238-249. doi:10.1016/j.jfbs.2018.10.002

Chan, D. K., Chow, S. Y., Lam, C. B., \& Cheung, S. F. (2008). Examining the jobrelated, psychological, and physical outcomes of workplace sexual harassment: A meta-analytic review. Psychology of Women Quarterly, 32, 362-376. doi:10.1111/j.1471-6402.2008.00451.x

Chang, S., Van Witteloostuijn, A., \& Eden, L. (2010). From the editors: Common method variance in international business research. Journal of International Business Studies, 41, 178-184. doi:http://dx.doi.org.proxy.library.carleton.ca/10.1057/jibs.2009.88

Chemers, M. M. (2000). Leadership research and theory: A functional integration. Group Dynamics: Theory, Research, and Practice, 4, 27-43. doi:10.1037/10892699.4.1.27

Chesterman, C., \& Ross-Smith, A. (2006). Not tokens: Reaching a "critical mass" of senior women managers. Employee Relations, 28, 540-552. doi:10.1108/01425450610704489

Chiaburu, D. S., Peng, A. C., Oh, I. S., Banks, G. C., \& Lomeli, L. C. (2013). Antecedents and consequences of employee organizational cynicism: A metaanalysis. Journal of Vocational Behavior, 83, 181-197. 
Chng, D. H. M., \& Wang, J. C. Y. (2016). An experimental study of the interaction effects of incentive compensation, career ambition, and task attention on Chinese managers' strategic risk behaviors: Incentive, ambition, and task attention. Journal of Organizational Behavior, 37, 719-737. doi:10.1002/job.2062

Conway, J., \& Lance, C. (2010). What reviewers should expect from authors regarding common method bias in organizational research. Journal of Business and Psychology, 25, 325-334. https://doi.org/10.1007/s10869-010-9181-6

Cook, A., \& Glass, C. (2014). Above the glass ceiling: When are women and racial/ethnic minorities promoted to CEO? Strategic Management Journal, 35, 1080-1089. doi:10.1002/smj.2161

Coombs, A., \& King, R. (2005). Workplace discrimination: Experiences of practicing physicians. Journal of the National Medical Association, 97, 467-477.

Cortina, L. (2008). Unseen injustice: Incivility as modern discrimination in organizations. The Academy of Management Review, 33, 55-75. https://doi.org/10.5465/AMR.2008.27745097

Cortina, L., Kabat-Farr, D., Leskinen, E., Huerta, M., \& Magley, V. (2013). Selective incivility as modern discrimination in organizations: Evidence and impact. Journal of Management, 39, 1579-1605. https://doi.org/10.1177/0149206311418835

Cortina, L., Magley, V., Williams, J., \& Langhout, R. (2001). Incivility in the workplace: Incidence and impact. Journal of Occupational Health Psychology, 6, 64-80. https://doi.org/10.1037/1076-8998.6.1.64 
Cuddy, A. J. C., Fiske, S. T., \& Glick, P. (2007). The BIAS map: Behaviors from intergroup affect and stereotypes. Journal of Personality and Social Psychology, 92, 631-648. doi:10.1037/0022-3514.92.4.631

Cuddy, A. J. C., Glick, P., \& Beninger, A. (2011). The dynamics of warmth and competence judgments, and their outcomes in organizations. Research in Organizational Behavior, 31, 73-98.

Davies, P. G., Spencer, S. J., \& Steele, C. M. (2005). Clearing the air: Identity safety moderates the effects of stereotype threat on women's leadership aspirations. Journal of Personality and Social Psychology, 88, 276-287. doi:10.1037/00223514.88 .2 .276

Deery, S., Walsh, J., \& Guest, D. (2011). Workplace aggression: The effects of harassment on job burnout and turnover intentions. Work, Employment \& Society, 25, 742-759. doi:10.1177/0950017011419707

De Gieter, S., \& Hofmans, J. (2015). How reward satisfaction affects employees’ turnover intentions and performance: An individual differences approach. Human Resource Management Journal, 25, 200-216. https://doi.org/10.1111/17488583.12072

De Mascia, S. (2015). Are women better leaders than men? Human Resource Management International Digest, 23, 1-4. doi:10.1108/HRMID-07-2015-0122

Denissen, A. M., \& Saguy, A. C. (2014). Gendered homophobia and the contradictions of workplace discrimination for women in the building trades. Gender and Society, 28, 381-403. doi:10.1177/0891243213510781 
DeRue, D. S., \& Ashford, S. J. (2010). Who will lead and who will follow: A social process of leadership identity construction in organizations. Academy of Management Review, 35, 627-647.

Desrochers, S., \& Dahir, V. (2000). Ambition as a motivational basis of organizational and professional commitment: Preliminary analysis of a proposed career advancement ambition scale. Perceptual and Motor Skills, 91, 563-570. doi:10.2466/pms.2000.91.2.563

Dezco, C. L., \& Ross, D. G. (2012). Does female representation in top management improve firm performance? A panel data investigation. Strategic Management Journal, 33, 1072-1089. doi:10.1002/smj.1955

Dice. (2018). Diversity and Inclusion Report 2018. Retrieved from https://marketing.dice.com/pdf/201806_DiceDiversity_InclusionReport_FINAL.pdf

Diehl, A. B., \& Dzubinski, L. M. (2016). Making the invisible visible: A cross-sector analysis of gender-based leadership barriers. Human Resource Development Quarterly, 27, 181-206. doi:10.1002/hrdq.21248

Di Fabio, A. (2017). Positive healthy organizations: Promoting well-being, meaningfulness, and sustainability in organizations. Frontiers in Psychology, 8, 1938-1942. https://doi.org/10.3389/fpsyg.2017.01938

Dill, J. S., Price-Glynn, K., \& Rakovski, C. (2016). Does the "glass escalator" compensate for the devaluation of care work occupations? The careers of men in low- and middle-skill health care jobs. Gender \& Society, 30, 334-360. doi:10.1177/0891243215624656 
Dimitrios, B., \& Athanasios, K. (2014). Organizational culture and job satisfaction: A review. International Review of Management and Marketing, 4, 132-149.

Dionisi, A. M., Barling, J., \& Dupré, K. E. (2012). Revisiting the comparative outcomes of workplace aggression and sexual harassment. Journal of Occupational Health Psychology, 17, 398-408. doi:10.1037/a0029883

Dunn-Jensen, L. M., \& Stroh, L. K. (2007). Myths in the media: How the news media portrays women in the workforce. Handbook on Women in Business and Management, 13-35. doi: 10.4337/9781847204134.00008

Eagly, A., \& Chin, J. (2010). Diversity and leadership in a changing world. American Psychologist, 65, 216-224. https://doi.org/10.1037/a0018957

Eagly, A. H., \& Heilman, M. E. (2016). Gender and leadership: Introduction to the special issue. The Leadership Quarterly, 27, 349-353.

Eagly, A. H., \& Johannesen-Schmidt, M. C. (2001). The leadership styles of women and men. Journal of Social Issues, 57, 781-797. doi:10.1111/0022-4537.00241

Eagly, A. H., Johannesen-Schmidt, M. C., \& van Engen, M. L. (2003). Transformational, transactional, and laissez-faire leadership styles: A meta-analysis comparing women and men. Psychological Bulletin, 129, 569-591. doi:10.1037/00332909.129.4.569

Eagly, A. H., \& Karau, S. J. (2002). Role congruity theory of prejudice toward female leaders. Psychological Review, 109, 573-598. doi:10.1037//0033-295X.109.3.573

Ehlers, C., Greene-Shortridge, T. M., Weekley, J. A., \& Zajack, M. D. (2009). The exploration of statistical methods in detecting random responding. Paper 
presented at the annual meeting of the Society for Industrial/Organizational Psychology, Atlanta, GA.

El Baroudi, S., Fleisher, C., Khapova, S., Jansen, P., \& Richardson, J. (2017). Ambition at work and career satisfaction. Career Development International, 22, 87-102. https://doi.org/10.1108/CDI-07-2016-0124

Ellemers, N. (2014). Women at work: How organizational features impact career development. Policy Insights from the Behavioral and Brain Sciences, 1, 46-54. doi: $10.1177 / 2372732214549327$

Elmuti, D., Jia, H., \& Davis, H. H. (2009). Challenges women face in leadership positions and organizational effectiveness: An investigation. Journal of Leadership Education, 8, 167-187. doi:10.12806/V8/I2/RF4

Elprana, G., Felfe, J., Stiehl, S., \& Gatzka, M. (2015). Exploring the sex difference in affective motivation to lead: Furthering the understanding of women's underrepresentation in leadership positions. Journal of Personnel Psychology, 14, 142-152. doi:10.1027/1866-5888/a000137

Ely, R., Ibarra, H., \& Kolb, D. M. (2011). Taking gender into account: Theory and design for women's leadership development program. Academy of Management Learning \& Education, 10, 474-493. doi:http://dx.doi.org.proxy.library.carleton.ca/10.5465/amle.2010.0046

Fassinger, R. E., Shullman, S. L., \& Stevenson, M. R. (2010). Toward an affirmative lesbian, gay, bisexual, and transgender leadership paradigm. American Psychologist, 65, 201-215. https://doi.org/10.1037/a0018597 
Festinger, L. (1957). A theory of cognitive dissonance. Stanford, California: Stanford University Press.

Fisher, G., Matthews, R., \& Gibbons, A. (2016). Developing and investigating the use of single-item measures in organizational research. Journal of Occupational Health Psychology, 21, 3-23. https://doi.org/10.1037/a0039139

Fitzgerald, L. F., Drasgow, F., Hulin, C. L., Gelfand, M. J., \& Magley, V. J. (1997). Antecedents and consequences of sexual harassment in organizations: A test of an integrated model. Journal of Applied Psychology, 82, 578-589. doi:10.1037/00219010.82 .4 .578

Fitzgerald, L. F., Magley, V. J., Drasgow, F., \& Waldo, C. R. (1999). Measuring sexual harassment in the military: The sexual experiences questionnaire (SEQDoD). Military Psychology, 11, 243-263. doi:10.1207/s15327876mp1103_3

Flabbi, L., Piras, C., \& Abrahams, S. (2017). Female corporate leadership in Latin America and the Caribbean region representation and firm-level outcomes. International Journal of Manpower, 38, 790-818. doi:10.1108/IJM-10-2015-0180

Flanagan, J. (2015). Gender and the workplace: The impact of stereotype threat on selfassessment of management skills of female business students. Advancing Women in Leadership, 35, 166-171.

Fortune. (2018). Fortune 500 companies 2018: Who made the list. Retrieved from http://fortune.com/fortune500/list/

Francoeur, C., Labelle, R., \& Sinclair-Desgagné, B. (2008). Gender diversity in corporate governance and top management. Journal of Business Ethics, 81, 83-95. doi:10.1007/s10551-007-9482-5 
Gagliarducci, S., \& Paserman, M. D. (2015). The effect of female leadership on establishment and employee outcomes: Evidence from linked employer-employee data. Research in Labor Economics, 41, 343-375.

Ghani, F. A., Shuhada Derani, N. E., Aznam, N., Mohamad, N., Athirah Zakaria, S. A., \& Toolib, S. N. (2018). An empirical investigation of the relationship between transformational, transactional female leadership styles and employee engagement. Global Business and Management Research, 1, 724.

Gino, F., Wilmuth, C. A., \& Brooks, A. W. (2015). Compared to men, women view professional advancement as equally attainable, but less desirable. Proceedings of the National Academy of Sciences of the United States of America, 112, 1235412359. doi:10.1073/pnas.1502567112

Gipson, A. N., Pfaff, D. L., Mendelsohn, D. B., Catenacci, L. T., \& Burke, W. W. (2017). Women and leadership: Selection, development, leadership style, and performance. The Journal of Applied Behavioral Science, 53, 32-65. doi:10.1177/0021886316687247

Glauser, W. (2018). Rise of women in medicine not matched by leadership roles. Canadian Medical Association Journal, 190, E479-E480. doi:10.1503/cmaj.1095567

Gousman, R. S., \& Erb, D. W. (2019). Examining the impact of the \#MeToo movement on workplace policies. Retrieved from https://www.cutimes.com/2019/04/12/examining-the-impact-of-the-metoomovement-on-workplace-policies/?slreturn=20200631011832 
Grant, A., \& Sandberg, S. (2015). Madam C.E.O., get me a coffee. Retrieved from https://www.nytimes.com/2015/02/08/opinion/sunday/sheryl-sandberg-and-adamgrant-on-women-doing-office-housework.html

Gregor, M. A., \& O’Brien, K. M. (2016). Understanding career aspirations among young women: Improving instrumentation. Journal of Career Assessment, 24, 559-572. doi:10.1177/1069072715599537

Guillaume, Y., Dawson, J., Otaye-Ebede, L., Woods, S., \& West, M. (2017). Harnessing demographic differences in organizations: What moderates the effects of workplace diversity? Journal of Organizational Behavior, 38, 276-303. https://doi.org/10.1002/job.2040

Gupta, V. K., \& Bhawe, N. M. (2007). The influence of proactive personality and stereotype threat on women's entrepreneurial intentions. Journal of Leadership \& Organizational Studies, 13, 73-85. doi:10.1177/10717919070130040901

Hancock, A. B., \& Rubin, B. A. (2015). Influence of communication partner's gender on language. Journal of Language and Social Psychology, 34, 46.

Harlow, E. (2002). Gender, parenting and managerial ambition in social work. Journal of Social Work, 2, 65-82. doi:http://dx.doi.org.proxy.library.carleton.ca/10.1177/146801730200200105

Harman, C., \& Sealy, R. (2017). Opt-in or opt-out: Exploring how women construe their ambition at early career stages. Career Development International, 22, 372-398. doi:10.1108/CDI-08-2016-0137 
Harms, P., \& Credé, M. (2010). Emotional intelligence and transformational and transactional leadership: A meta-analysis. Journal of Leadership \& Organizational Studies, 17, 5-17. https://doi.org/10.1177/1548051809350894

Hayes, A. F. (2013). Introduction to mediation, moderation, and conditional process analysis: A regression-based approach. New York, NY: The Guildford Press. doi: $10.1111 /$ jedm. 12050

Haynes, M. C., \& Heilman, M. E. (2013). It had to be you (not me)!: Women's attributional rationalization of their contribution to successful joint work outcomes. Personality \& Social Psychology Bulletin, 39, 956-969. doi: $10.1177 / 0146167213486358$

Heilman, M. E. (2012). Gender stereotypes and workplace bias. Research in Organizational Behavior, 32, 113-135. doi:10.1016/j.riob.2012.11.003

Heilman, M. E., \& Chen, J. J. (2005). Same behavior, different consequences: Reactions to men's and women's altruistic citizenship behavior. Journal of Applied Psychology, 90, 431-441. doi:10.1037/0021-9010.90.3.431

Hewlett, S. A., \& Luce, C. B. (2005). Off-ramps and on-ramps: Keeping talented women on the road to success. Harvard Business Review, 83, 43-54.

Holmvall, C., \& Sobhani, S. (2019). Incivility toward managers: Gender differences in well-being outcomes. Equality, Diversity and Inclusion: An International Journal, 39, 301-317. https://doi.org/10.1108/EDI-07-2018-0120

Hoobler, J. M., Lemmon, G., \& Wayne, S. J. (2011). Women's underrepresentation in upper management. Organizational Dynamics, 40, 151-156. doi:10.1016/j.orgdyn.2011.04.001 
Howard, L. W. (1999). Validity evidence for measures of procedural/distributive justice and pay/benefit satisfaction. Journal of Business and Psychology, 14, 135-147. doi:10.1023/A:1022966719583

Hoyt, C. L., \& Burnette, J. L. (2013). Gender bias in leader evaluations: Merging implicit theories and role congruity perspectives. Personality and Social Psychology Bulletin, 39, 1306-1319. doi:10.1177/0146167213493643

International Labour Organization. (2017). Breaking barriers: Unconscious gender bias in the workplace. Retrieved from https://www.ilo.org/wcmsp5/groups/public/--ed_dialogue/---act_emp/documents/publication/wcms_601276.pdf

International Labour Organization. (2015). Women in business and management:

Gaining momentum. Retrieved from https://www.ilo.org/wcmsp5/groups/public/--dgreports/---dcomm/---publ/documents/publication/wcms_316450.pdf

Jackson, D., Engstrom, E., \& Emmers-Sommer, T. (2007). Think leader, think male and female: Sex vs. seating arrangement as leadership cues. Sex Roles, 57, 713-723. doi:10.1007/s11199-007-9289-y

James, M. S. L., \& Shaw, J. C. (2016). Cynicism across levels in the organization. Journal of Managerial Issues, 28, 83-100.

Jansen, W. S., Otten, S., \& Van Der Zee, K. I. (2017). Being different at work: How gender dissimilarity relates to social inclusion and absenteeism. Group Processes \& Intergroup Relations, 20, 879-893. doi:10.1177/1368430215625783

Javdani, M., \& McGee, A. (2019). Moving up or falling behind? Gender, promotions, and wages in Canada. Industrial Relations: A Journal of Economy and Society, 58, 189-228. doi:10.1111/irel.12231 
Jenner, S., Djermester, P., Prügl, J., Kurmeyer, C., \& Oertelt-Prigione, S. (2019). Prevalence of sexual harassment in academic medicine. JAMA Internal Medicine, 179, 108-111. https://doi.org/10.1001/jamainternmed.2018.4859

Jones, C., \& Goulding, A. (1999). Is the female of the species less ambitious than the male? The career attitudes of students in departments of information and library studies. Journal of Librarianship and Information Science, 31, 7-19. doi:10.1177/096100069903100102

Jones, K. P., Peddie, C. I., Gilrane, V. L., King, E. B., \& Gray, A. L. (2016). Not so subtle: A meta-analytic investigation of the correlates of subtle and overt discrimination. Journal of Management, 42, 1588-1613. doi:10.1177/0149206313506466

Joshi, A., Son, J., \& Roh, H. (2015). When can women close the gap: A meta-analytic test of sex differences in performance and rewards. Academy of Management Journal, 58, 1516-1545.

Judge, T., \& Piccolo, R. (2004). Transformational and transactional leadership: A metaanalytic test of their relative validity. Journal of Applied Psychology, 89, 755-768. https://doi.org/10.1037/0021-9010.89.5.755

Judge, T. A., Van Vianen, A. E. M, \& De Pater, I. E. (2004). Emotional stability, core self-evaluations, and job outcomes: A review of the evidence and an agenda for future research. Human Performance, 17, 325-346. doi:10.1207/s15327043hup1703_4 
Jyoti, J., \& Bhau, S. (2015). Assessing the employee related outcomes of transformational leadership. International Journal of Applied Business and Economic Research, 13, 1301-1317.

Koenig, A. M. (2018). Comparing prescriptive and descriptive gender stereotypes about children, adults, and the elderly. Frontiers in Psychology, 9, 1086-1086. doi:10.3389/fpsyg.2018.01086

Koenig, A. M., Eagly, A. H., Mitchell, A. A., \& Ristikari, T. (2011). Are leader stereotypes masculine? A meta-analysis of three research paradigms. Psychological Bulletin, 137, 616-642. doi:10.1037/a0023557

Kolb, D. M., \& Porter, J. L. (2015). Negotiating at work: Turn small wins into big gains. San Francisco, CA: Jossey-Bass, a Wiley brand.

Kolev, G. I. (2012). Underperformance by female CEOs: A more powerful test. Economics Letters, 117, 436-440.

Konrad, A. M., Cannings, K., \& Goldberg, C. B., (2010). Asymmetrical demography effects on psychological climate for gender diversity: Differential effects of leader gender and work unit gender composition among Swedish doctors. Human Relations, 63, 1661-1685. doi:10.1177/0018726710369397

Kubu, C. (2018). Who does she think she is? Women, leadership and the 'B'(ias) word. Clinical Neuropsychologist, 32, 235-251. doi:10.1080/13854046.2017.1418022 Kuo, C., Chang, K., Quinton, S., Lu, C., \& Lee, I. (2014). Gossip in the workplace and the implications for HR management: A study of gossip and its relationship to employee cynicism. International Journal of Human Resource Management, 26, 2288-2307. https://doi.org/10.1080/09585192.2014.985329 
Kurtulus, F. A., \& Tomaskovic-Devey, D. (2012). Do female top managers help women to advance? A panel study using EEO-1 records. The Annals of the American Academy of Political and Social Science, 639, 173-197. doi: $10.1177 / 0002716211418445$.

Leaper, C., \& Starr, C. R. (2019). Helping and hindering undergraduate women's STEM motivation: Experiences with STEM encouragement, STEM-related gender bias, and sexual harassment. Psychology of Women Quarterly, 43, 165-183. doi: $10.1177 / 0361684318806302$

Leppel, K. (2016). The labor force status of transgender men and women. International Journal of Transgenderism, 17, 155-164. doi:10.1080/15532739.2016.1236312

Leung, K., Li, F., \& Zhou, F. (2012). Sex differences in social cynicism across societies: The role of men's higher competitiveness and male dominance. Journal of CrossCultural Psychology, 43, 1152-1166. https://doi.org/10.1177/0022022111422259

Li, S., \& Chen, Y. (2018). The relationship between psychological contract breach and employees' counterproductive work behaviors: The mediating effect of organizational cynicism and work alienation. Frontiers in Psychology, 9, 1273. https://doi.org/10.3389/fpsyg.2018.01273

Li, G., Liu, H., \& Luo, Y. (2018). Directive versus participative leadership: Dispositional antecedents and team consequences. Journal of Occupational and Organizational Psychology, 91, 645-664. doi:10.1111/joop.12213

Lim, S., \& Cortina, L. M. (2005). Interpersonal mistreatment in the workplace: The interface and impact of general incivility and sexual harassment. Journal of Applied Psychology, 90, 483-496. doi:10.1037/0021-9010.90.3.483 
Lin, B. C., Kain, J. M., \& Fritz, C. (2013). Don't interrupt me! An examination of the relationship between intrusions at work and employee strain. International Journal of Stress Management, 20, 77-94. doi:10.1037/a0031637

Lippel, K., Vézina, M., Bourbonnais, R., \& Funes, A. (2016). Workplace psychological harassment: Gendered exposures and implications for policy. International Journal of Law and Psychiatry, 46, 74-87. doi:10.1016/j.ijlp.2016.05.001

Lyness, K. S., \& Grotto, A. R. (2018). Women and leadership in the United States: Are we closing the gender gap? Annual Review of Organizational Psychology and Organizational Behavior, 5, 227-265. doi:10.1146/annurev-orgpsych-032117104739

MacDonald, D. (2019). The double-pane glass ceiling: The gender pay gap at the top of corporate Canada. Retrieved from https://www.policyalternatives.ca/publications/reports/double-pane-glass-ceiling Manzoor, M., Manzoor, T., \& Khan, M. (2020). Workplace incivility: A cynicism booster leading to turnover intentions. Decision (Calcutta), 47, 91-99. https://doi.org/10.1007/s40622-020-00238-6

Martin, A. D., Nishikawa, T., \& Williams, M. A. (2009). CEO gender: Effects on valuation and risk. Quarterly Journal of Finance and Accounting, 48, 23.

Mattis, M. C. (2001). Advancing women in business organizations: Key leadership roles and behaviors of senior leaders and middle managers. Journal of Management Development, 20, 371-388. doi:10.1108/02621710110389009

McClean, E. J., Martin, S. R., Emich, K. J., \& Woodruff, T. (2018). The social consequences of voice: An examination of voice type and gender on status and 
subsequent leader emergence. Academy of Management Journal, 61, 1869-1891. doi:10.5465/amj.2016.0148

McDonald, P. (2012). Workplace sexual harassment 30 years on: A review of the literature. International Journal of Management Reviews, 14, 1-17. doi:10.1111/j.1468-2370.2011.00300.x

McKinsey \& Company. (2018). Women in the workplace. Retrieved from https://womenintheworkplace.com/

McKinsey \& Company. (2015). How advancing women's equality can add \$12 trillion to global growth. Retrieved from https://www.mckinsey.com/featuredinsights/employment-and-growth/how-advancing-womens-equality-can-add-12trillion-to-global-growth

McKinsey \& Company. (2011). Unlocking the full potential of women in the U.S. economy. Retrieved from https://www.mckinsey.com/ /media/McKinsey/dotcom/client_service/Organizati on/PDFs/Exec_Summ_WSJ_Preview_Special_Report.ashx

McLaughlin, H., Silvester, J., Bilimoria, D., Jané, S., Sealy, R., Peters, K., . . Göke, J. (2018). Women in power. Organizational Dynamics, 47, 189-199. doi:10.1016/j.orgdyn.2017.09.001

McLaughlin, H., Uggen, C., \& Blackstone, A. (2017). The economic and career effects of sexual harassment on working women. Gender \& Society, 31, 333-358. doi:10.1177/0891243217704631 
McLaughlin, H., Uggen, C., \& Blackstone, A. (2012). Sexual harassment, workplace authority, and the paradox of power. American Sociological Review, 77, 625-647. doi: $10.1177 / 0003122412451728$

Meade, A. W., \& Craig, S. B. (2012). Identifying careless responses in survey data. Psychological Methods, 17, 437-455. doi:10.1037/a0028085

Melero, E. (2011). Are workplaces with many women in management run differently? Journal of Business Research, 64, 385-393. doi:10.1016/j.jbusres.2010.01.009

Merkin, R. S., \& Shah, M. K. (2014). The impact of sexual harassment on job satisfaction, turnover intentions, and absenteeism: Findings from Pakistan compared to the United States. Springerplus, 3, 1-13. doi:10.1186/2193-1801-3215

Miner, K., Settles, I., Pratt-Hyatt, J., \& Brady, C. (2012). Experiencing incivility in organizations: The buffering effects of emotional and organizational support. Journal of Applied Social Psychology, 42, 340-372. https://doi.org/10.1111/j.1559-1816.2011.00891.x

Moss-Racusin, C. A., Dovidio, J. F., Brescoll, V. L., Graham, M. J., \& Handelsman, J. (2012). Science faculty's subtle gender biases favor male students. Proceedings of the National Academy of Sciences of the United States of America, 109, 1647416479. doi:10.1073/pnas.1211286109

Muench, U., Busch, S. H., Sindelar, J., \& Buerhaus, P. I. (2016). Exploring explanations for the female-male earnings difference among registered nurses in the united states. Nursing Economic, 34, 214. 
Nash, M., Davies, A., \& Moore, R. (2017). What style of leadership do women in STEMM fields perform? Findings from an international survey. Plos One, 12, e0185727-e0185727. doi:10.1371/journal.pone.0185727

Neuman, J. H., \& Baron, R. A. (1998). Workplace violence and workplace aggression: Evidence concerning specific forms, potential causes, and preferred targets. Journal of Management, 24, 391-419. doi:10.1177/014920639802400305

Nicholson, R., Leiter, M., \& Laschinger, H. (2014). Predicting cynicism as a function of trust and civility: A longitudinal analysis. Journal of Nursing Management, 22, 974-983. https://doi.org/10.1111/jonm.12073

Nielsen, M. B., \& Einarsen, S. (2012). Prospective relationships between workplace sexual harassment and psychological distress. Occupational Medicine, 62, 226228. doi:10.1093/occmed/kqs010

Nishii, L. H. (2013). The benefits of climate for inclusion for gender-diverse groups. The Academy of Management Journal, 56, 1754-1774. doi:10.5465/amj.2009.0823

Noland, M., Moran, T., \& Kotschwar, B. R. (2016). Is Gender Diversity Profitable? Evidence from a Global Survey. SSRN Electronic Journal. doi: $10.2139 /$ ssrn. 2729348

Nosek, B. A., Banaji, M. R., \& Greenwald, A. G. (2002). Harvesting implicit group attitudes and beliefs from a demonstration web site. Group Dynamics: Theory, Research, and Practice, 6, 101-115. doi:10.1037/1089-2699.6.1.101

Ontario Ministry of Labour. (2010). Occupational health and safety act and WHMIS regulation: Revised statutes of Ontario, 1990, chapter O.1, as amended: R.R.O. 
1990, reg. 860 as amended by O. reg. 36/93. Toronto: Ministry of Labour, Operations Division.

Ontario Nonprofit Network. (2018). Women's voices: Stories about working in Ontario's nonprofit sector. Retrieved from https://theonn.ca/wpcontent/uploads/2018/10/Womens-Voices-October-2018.pdf

O'Reilly, A., \& Garrett, P. M. (2019). 'Playing the game?': The sexual harassment of female social workers across professional workspaces. International Social Work, 62, 105-118. doi:http://dx.doi.org.proxy.library.carleton.ca/10.1177/0020872817706410

Otto, K., Roe, R., Sobiraj, S., Baluku, M., \& Garrido Vásquez, M. (2017). The impact of career ambition on psychologists' extrinsic and intrinsic career success: The less they want, the more they get. Career Development International, 22, 23-36. https://doi.org/10.1108/CDI-06-2016-0093

Palan, S., \& Schitter, C. (2018). Prolific.ac - A subject pool for online experiments. Journal of Behavioral and Experimental Finance, 17, 22-27. https://doi.org/10.1016/j.jbef.2017.12.004

Paolacci, G., \& Chandler, J. (2014). Inside the turk: Understanding Mechanical Turk as a participant pool. Current Directions in Psychological Science, 23, 184-188. https://doi.org/10.1177/0963721414531598

Paustian-Underdahl, S., Walker, L. S., \& Woehr, D. J. (2014). Gender and perceptions of leadership effectiveness: A meta-analysis of contextual moderators. Journal of Applied Psychology, 99, 1129-1145. 
Peakon. (2019). The Strategic Benefits of Women in Leadership. Retrieved from https://peakon.com/blog/workplace-culture/strategic-benefits-women-leadership/

Peer, E., Brandimarte, L., Samat, S., \& Acquisti, A. (2017). Beyond the Turk: Alternative platforms for crowdsourcing behavioral research. Journal of Experimental Social Psychology, 70, 153-163. https://doi.org/10.1016/j.jesp.2017.01.006

Peters, L. H., Terborg, J. R., \& Taynor, J. (1974). Women as Managers Scale (WAMS): A measure of attitudes toward women in management positions. JSAS Catalog of Selected Documents in Psychology, 4, 27.

Podsakoff, P. M., MacKenzie, S. B., Lee, J., \& Podsakoff, N. P. (2003). Common method biases in behavioral research: A critical review of the literature and recommended remedies. Journal of Applied Psychology, 88, 879-903. doi:10.1037/00219010.88 .5 .879

Podsakoff, P. M., MacKenzie, S. B., \& Podsakoff, N. P. (2012). Sources of method bias in social science research and recommendations on how to control it. Annual Review of Psychology, 63, 539-569. doi:10.1146/annurev-psych-120710-100452

Podsakoff, N., Whiting, S., Podsakoff, P., \& Blume, B. (2009). Individual- and organizational-level consequences of organizational citizenship behaviors: A meta-analysis. Journal of Applied Psychology, 94, 122-141. https://doi.org/10.1037/a0013079

Post, C. (2015). When is female leadership an advantage? Coordination requirements, team cohesion, and team interaction norms. Journal of Organizational Behavior, 36, 1153-1175. doi:10.1002/job.2031 
Post, C., \& Byron, K. (2015). Women on boards and firm financial performance: A metaanalysis. Academy of Management Journal, 58, 1546-1571. doi:10.5465/amj.2013.0319

Powell, G. N. (2012). Six ways of seeing the elephant: The intersection of sex, gender, and leadership. Gender in Management: An International Journal, 27, 119-141. doi:10.1108/17542411211214167

Powell, G. N., \& Butterfield, D. A. (2002). Exploring the influence of decision makers' race and gender on actual promotions to tip management. Personnel Psychology, $55,397$.

Price, J. L., \& Mueller, C. W. (1986). Handbook of Organizational Measurement. Marshfield, MA: Pitman.

Pryce, P., \& Sealy, R. (2013). Promoting women to MD in investment banking: Multilevel influences. Gender in Management: An International Journal, 28, 448-467. doi:10.1108/GM-11-2012-0095

Purvanova, R. K., \& Muros, J. P. (2010). Gender differences in burnout: A meta-analysis. Journal of Vocational Behavior, 77, 168-185. http://dx.doi.org/10.1016/j.jvb.2010.04.006

Quinn, B. A. (2002). Sexual harassment and masculinity: The power and meaning of "girl watching". Gender and Society, 16, 386-402.

Rink, F., Ryan, M. K., Stoker, J. I. (2012). Influence in times of crisis: How social and financial resources affect men's and women's evaluations of glass cliff positions. Psychological Science, 23, 1306-1313. 
Rospenda, K. M., \& Richman, J. A. (2004). The factor structure of generalized workplace harassment. Violence and Victims, 19, 221-238. doi:10.1891/vivi.19.2.221.64097

Rospenda, K. M., Richman, J. A., \& Shannon, C. A. (2009). Prevalence and mental health correlates of harassment and discrimination in the workplace: Results from a national study. Journal of Interpersonal Violence, 24, 819-843.

doi:10.1177/0886260508317182

Roulin, N. (2015). Don't throw the baby out with the bathwater: Comparing data quality of crowdsourcing, online panels, and student samples. Industrial and Organizational Psychology, 8, 190-196. https://doi.org/10.1017/iop.2015.24

Rudman, L. A., Moss-Racusin, C. A., Glick, P., \& Phelan, J. E. (2012). Reactions to vanguards: Advances in backlash theory. Advances in Experimental Social Psychology, 45, 167-227. doi:10.1016/B978-0-12-394286-9.00004-4

Rudman, L. A., Moss-Racusin, C. A., Phelan, J. E., \& Nauts, S. (2012). Status incongruity and backlash effects: Defending the gender hierarchy motivates prejudice against female leaders. Journal of Experimental Social Psychology, 48, 165-179. doi:10.1016/j.jesp.2011.10.008

Rudman, L. A., \& Phelan, J. E. (2010). The effect of priming gender roles and women's implicit gender beliefs and career aspirations. Social Psychology, 41, 192-202. doi:10.1027/1864-9335/a000027

Ryan, M. K., Haslam, S. A, \& Postmes, T. (2007). Reactions to the glass cliff: Gender differences in the explanations for the precariousness of women's leadership positions. Journal of Organizational Change Management, 20, 182-197. doi:10.1108/09534810710724748 
Sak, R. (2018). Gender differences in Turkish early childhood teachers' job satisfaction, job burnout and organizational cynicism. Early Childhood Education Journal, 46, 643-653. https://doi.org/10.1007/s10643-018-0895-9

Salary Finance. (2019). Women's Wellbeing at Work. Retrieved from https://www.salaryfinance.com/uk/blog/womens-wellbeing-at-work/

Salles, A., Awad, M., Goldin, L., Krus, K., Lee, J. V., Schwabe, M. T., \& Lai, C. K. (2019). Estimating implicit and explicit gender bias among health care professionals and surgeons. JAMA Network Open, 2, e196545-e196545. doi:10.1001/jamanetworkopen.2019.6545

Sanchez-Hucles, J., \& Davis, D. D. (2010). Women and women of color in leadership: Complexity, identity, and intersectionality. American Psychologist, 65, 171-181. doi:http://dx.doi.org.proxy.library.carleton.ca/10.1037/a0017459

Sandberg, S. (2013). Lean in: Women, work, and the will to lead (First ed.). New York: Alfred A. Knopf.

Sandberg, S., \& Grant, A. (2015). Speaking While Female. Retrieved from https://www.nytimes.com/2015/01/11/opinion/sunday/speaking-whilefemale.html

Saxena, M., Geiselman, T., \& Zhang, S. (2019). Workplace incivility against women in STEM: Insights and best practices. Business Horizons, 62, 589-594. https://doi.org/10.1016/j.bushor.2019.05.005

Schein, V. E., Mueller, R., Lituchy, T., \& Liu, J. (1996). Think manager - think male: A global phenomenon? Journal of Organizational Behaviour, 17, 33-41. 
Schmader, T., \& Johns, M. (2003). Converging evidence that stereotype threat reduces working memory capacity. Journal of Personality and Social Psychology, 85, 440-452. doi:10.1037/0022-3514.85.3.440

Schoon, I., \& Polek, E. (2011). Teenage career aspirations and adult career attainment: The role of gender, social background and general cognitive ability. International Journal of Behavioral Development, 35, 210-217. https://doi.org/10.1177/0165025411398183

Schwarz, A., Rizzuto, T., Carraher-Wolverton, C., Roldán, J., \& Barrera-Barrera, R. (2017). Examining the impact and detection of the "urban legend" of common method bias. ACM SIGMIS Database: The DATABASE for Advances in Information Systems, 48, 93-119. https://doi.org/10.1145/3051473.3051479

Scott, K., \& Zweig, D. (2016). Understanding and mitigating cynicism in the workplace. Journal of Managerial Psychology, 31, 552-569. https://doi.org/10.1108/jmp-01-2015-0023

Sealy, R. (2010). Changing perceptions of meritocracy in senior women's careers. Gender in Management: An International Journal, 25, 184-197. doi:10.1108/17542411011036392

Simpson, R. (2004). Masculinity at work: The experiences of men in female-dominated occupations. Work, Employment and Society, 18, 349-368.

Sipe, S., Johnson, C., \& Fisher, D. (2009). University students' perceptions of gender discrimination in the workplace: Reality versus fiction. Journal of Education for Business, 84, 339-349. https://doi.org/10.3200/joeb.84.6.339-349 
Sjogren, E., Kristenson, M., \& Linquestgroup, T. (2006). Can gender differences in psychosocial factors be explained by socioeconomic status? Scandinavian Journal of Public Health, 34, 59-68. https://doi.org/10.1080/14034940510006049

Smith, J. L., \& White, P. H. (2002). An examination of implicitly activated, explicitly activated, and nullified stereotypes on mathematical performance: It's not just a woman's issue. Sex Roles, 47, 179-191. doi:10.1023/A:1021051223441

Spence-Laschinger, H. K., Leiter, M., Day, A., \& Gilin, D. (2009). Workplace empowerment, incivility, and burnout: Impact on staff nurse recruitment and retention outcomes. Journal of Nursing Management, 17, 302-311. https://doi.org/10.1111/j.1365-2834.2009.00999.x

Spencer, S. J., Logel, C., \& Davies, P. G. (2016). Stereotype threat. Annual Review of Psychology, 67, 415-437. doi:10.1146/annurev-psych-073115-103235

Sperry, D. M., \& Widom, C. S. (2013). Child abuse and neglect, social support, and psychopathology in adulthood: A prospective investigation. Child Abuse \& Neglect, 37, 415-425. doi:10.1016/j.chiabu.2013.02.006

Statistics Canada. (2018). The surge of women in the workforce. Retrieved from https://www150.statcan.gc.ca/n1/pub/11-630-x/11-630-x2015009-eng.htm

Statistics Canada. (2016). Data products, 2016 census. Retrieved from https://www12.statcan.gc.ca/census-recensement/2016/dp-pd/index-eng.cfm

Steele, C. M. (1997). A threat in the air. How stereotypes shape intellectual identity and performance. The American Psychologist, 52, 613-629. doi:10.1037//0003066X.52.6.613 
Steele, C. M., \& Aronson, J. (1995). Stereotype threat and the intellectual test performance of African Americans. Journal of Personality and Social Psychology, 69, 797-811. https://doi.org/10.1037//0022-3514.69.5.797

Stern, D., Stone, J. R., Hopkins, C., \& McMillion, M. (1990). Quality of students' work experience and orientation toward work. Youth \& Society, 22, 263-282.

Stone, P., \& Hernandez, L. A. (2013). The all-or-nothing workplace: Flexibility stigma and "opting out" among professional-managerial women. Journal of Social Issues, 69, 235-256. doi:10.1111/josi.12013

Sturm, R. E., Taylor, S. N., Atwater, L. E., \& Braddy, P. W. (2014). Leader selfawareness: An examination and implications of women's under-prediction. Journal of Organizational Behavior, 35, 657-677. doi:10.1002/job.1915

Tabachnick, B. G., Fidell, L. S., \& Ullman, J. B. (2019). Using multivariate statistics. Boston: Pearson.

Tinsley, C. H. \& Ely. R. J. (2018). What most people get wrong about men and women. Retrieved from https://hbr.org/2018/05/what-most-people-get-wrong-about-menand-women

Van Engen, M. L., \& Willemsen, T. M. (2004). Sex and leadership styles: A metaanalysis of research published in 1990s. Psychological Reports, 94, 3-18. doi:10.2466/pr0.94.1.3-18

Van Esch, C., Hopkins, M. M., O'Neil, D. A., \& Bilimoria, D. (2018). How perceived riskiness influences the selection of women and men as senior leaders. Human Resource Management, 57, 915-930. doi:10.1002/hrm.21902 
Van Ogtrop, K. (2015). Why ambition isn't working for women. Retrieved from https://ime.com/4038107/why-ambition-isnt-working-for-women/

Van Vianen, A. E. M. (1999). Managerial self-efficacy, outcome expectancies, and workrole salience as determinants of ambition for a managerial position. Journal of Applied Social Psychology, 29, 639-665.

Vial, A. C., Napier, J. L., \& Brescoll, V. L. (2016). A bed of thorns: Female leaders and the self-reinforcing cycle of illegitimacy. The Leadership Quarterly, 27, 400-414. doi:10.1016/j.leaqua.2015.12.004

Viewpoint Leadership. (2018). The Tallest Poppy Report. Retrieved from https://www.tallestpoppy.ca/

Walster, E., Berscheid, E., \& Walster, G. W. (1973). New directions in equity research. Journal of Personality and Social Psychology, 25, 151-176.

Walter, S. L., Seibert, S. E., Goering, D., \& O’Boyle, E. H. (2019). A tale of two sample sources: Do results from online panel data and conventional data converge? Journal of Business and Psychology, 34, 425-452. doi:10.1007/s10869-018-9552$\mathrm{y}$

Williams, C. L. (1992). The glass escalator: Hidden advantages for men in the "female" professions. Social Problems, 39, 253-267.

Williams, J., Dempsey, R., \& Slaughter, A. M. (2018). What works for women at work: Four patterns working women need to know. New York: New York University Press. 
Yoon, E., Stiller Funk, R., \& Kropf, N. (2010). Sexual harassment experiences and their psychological correlates among a diverse sample of college women. Affilia, 25, 818. https://doi.org/10.1177/0886109909354979

Zeinabadi, H. R. (2013). Social exchange outcomes of transformational leadership: Comparing male and female principals of public primary schools in Iran. International Journal of Educational Management, 27, 730-743. doi:10.1108/IJEM-04-2012-0051

Zell, E., Krizan, Z., \& Teeter, S. R. (2015). Evaluating gender similarities and differences using metasynthesis. The American Psychologist, 70, 10-20. doi: $10.1037 / \mathrm{a} 0038208$

Zenger, J., \& Folkman, J. (2012). Are women better leaders than men? Retrieved from https://hbr.org/2012/03/a-study-in-leadership-women-do

Zhu, H., Lyu, Y., \& Ye, Y. (2019). Workplace sexual harassment, workplace deviance, and family undermining. International Journal of Contemporary Hospitality Management, 31, 594-614. doi:http://dx.doi.org.proxy.library.carleton.ca/10.1 108/IJCHM-11-2017-0776 
Appendix A

Recruitment Notice

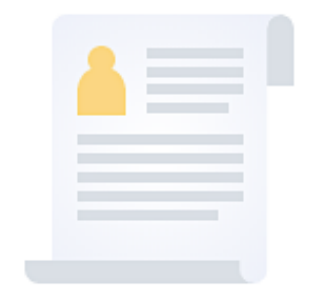

\section{Your first study (click here)}

Hosted by Prolific

$£ 0.00 \cdot 6$ minutes $\bullet £ 0.00 / \mathrm{hr} \bullet 1$ place remaining

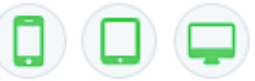

Welcome to Prolific

This demonstration study will show you what a typical Prolific study looks like.

We'll walk you through some of the key elements of the site, and explain the terms you need to know. With our help, you'll be taking part in studies in no time!

Ready? Click the button below to "Reserve a place", then click "Start now". 
Appendix B

\section{Eligibility Screening Form}

The following are screening questions to determine whether you are eligible to participate in this study.

Please select the option that best describes your employment situation.

1. Part-time (i.e., less than 30 hours worked per week)

2. Full-time (i.e., 30 hours or more worked per week)

3. Unemployed

Please select the option that best describes your job level.

1. Lower management (e.g., Shift Manager, Supervisor, Line Manager, etc.)

2. Middle management (e.g., Departmental Manager, Branch Manager, etc.)

3. Senior management (e.g., Executive Director, Chief Executive Officer (CEO), Chief Operations Officer (COO), etc.)

4. None of the above

Where do you currently reside?

1. Canada

2. The United Kingdom

3. The United States

4. None of the above 
Appendix C

Consent Form

Project Title: Leadership Ambitions and Workplace Experiences

Name and Contact Information of Researchers: The following people are involved in this study and may be contacted at any time if you have questions or concerns: Sepi Parvizian (Department of Psychology, Carleton University, Ottawa, Canada. Sepi.Parvizian@carleton.ca) and Dr. Janet Mantler (Department of Psychology, Carleton University, Ottawa, Canada. Janet.Mantler@carleton.ca).

Should you have any ethical concerns with the study, please contact the Chair of the Carleton University Research Ethics Board-B (by phone: 613-520-2600 ext. 4085 or by email: ethics@carleton.ca). For all other questions about the study, please contact the researchers.

Project Sponsor and Funder: This research is funded by SSHRC (Joseph-Armand Bombardier Canada Graduate Scholarship-Master's).

\section{Carleton University Project Clearance:}

CUREB-B Clearance: \#112327

Date of Clearance: March 13, 2020

Ethics Clearance for the Collection of Data Expires: March 31, 2021

Data Storage: Data will be kept indefinitely.

Invitation: You have been invited to take part in this research because you are a lowerlevel or middle-level leader who is working full-time or part-time in Canada, the United Kingdom, or the United States. The information in this form is intended to help you understand what we are asking of you so that you can decide whether you agree to participate in this study. Your participation in this study is completely voluntary.

Purpose: This study aims to understand how various workplace experiences affect leaders' senior leadership ambitions.

Task Requirements: If you agree to take part in this study, the survey will take approximately 15 minutes to complete. To participate in this study, you must (a) be currently employed in a full-time or part-time lower-level or middle-level leadership position, and (b) currently reside in Canada, the United Kingdom, or the United States. If you meet the eligibility criteria and agree to complete the survey, you will be asked questions about your senior leadership ambitions, perceptions of fairness in the 
workplace, experiences with workplace mistreatment, and feelings about work. Please answer all questions honestly.

Attention Check Items: You will be asked to respond to one or more attention check items within the survey. These items will ask you to follow an instruction (i.e., to select 'Strongly agree' for one of your responses on a particular measure). Such items are included to ensure that participants are paying attention during the survey.

Potential Risks/Discomfort: There are no known risks associated with completing this survey. If you feel any discomfort or distress at any point, you may choose to skip specific questions without penalty. The information at the end of the study provides contact information for support services that you may contact if you feel any discomfort and would like to speak with someone.

Benefits: You may not receive any direct benefit from your participation in this study. However, your participation may allow researchers to better understand how various workplace experiences affect leaders' senior leadership ambitions.

Compensation: You will be compensated directly through Prolific. In accordance with Prolific's policy, you will only be able to receive full credit if you qualify for this study by passing the screening questions and complete the entire survey in a timely manner. This means that if you respond to the survey items too quickly (speeding) or exceed the maximum time allowed for this survey, you will not receive compensation.

No Waiver of Your Rights: By consenting to this form, you are not waiving any rights or releasing the researchers from any liability.

Right to Withdraw: Your participation in this survey is voluntary and you have the right to end your participation at any time, for any reason. If you choose to withdraw, simply skip to the end of the survey or close the browser and return your submission on Prolific by selecting the 'Stop without completing' button. Given that your survey response is anonymous, it will not be possible for you to withdraw your answers after the survey has been submitted.

Anonymity/Confidentiality: Your participation in this study is strictly anonymous and confidential. We will treat your personal information as confidential, although absolute privacy cannot be guaranteed. Research records may be accessed by the Carleton University Research Ethics Board in order to ensure continuing ethics compliance. Your data will be removed from the Qualtrics server by April 2020 and stored on a passwordprotected computer at Carleton University. The anonymized data will be kept for future reference and will be used in academic publications and presentations. Your data will be stored and protected by Carleton University, but may be disclosed via a court order or data breach. We will password protect any research data that we store or transfer. The results of this study may be published or presented at an academic conference or meeting, however, the data is anonymous and will be presented so that it will not be possible to identify any participants. 
Data Retention: After the study is completed, your anonymous data will be retained for future reference and will be used in academic publications and presentations.

Ethics Review: This project was reviewed and cleared by the Carleton University Research Ethics Board B. If you have any ethical concerns with the study, please contact Carleton University Research Ethics Board by phone at 613-520-2600 [ext. 4085] or by email at ethics@carleton.ca.

[] I consent to participate in this research

[] I do NOT consent to participate in this research (if you do not consent to participate in this research, please return your submission on Prolific by selecting the 'Stop without completing' button) 
Questionnaire

Career Aspiration Scale - The Leadership Aspirations Subscale (Gregor \& O'Brien, 2016)

Please indicate how much you relate or do not relate to the following statements.

Response options: $1=$ Untrue of me, to $5=$ True of me

1. I hope to become a senior leader in my career field.

2. I do NOT plan to devote energy to getting promoted to a senior leadership position in the organization or business in which I am working.*

3. Becoming a senior leader in my job is NOT at all important to me.*

4. I want to have responsibility for the future direction of my organization or business.

5. Attaining senior leadership status in my career is NOT that important to me.*

6. I hope to move up to a senior leadership position in my organization or business.

7. I plan to rise to the top leadership position of my organization or business.

Women as Managers Scale (Peters, Terborg, \& Taynor, 1974)

Please think about the behaviour of OTHERS in your workplace when answering the following questions.

As a leader who is a woman, I often feel that those around me at work treat me as if... (prompt for women taking the survey)

Response options: $1=$ Strongly disagree, to $5=$ Strongly agree

1. It is NOT acceptable for women to assume leadership roles as often as men.

2. It is NOT acceptable for women to compete with men for top executive positions.

3. To be a successful leader, a woman must sacrifice some of her femininity.

4. Women are NOT ambitious enough to be successful in the working world.

5. Women CANNOT be assertive in business situations that demand it.

6. Women are NOT competitive enough to be successful in the working world.

7. This is an attention check item. Please select 'Disagree' as your answer.

Please think about the behaviour of OTHERS in your workplace when answering the following questions.

As a leader who is a man, I often feel that those around me at work treat me as if... (prompt for men taking the survey) 
Response options: $1=$ Strongly disagree, to $5=$ Strongly agree

1. It is NOT acceptable for men to assume leadership roles as often as women.

2. It is NOT acceptable for men to compete with women for top executive positions.

3. To be a successful leader, a man must sacrifice some of his masculinity.

4. Men are NOT ambitious enough to be successful in the working world.

5. Men CANNOT be assertive in business situations that demand it.

6. Men are NOT competitive enough to be successful in the working world.

7. This is an attention check item. Please select 'Disagree' as your answer.

Four-item developed measure used to assess silencing (Lin, Kain, \& Fritz, 2013)

Please indicate how much you agree or disagree with the following statements.

Response options: $1=$ Strongly disagree, to $5=$ Strongly agree

1. I am frequently interrupted by others when I am speaking at work.

2. I am able to make my point when I speak at work without someone interrupting me.*

3. People frequently disturb me while I am trying to speak in meetings.

4. Being interrupted while I am speaking is a frequent occurrence.

Four-item measure created for the present study to assess silencing

Please indicate how much you agree or disagree with the following statements.

Response options: $1=$ Strongly disagree, to $5=$ Strongly agree

1. My ideas or suggestions are ignored by others at work.

2. My ideas or suggestions are negatively scrutinized by others at work.

3. I avoid sharing my ideas or suggestions during meetings.

4. I avoid speaking too much during meetings.

Distributive Justice Index (DJI) (Price \& Mueller, 1986)

To what extent are you paid fairly at work compared to your co-workers who have the same job title as you...

Response options: $1=$ Not at all fair, to $5=$ Very much fair

1. Considering the responsibilities that you have?

2. Taking into account the amount of education and training that you have had?

3. In view of the amount of experience that you have?

4. For the amount of effort that you put forth?

5. For work that you have done well?

6. For the stresses and strains of your job? 
Distributive Justice Index (DJI) (Price \& Mueller, 1986)

To what extent are you given fair opportunities (such as promotions) at work compared to your co-workers who have the same job title as you...

Response options: $1=$ Not at all fair, to $5=$ Very much fair

1. Considering the responsibilities that you have?

2. Taking into account the amount of education and training that you have had?

3. In view of the amount of experience that you have?

4. For the amount of effort that you put forth?

5. For work that you have done well?

6. For the stresses and strains of your job?

\section{Six-item measure created for the present study to assess workplace housework}

Please indicate how much you agree or disagree with the following statements. At work, I feel obligated to...

Response options: $1=$ Strongly disagree, to $5=$ Strongly agree

1. Help others by taking notes during meetings.

2. Fill in for colleagues who are absent.

3. Plan events (e.g., holiday parties) although it is NOT required.

4. Ensure that there are snacks or beverages for meetings.

5. Provide my employees with informal incentives (e.g., treats).

6. Engage in tasks that go beyond my typical job requirements.

Workplace Incivility Scale (Cortina, Magley, Williams, \& Langhout, 2001)

During the last 12 months at your workplace, how often have you been in a situation where any of your supervisors or co-workers...

Response options: $1=$ Never, to $5=$ Many times

1. Put you down or were condescending to you?

2. Paid little attention to your statement or showed little interest in your opinion?

3. Made demeaning or derogatory remarks about you?

4. Addressed you in unprofessional terms, either publicly or privately?

5. Ignored or excluded you from professional camaraderie?

6. Doubted your judgment on a matter over which you have responsibility?

7. Made unwanted attempts to draw you into a discussion of personal matters?

8. This is an attention check item. Please select 'Often' as your answer. 
The Sexual Experiences Questionnaire (Fitzgerald, Magley, Drasgow, \& Waldo, 1999) As recommended by Donovan and Drasgow (1999) in the format that can be used as a measure of sexual harassment for both women and men.

During the last 12 months at your workplace, how often have you been in a situation where any of your supervisors or co-workers...

Response options: $1=$ Never, to $5=$ Many times

\section{Gender harassment, sexual hostility}

1. Repeatedly told sexual stories or jokes that were offensive to you?

2. Whistled, called, or hooted at you in a sexual way?

3. Made unwelcome attempts to draw you into a discussion of sexual matters (for example, attempted to discuss or comment on your sex life)?

4. Made crude and offensive sexual remarks, either publicly (for example, in your workplace) or to you privately?

5. Made offensive remarks about your appearance, body, or sexual activities?

6. Made gestures or used body language of a sexual nature which embarrassed or offended you?

7. Exposed themselves physically in a way that embarrassed you or made you feel uncomfortable?

Unwanted sexual attention

8. Displayed, used, or distributed sexist or suggestive materials (for example, pictures, stories, or pornography which you found offensive)?

9. Made unwanted attempts to establish a romantic sexual relationship with you despite your efforts to discourage it?

10. Continued to ask you for dates, drinks, dinner, etc., even though you said "No"?

11. Touched you in a way that made you feel uncomfortable?

12. Made unwanted attempts to stroke, fondle, or kiss you?

Workplace Cynicism Scale (Stern, Stone, Hopkins, \& McMillion, 1990)

Please indicate how much you agree or disagree with the following statements.

Response options: $1=$ Strongly disagree, to $5=$ Strongly agree

1. To me, working is nothing more than making a living.

2. People who take their work home with them probably don't have a very interesting home life.

3. There's no such thing as a company that cares about its employees.

4. Most people today are stuck in dead-end, go-nowhere jobs.

5. Workers are entitled to "call in sick" when they don't feel like working.

6. I believe in working only as hard as I have to.

7. If a person can get away with it, he/she should try to work just a little slower than the boss expects him/her to. 
8. The best job a worker can get is one which permits him/her to do almost nothing during the working day.

9. Very often I forget work I am supposed to do.

10. If I had the chance, I would go through life without ever having to work.

\section{Demographics}

The following are a series of demographic questions to help us get a better sense of who participated in this survey.

Which gender do you identify with?

1. Man

2. Woman

3. Transgender man

4. Transgender woman

5. Non-binary

6. Genderfluid

7. Genderqueer

8. Two-spirit

9. My gender is not listed, or I prefer not to specify

What is your ethnic/racial background? Please check all that apply.

1. White/Euro-Caucasian

2. Latin American/Hispanic

3. Black (African, Caribbean, etc.)

4. West Asian (Egyptian, Moroccan, Lebanese, Turkish, Israeli, Iranian, etc.)

5. South Asian (Indian, Pakistani, Bangladeshi, Nepali, Sri Lankan, etc.)

6. East Asian (Chinese, Japanese, Korean, etc.)

7. Southeast Asian (Thai, Vietnamese, Cambodian, Indonesian, etc.)

8. Indigenous (Status First Nations, Non-Status First Nations, Métis, Inuit/Inuk, etc.)

9. Other (please specify)

You indicated that you are Indigenous. Please specify which group you belong to.

1. First Nations (Status)

2. First Nations (Non-Status)

3. Métis

4. Inuit/Inuk

5. Other (please specify)

What is your age?

(Drop down menu. 0-100)

What is your current relationship status?

1. Single

2. In a relationship

3. Married 
4. Separated

5. Divorced

6. Widowed

7. Other

How many children are currently living full-time or part-time in your home?

(Drop down menu. 0-6+)

Which of the following most closely resembles the industry that you are currently employed in?

1. Manufacturing

2. Finance

3. Construction

4. Retail

5. Restaurant

6. Agriculture

7. Mining

8. Information and Technology

9. Transportation

10. Health

11. Education

12. Arts and Entertainment

13. Government

14. Military

15. Other (please specify)

How long have you been employed in a leadership role?

1. Less than 1 year

2. 1 year

3. 2 years

4. 3 years

5. 4 years

6. 5 years

7. 6 years

8. 7 years

9. 8 years

10. 9 years

11. 10 years

12. More than 10 years

Job Gender Context (Bergman \& Drasgow, 2003; Larsen et al., 2019; Nye et al., 2009) Which statement best describes the gender mix of your current workplace?

1. Male-dominated (i.e., there are many more men than there are women)

2. Gender diverse (i.e., there are roughly the same amount of men and women)

3. Female-dominated (i.e., there are many more women than there are men) 
Appendix E

Debriefing Form

Thank you for taking the time to participate in this study! After you have read the following information, please select the final arrow below to submit your response and be redirected to Prolific.

Project Title: Leadership Ambitions and Workplace Experiences

Name and Contact Information of Researchers: Sepi Parvizian (Department of Psychology, Carleton University, Ottawa, Canada. Sepi.Parvizian@carleton.ca) and Dr. Janet Mantler (Department of Psychology, Carleton University, Ottawa, Canada. Janet.Mantler@carleton.ca).

Project Sponsor and Funder: This research is funded by SSHRC (Joseph-Armand Bombardier Canada Graduate Scholarship-Master's).

\section{Carleton University Project Clearance:}

CUREB-B Clearance: \#112327

Date of Clearance: March 13, 2020

\section{What are we trying to learn in this research?}

This research examines whether perceptions of subtle gender bias, inequity, and mistreatment affect senior leadership ambitions in both women and men leaders. Overall, we are interested in determining whether women leaders who experience these issues will have lower ambitions for senior leadership, and whether this occurs because of feelings of cynicism towards work. Thank you for participating in this research and providing us with an opportunity to gain a stronger understanding about this relation.

Why is this important to researchers or the general public?

While women have had success in attaining lower-level and middle-level leadership positions in recent years, very few women are in senior leadership positions. Previous research has identified the various barriers that women face on the path to leadership, yet recent research indicates that women themselves often choose not to pursue senior positions. As such, more information is needed to determine why there are so few women at the top because representation is vital and women in senior leadership have many benefits for organizations and employees. It is also important to find out whether men have similar experiences because this is seldom discussed.

\section{Is there anything I can do if I found filling out this survey to be emotionally upsetting?}

If you feel any distress or anxiety after participating in this study, please feel free to contact a local crisis/distress centre or call a distress helpline: 
Canada: 1-833-456-4566

United Kingdom: 0844-477-5774

United States: 1-800-273-8255

\section{Where can I learn more?}

If you are interested in learning about women leaders in the workplace, the following are links intended to provide you with more information:

https://www.forbes.com/sites/dennisjaffe/2018/10/25/women-business-leaders-why-sofew-and-how-to-have-more/\#532d57852f42

https://hbr.org/2013/09/women-rising-the-unseen-barriers

\section{What if I have questions later?}

If you have any remaining concerns, questions, or comments about this study, please feel free to contact Sepi Parvizian (Department of Psychology, Carleton University, Ottawa, Canada. Sepi.Parvizian@carleton.ca) or Dr. Janet Mantler (Department of Psychology, Carleton University, Ottawa, Canada. Janet.Mantler@carleton.ca).

If you have any ethical concerns with the study, please contact the Carleton University Research Ethics Board-B (by phone at 613-520-2600 ext. 4085 or via email at ethics@carleton.ca).

Thank you for participating in this research! 
Carleton

U N I V E R I T Y

Canada's Capital University
Appendix F

Ineligibility Debriefing Form

Ineligibility Debriefing for the Study: Leadership Ambitions and Workplace Experiences

Unfortunately, based on your responses to our initial screening questions, you are ineligible to continue with the survey. This research is focused specifically on people who are currently employed in a full-time or part-time lower-level or middle-level leadership position and currently reside in Canada, the United Kingdom, or the United States. We appreciate your time and thank you for your interest in this research.

Please return your submission on Prolific by selecting the 'Stop without completing' button. Additionally, please select the final arrow below to submit your response. 